\title{
Revision of Tympanopleura Eigenmann (Siluriformes: Auchenipteridae) with description of two new species
}

\author{
Stephen J. Walsh¹, Frank Raynner Vasconcelos Ribeiro² and Lúcia Helena Rapp Py-Daniel ${ }^{3}$
}

The Neotropical catfish genus Tympanopleura, previously synonymized within Ageneiosus, is revalidated and included species are reviewed. Six species are recognized, two of which are described as new. Tympanopleura is distinguished from Ageneiosus by having an enlarged gas bladder not strongly encapsulated in bone; a prominent pseudotympanum consisting of an area on the side of the body devoid of epaxial musculature where the gas bladder contacts the internal coelomic wall; short, blunt head without greatly elongated jaws; and smaller adult body size. Species of Tympanopleura are distinguished from each other on the basis of unique meristic, morphometric, and pigmentation differences. Ageneiosus melanopogon and Tympanopleura nigricollis are junior synonyms of Tympanopleura atronasus. Tympanopleura alta is a junior synonym of Tympanopleura brevis. A lectotype is designated for T. brevis. Ageneiosus madeirensis is a junior synonym of Tympanopleura rondoni. Tympanopleura atronasus, T. brevis, T. longipinna, and T. rondoni are relatively widespread in the middle and upper Amazon River basin. Tympanopleura cryptica is described from relatively few specimens collected in the upper portion of the Amazon River basin in Peru and the middle portion of that basin in Brazil. Tympanopleura piperata is distributed in the upper and middle Amazon River basin, as well as in the Essequibo River drainage of Guyana.

O gênero de bagres neotropicais Tympanopleura, anteriormente sinonimizado em Ageneiosus, é revalidado e as espécies incluídas são revisadas. Seis espécies são reconhecidas, duas das quais são descritas como novas. O gênero Tympanopleura é distinto de Ageneiosus por possuir uma bexiga natatória grande e não fortemente encapsulada em osso; um pseudotímpano proeminente consistindo de uma área no lado do corpo sem musculatura epaxial onde a bexiga natatória contacta a parede interna da cavidade celômica; cabeça curta, sem mandíbulas muito prolongadas, e menor tamanho do corpo de adultos. Espécies de Tympanopleura são distintas umas das outras com base em diferenças únicas em dados merísticos, morfométricos e de pigmentação. Ageneiosus melanopogon e Tympanopleura nigricollis são sinônimos júnior de Tympanopleura atronasus. Tympanopleura alta é um sinônimo júnior de Tympanopleura brevis. Um lectótipo é designado para T. brevis. Ageneiosus madeirensis é sinônimo júnior de Tympanopleura rondoni. Tympanopleura atronasus, T. brevis, T. longipinna e T. rondoni são relativamente bem distribuídas nas porções média e alta da bacia Amazônica. Tympanopleura cryptica é descrita a partir de alguns espécimes coletados na porção alta da bacia Amazônica no Peru e porção média dessa bacia no Brasil. Tympanopleura piperata está distribuída nas regiões alta e média da bacia Amazônica, bem como na drenagem do rio Essequibo, na Guiana.

Keywords: Amazon River, Morphology, Identification key, Systematics, Taxonomy.

\section{Introduction}

The Auchenipteridae, commonly known as driftwood catfishes, is a monophyletic group that currently includes approximately 113 valid species in 23 genera and two subfamilies, the Auchenipterinae and Centromochlinae (Ferraris, 2003, 2007; Eschmeyer \& Fong, 2015). The family is endemic to the Neotropics and widely distributed throughout South America and lower Central America. Species of the family are small- to medium-sized, generally secretive and nocturnal in their habits, and are unique in their reproductive biology among doradoid catfishes by having internal insemination (Ferraris, 2003). In recent years a number of revisionary and phylogenetic studies have greatly improved knowledge about the taxonomy and relationships of species and genera in this group, whereas unresolved problems and additional studies and discoveries are expected to add significantly to the number of recognized taxa in the future (Ferraris, 2003).

${ }^{1}$ U.S. Geological Survey, 7920 NW 71st Street, Gainesville, FL 32653, USA. swalsh@usgs.gov

${ }^{2}$ Instituto de Ciências e Tecnologia das Águas, Universidade Federal do Oeste do Pará, Rua Vera Paz s/n, Bairro Salé, 68035-110 Santarem, PA, Brazil. fraynner@hotmail.com

${ }^{3}$ Instituto Nacional de Pesquisas da Amazônia, Av. André Araújo, 2936, Petrópolis, 69011-830 Manaus, AM, Brazil. lucia.rapp@ gmail.com 
The genus Tympanopleura was proposed by Eigenmann (1912) for a single species of auchenipterid catfish, $T$. piperata, described from eight specimens collected in the Essequibo River, Guyana. Eigenmann (1912) recognized $T$. piperata as distinct from species of Ageneiosus Lacepède, 1803 , on the basis of an enlarged gas bladder projecting laterally to the sides of the coelomic cavity, devoid of overlying musculature and with a thin external cutaneous covering, forming a "pseudo-tympanum". Subsequently, Eigenmann \& Myers in Myers (1928) described T. alta from the río Marañon, Peru, and Eigenmann \& Allen (1942) described T. nigricollis from the Iquitos region of Peru, stating that the species was "related to T. polystictus (Steindachner, 1915) and T. rondoni (Miranda Ribeiro, 1914)", the later two species of which were originally described in Ageneiosus. In addition to the aforementioned taxa, some species described prior to or after Eigenmann's (1912) designation of Tympanopleura were subsequently considered by various authors (e.g., Britski, 1972; Ferraris, 1988; Walsh, 1990) to be related on the basis of the enlarged gas bladder and other morphological similarities. These species include Ageneiosus brevis Steindachner, 1881, Ageneiosus atronasus Eigenmann \& Eigenmann, 1888, and Ageneiosus rondoni Miranda Ribeiro, 1914. A few other nominal species described in Ageneiosus were treated by recent investigators as junior synonyms of the species listed above, but taxonomy of the group has remained problematic.

For many years nominal species of Tympanopleura and Ageneiosus were treated together in a single family, the Ageneiosidae, and their putative relationship was recognized within a larger clade of catfishes, primarily on the basis of derived morphological modifications of the Weberian complex and presence of an elastic spring apparatus used for sound production (Fine \& Ladich, 2003). Ferraris (1988) hypothesized that species previously recognized in the Ageneiosidae were most closely related to species of Trachelyopterus Valenciennes, Trachelyichthys Mees, and an Auchenipterus-group (=Auchenipterus Valenciennes + Entomocorus Eigenmann + Epapterus Cope), all of which he included in an "Auchenipterini" tribe. He also expanded the Auchenipteridae to include the species previously grouped in the Ageneiosidae.

The higher family-group relationships of taxa within the Auchenipteridae, inclusive of what has been hypothesized as a monophyletic clade uniting species of Tympanopleura, Ageneiosus, and Tetranematichthys Bleeker, has a complex history as a result of early classification schemes and many landmark revisionary and phylogenetic studies of doradoid catfishes in recent decades (e.g., Britski, 1972; Ferraris, 1988; Curran, 1989; Walsh, 1990; Higuchi, 1992; Royero, 1987, 1999; de Pinna, 1993; Soares-Porto, 1996, 1998; Ferraris \& Vari, 1999; Akama, 2004; Moyer et al., 2004; Ferraris et al., 2005; Vari \& Ferraris, 1998, 2006; Sarmento-Soares \& Martins-Pinheiro, 2008; Birindelli, 2010, 2014; Sousa, 2010; Ribeiro, 2011; Arce et al., 2013). The multifaceted history of intra- and inter-familial classifications of auchenipterids was reviewed in detail by de Pinna (1998) and Soares-Porto (1998). As currently recognized, the Auchenipteridae is considered to be a monophyletic group nested within a large natural clade, the Neotropical Doradoidea (= Doradidae + Auchenipteridae [= Auchenipterinae + Centromochlinae $]$ ) (de Pinna, 1998; Soares-Porto, 1998; Ferraris, 2003), yet relationships of this group to other catfishes worldwide is inconclusively resolved (e.g., Hardman, 2005; Sullivan et al., 2006). Systematic history of the Doradoidea was reviewed by Birindelli (2014). Ribeiro (2011) expanded upon previous studies of the Auchenipterinae and proposed a revised phylogenetic hypothesis of intergeneric relationships, in which he recognized two tribes within the subfamily, the Trachelyopterini and Auchenipterini, the latter represented by one putative clade comprised of (Entomocorus $+(($ Auchenipterus $)+$ (Epapterus + Pseudepapterus Steindachner))), and another comprised of (Tetranematichthys + (Ageneiosus, including species of Tympanopleura as treated herein)).

Britski (1972), Ferraris (1988), and Walsh (1990) considered nominal species of Tympanopleura to be members of the genus Ageneiosus, and most subsequent investigators followed this classification (Eschmeyer, 2015). However, recent phylogenetic hypotheses proposed by Ribeiro (2011) and Birindelli et al. (2012), in combination with previous studies, suggest that species of Tympanopleura merit recognition as distinct from a clade of species in Ageneiosus that share the derived condition of a reduced gas bladder encapsulated in bone. Herein, we re-elevate Tympanopleura to generic status, review taxonomy of the species included in the genus, and describe two as new.

\section{Material and Methods}

Meristic and morphometric data were collected from whole specimens deposited at the institutions listed below. Rays of paired and unpaired fins were counted by examining specimens under a stereomicroscope with the aid of substage transmitted light, from radiographs, and in a few cases from cleared-and-stained specimens. Clearing and staining methods followed the procedure of Potthoff (1984) and Taylor \& van Dyke (1985), and these specimens are indicated as "c/s" in material examined; skeletonized specimens are indicated as "skel". Dissection and photography of gas bladders followed the methods of Birindelli et al. (2009, 2012). Nomenclature of osteology and other morphological features follows Cailliet et al. (1986), Arratia (2003a,b) and Chardon et al. (2003). Fin-ray counts included all lepidotrichia; for the dorsal and anal fins, counts included two rays that articulate on the last distal pterygiophore. Rudimentary fin rays occur irregularly on the anterior-most distal pterygiophore of the anal fin. Such rudimentary elements were included in anal-fin ray counts if they appeared to articulate with the first distal pterygiophore or extended into the membranous portion of 
the fin sufficiently to be visible under magnification. In cases where an anterior rudimentary element was visible only as a small "floating" splint in a radiograph it was not included in the anal-fin ray count. Pectoral-fin rays were preferentially counted on the left side, but occasionally on the right side when the left was damaged or distorted. No effort was made to discern unbranched from branched rays except in the case of the pelvic fin (always with one unbranched and six branched), the caudal fin, where counts are reported for principal rays (one unbranched and all branched rays each for the dorsal and ventral lobes) and the upper and lower procurrent rays, and for the anal fin in delimiting rays associated with the intromittent organ of nuptial males. Vertebral counts were made from radiographs and clearedand-stained specimens, and the total number included six for the Weberian apparatus, and one for the fused preural and ural (PU1+U1) centra following the terminology of Lundberg \& Baskin (1969). Preanal vertebrae were defined as those with hemal spines anterior to the first proximal anal pterygiophore. Number of pleural rib pairs was determined from radiographs or from cleared-and-stained specimens. Gill raker counts, taken from either side but preferentially on the left, were those of the lateral row on the first branchial arch and recorded as upper, lower, and total. Any gill raker at the articulation between epibranchial and ceratobranchial was included with the upper count. Mean counts of meristic characters among species were tested for significant differences using analysis of variance (Kruskal-Wallis ANOVA and Tamhane's T2 posthoc individual comparison between species with unequal variances; $p \leq 0.01$ ), with PASW Statistics Base Version 17.0 (IBM SPSS, 2009).

A combination of 31 truss and conventional measurements were taken to evaluate differences in body shape among species. Measurements involving bilateral landmarks were preferentially made on the left side of the body. Morphometric data were taken as straight-line, pointto-point measurements with needlepoint dial calipers, or, in the case of small specimens (e.g., T. piperata), using an ocular micrometer fitted to a stereomicroscope. Measurements were recorded to the nearest $0.1 \mathrm{~mm}$ and are summarized in species accounts and tables as percentages of Standard Length (SL) or Head Length (HL), the latter measured as the distance from the tip of the snout to the upper apex of the opercular opening. Distances between fins were measured from landmarks using the terms "origin" and "insertion" to indicate the anterior and posterior points of contact between fin rays and the body, respectively (Cailliet et al., 1986). The limits of most measurements are self-evident from the descriptors. Select measurements are delimited as follows: caudal peduncle length was measured from the anal-fin insertion to the base of the hypural plate; head depth was the vertical distance between the center of the supraoccipital and the isthmus; dorsal interopercular width was the distance between the dorsal apex of the opercular openings; anterior internarial width was the distance between the anterior narial openings; snout length was measured from the median tip of the upper jaw to the front margin of the eye; preisthmus length was the distance from the median tip of the upper jaw to the midpoint between where the branchiostegal membranes attach to the symphysis; eye diameter was the horizontal length of the eyeball excluding any fleshy tissue overlying the orbit.

To evaluate shape differences among species, the covariance matrix of log-transformed measurements was analyzed using sheared principal component analysis (PCA) [Bookstein et al. (1985) and a modified, unpublished algorithm by D.L. Swofford] with SAS Version 9.1 Software (SAS Institute, 2008). Scores on the second and third sheared principal components, which represent size-free shape factors, were plotted for individual specimens to examine multivariate differences among species. Dorsal-fin length and maxillary barbel length were omitted from multivariate analyses due to sexual dimorphism of these structures in nuptial adults. Morphometric data from primary types of each species were included in PCA computations. Variation in meristic and morphometric data of material examined are reported as means (mean \pm one standard seviation (SD)).

The base distribution map used to plot species records was modified from HydroSHEDS geospatial data compiled and developed by the Conservation Science Program of the World Wildlife Fund (http://hydrosheds.cr.usgs.gov/ index.php). Citations listed under synonyms in each species account are not purported to be exhaustive. Rather, citations are intended to provide the reader with the most relevant published and unpublished literature about this relatively poorly studied group of fishes.

Institutional abbreviations are: AMNH, American Museum of Natural History, New York; ANSP, Academy of Natural Sciences, Philadelphia; BMNH, British Museum of Natural History, London; CAS, California Academy of Sciences, San Francisco; CM, Carnegie Museum, Pittsburgh; FMNH, Field Museum of Natural History, Chicago; ICNMHN, Instituto de Ciencias Naturales, Museo de Historia Natural, Facultad de Ciencias, Universidad Nacional de Colombia, Bogotá; IDSM, Instituto de Desenvolvimento Sustentável Mamirauá, Mamiraua, Tefé; INHS, Illinois Natural History Survey, Champaign; INPA, Instituto Nacional de Pesquisas da Amazônia, Manaus; IU, Indiana University, Bloomington; MCP, Museu de Ciências e Tecnologia, Pontifícia Universidade Católica do Rio Grande do Sul, Porto Alegre; MCZ, Museum of Comparative Zoology, Harvard University, Cambridge; MEPN, Museo de Historia Natural, Escuela Politécnica Nacional, Quito; MHNG, Museum d'Histoire Naturelle, Genève; MNHN, Museum National d'Histoire Naturelle, Paris; MNRJ, Museu Nacional, Universidade Federal do Rio de Janeiro, Rio de Janeiro; MPEG, Museu Paraenese 'Emilio Goeldi', Belém; MUSM, Museo de Historia Natural, Universidad Nacional Mayor de San Marcos, Lima; MZUSP, Museu de Zoologia da Universidade de São Paulo, São Paulo; NMW, Naturhistorisches Museum, Wien; SIUC, Southern Illinois University, Carbondale; SU, Stanford 
University, Palo Alto (material deposited at CAS); UF, Florida Museum of Natural History, Gainesville; UMMZ, University of Michigan Museum of Zoology, Ann Arbor; UNIR \& UFRO-I, Universidade Federal de Rondônia, Porto Velho; USNM, National Museum of Natural History, Smithsonian Institution, Washington, D.C. The provenance of a few collections that were examined at the University of Arizona during the "Calhamazon" expeditions is currently unknown; these collections are listed as "CAL unk." in the material examined along with associated field numbers.

\section{Results}

\section{Tympanopleura Eigenmann, 1912}

Tympanopleura Eigenmann, 1912: 203. Type-species: Tympanopleura piperata Eigenmann, 1912. Type by original designation. Gender: feminine.
Diagnosis. Tympanopleura shares the following putative synapomorphies with other members of the Auchenipterinae (sensu Ferraris, 1988): lateral line sinusoidal and forked at the base of the caudal fin; urogenital pore of reproductively active adult males located at the distal tip of the anterior margin of the anal fin; urogenital pore of reproductively active adult females enlarged; and sexually dimorphic dorsal-fin spine. In the Auchenipterinae, Tympanopleura, Ageneiosus, Tetranematichthys, Entomocorus, Auchenipterus, Epapterus, and Pseudepapterus are distinct by the ventrolaterally positioned eyes visible in both dorsal and ventral views. Compared to species of Ageneiosus, the species of Tympanopleura have a more gently rounded anterior profile of the head (Fig. 1) and less protruded upper jaw, reflected by a shorter relative preorbital distance and distinctive differences in osteology associated with the jaws and cranium as detailed below.

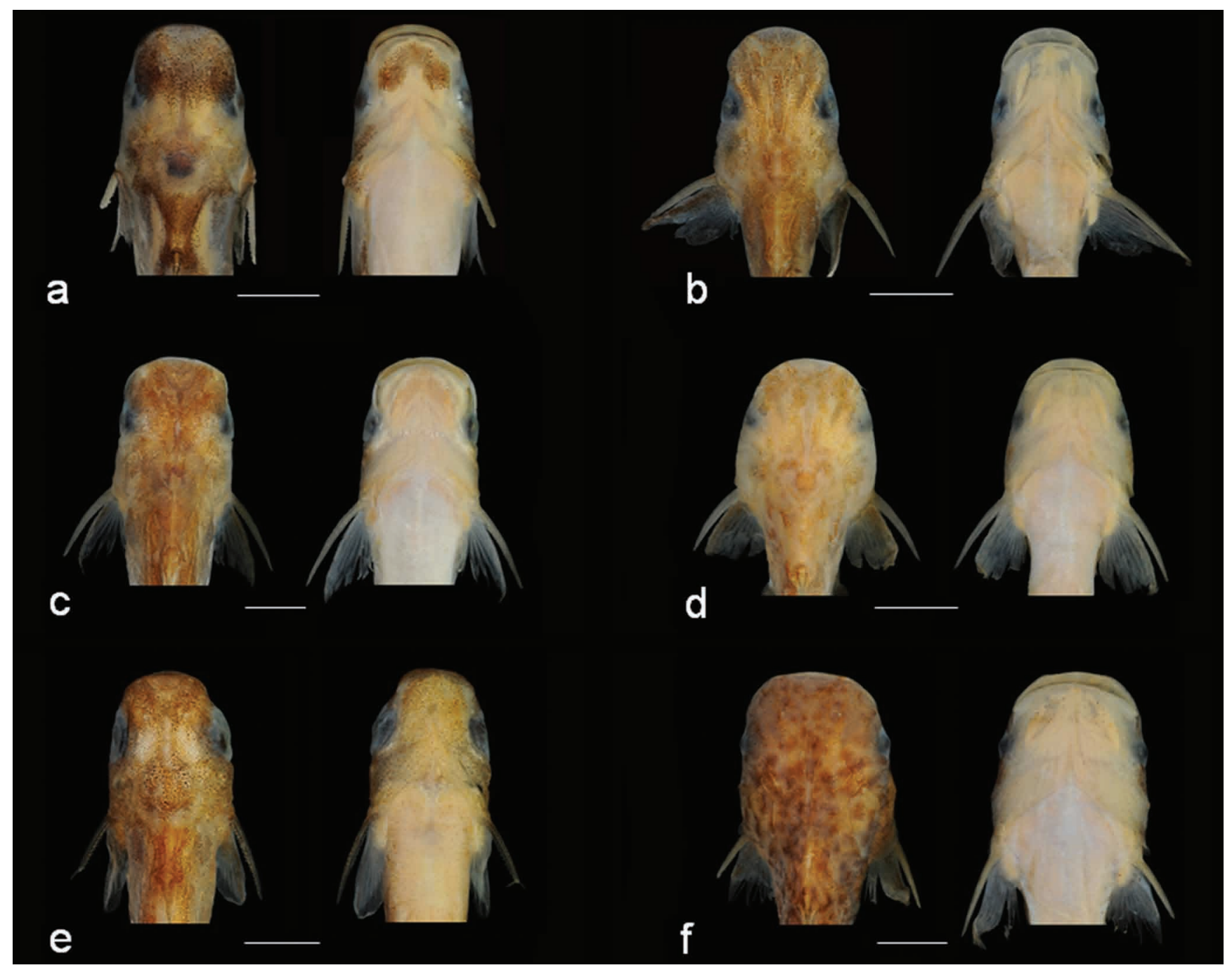

Fig. 1. Dorsal and ventral head profiles of species of Tympanopleura: (a) T. atronasus, INHS 106400 (82.4 mm SL); (b) T. brevis, ANSP 194010 (63.3 mm SL); (c) T. cryptica, INHS 40163 (84.9 mm SL); (d) T. longipinna, MZUSP 114000 (73.0 mm SL, holotype); (e) T. piperata, ANSP 194022 (45.6 mm SL); (f) T. rondoni, ANSP 194015 (75.3 mm SL). Scale bars: $\mathrm{a}-\mathrm{d}, \mathrm{f}=1 \mathrm{~cm} ; \mathrm{e}=5 \mathrm{~mm}$. 
Tympanopleura, Ageneiosus, and Tetranematichthys share the following unique combination of characters in the Auchenipterinae: anterior fork of the mesethmoid directed anterolaterally, at an approximate angle of $45^{\circ}$ relative to the anterior border of the bone (except in Ageneiosus inermis and A.polystictus); nasal bifurcated with an ossified accessory lateral tube directed anteriorly; vomer rounded anteriorly, without lateral projections (also in a number of unrelated siluriforms); snout elongate, greater than horizontal eye diameter (except in T. piperata); premaxilla variably developed posterolaterally, more elongated in species of Ageneiosus, less so in species of Tympanopleura and Tetranematichthys, where the posterior projection of the premaxilla does not reach past a plane passing through the posterior margin of the autopalatine; laminar expansion of bone on posteromedial margin of premaxilla; reduced number of teeth on posterior extremity of premaxilla; maxillary barbel very short; mandibular barbels absent in adults (Ageneiosus and Tympanopleura), or one pair present (Tetranematichthys; also in Gelanoglanis Böhlke); tooth-bearing surface of dentary expanded near symphysis, with variable number of tooth rows (greatest in Ageneiosus, reduced in Tympanopleura); reduction in number of bones in infraorbital series to four (also in Liosomadoras Fowler and Asterophysus Kner within the Auchenipteridae, in most doradids, and in a number of unrelated siluriforms); first infraorbital (lacrimal) bifurcated anteriorly; first infraorbital separated from neurocranium; second infraorbital flared posteriorly, funnel or trumpet shaped (tubular in Tetranematichthys); posterior infraorbital canal ossification separated from sphenotic, with an unossified section of the infraorbital sensory canal; parurohyal with medial projection directed dorsally and articulating with or extending between hypohyals (also in Tocantinsia Mees); osseus expansion on dorsal region of parurohyal weakly developed; anterior ceratohyal sutured to ventral hypohyal along ventromedial surface (also in Oxydoras Kner); anteriomedial tips of first two hypobranchials concave and obliquely angled anteriomedially; medial tip of first epibranchial larger than that of second, usually covering the latter element dorsally (except $T$. piperata); quadrate with enlarged dorsomedial lamina separating articular surfaces of hyomandibula and metapterygoid; bones of cephalic shield trabeculate; anterior nuchal plate absent [also in Epapterus, Pseudepapterus within the Auchenipteridae; but see Ferraris (1988)]; long anterolateral process on sphenotic (also in some doradids and unrelated African taxa); epioccipital bifurcated distally, with a posterior laminar extension, broadly sutured with expanded parapophyses of fifth and sixth vertebrae, median branch of posterior process larger than lateral branch (also in Pseudepapterus, Trachelyichthys, and Trachelyopterus); seventh vertebra not sutured to complex centrum (also in Pseudepapterus, Wertheimeria Steindachner within the Auchenipteridae), or in contact with an expansion of the ventral margin (Tetranematichthys); posterior process of coracoid absent or rudimentary (also in Diplomystes Bleeker); third pectoral-fin pterygiophore expanded distally and supporting several rays; postcleithral process absent, rudimentary, or only weakly developed (also in Pseudepapterus within the Auchenipteridae); anterior margin of dorsal-fin spine of nuptial males armed with antrorse serrae of varying configuration; 2-4 pairs of dorsal-fin inclinator muscles (also in Pseudepapterus and Trachelyopterus within the Auchenipteridae, versus 1 pair in other doradoids and unrelated taxa). Most of the derived features of the neurocranium as listed above are illustrated in Figs. 2-4.

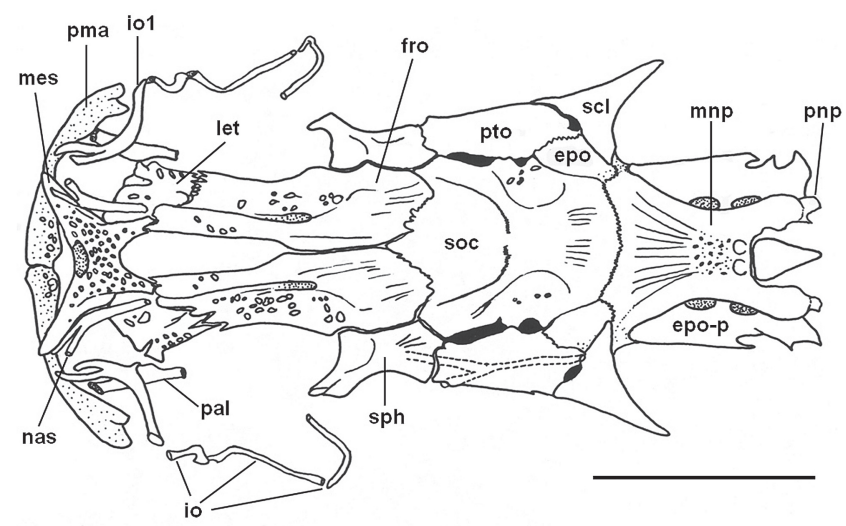

Fig. 2. Neurocranium of Tympanopleura rondoni in dorsal view, FMNH 58144 (50.3 mm SL; paratype of Ageneiosus madeirensis). Abbreviations: epo, epioccipital; epo-p, posterior process of epioccipital. fro, frontal; io, infraorbital; let, lateral ethmoid; mes, mesethmoid; mnp, median nuchal plate; nas, nasal; pal, autopalatine; pma, premaxilla; pnp, posterior nuchal plate; pto, pterotic; scl, posttemporalsupracleithrum; soc, supraoccipital; sph, sphenotic. Scale bar $=5 \mathrm{~mm}$.

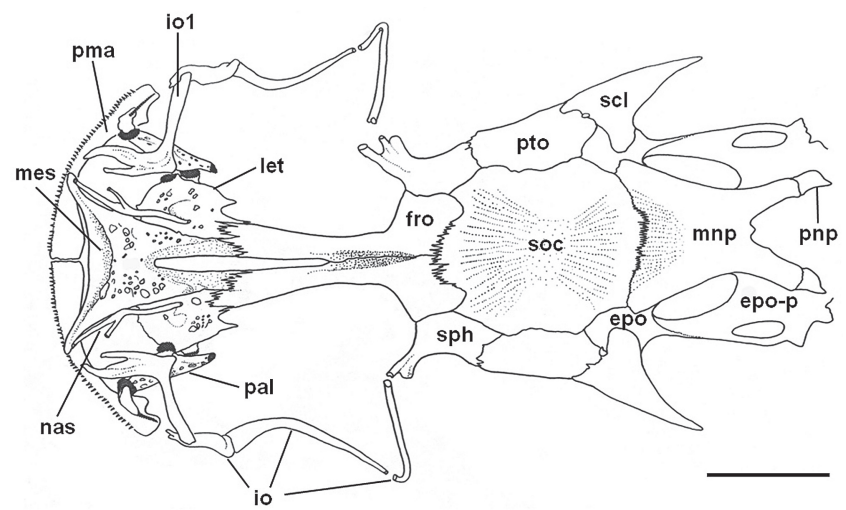

Fig. 3. Neurocranium of Tympanopleura atronasus in dorsal view, UF 185769 (91.0 mm SL). Abbreviations: epo, epioccipital; epo-p, posterior process of epioccipital. fro, frontal; io, infraorbital; let, lateral ethmoid; mes, mesethmoid; mnp, median nuchal plate; nas, nasal; pal, autopalatine; pma, premaxilla; pnp, posterior nuchal plate; pto, pterotic; scl, posttemporal-supracleithrum; soc, supraoccipital; sph, sphenotic. Scale bar $=5 \mathrm{~mm}$. 


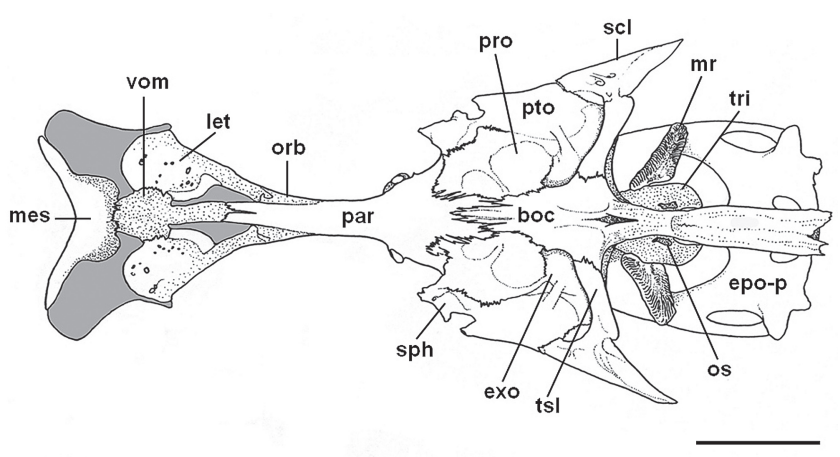

Fig. 4. Neurocranium of Tympanopleura atronasus in ventral view, UF 185769 (91.0 mm SL). Jaw apparatus, gas bladder, and some dorsomedial cranial bones omitted. Abbreviations: boc, basioccipital; epo-p, posterior process of epioccipital; exo, exoccipital; let, lateral ethmoid; mes, mesethmoid; mr, Müllerian ramus; orb, orbitosphenoid; os, os suspensorium par, parasphenoid; pro, prootic; pto, pterotic; scl, posttemporal-supracleithrum; sph, sphenotic; tri, tripus; tsl, transcapular ligament; vom, vomer. Scale bar $=5 \mathrm{~mm}$.

Tympanopleura and Ageneiosus are distinct from all other auchenipterids in lacking mandibular barbels as adults (but see Remarks), and, except for nuptial males, in having the maxillary barbels greatly reduced in size, filiform, and lying in a groove at the corner of the mouth above the upper lip. In nuptial males of species in these two genera, the maxillary barbel has an inner ossified core and is armed with sharp, recurved bony hooks on the anterodorsal and posterodorsal margins. Additionally, nuptial males of Tympanopleura and Ageneiosus have an elongated, sinusoidal or nearly straight dorsal-fin spine that can be hyperabducted anteriorly, and that is ornamented with prominent, sharp antrorse serrae on the anterior margin; these characters are shared to different degrees of development among genera and species in the Auchenipterini as proposed by Ferraris (1988), which includes Tympanopleura, Ageneiosus, Tetranematichthys, an Auchenipterus-group, Trachelyopterus, and Trachelyichthys.

Tympanopleura differs from Ageneiosus in having a smaller adult body size, a large cordiform gas bladder that is unencapsulated in bone, a prominent pseudotympanum, or hiatus of musculature where the gas bladder contacts the lateral body wall (Fig. 5) that is readily visible externally, and parapophyses of the fourth vertebrae (=Müllerian rami) consisting of large, discoidal plates closely adpressed to windows on the anterodorsal face of the anterior chamber of the the gas bladder. Tympanopleura, with the exception of T. piperata, also differs from Ageneiosus in having paired posterior diverticula on the gas bladder (but see Remarks).

In addition to the features described above that also distinguish Tympanopleura from Ageneiosus, Tympanopleura is further distinguished from Tetranematichthys by the absence of a single pair of mandibular barbels with serrated margins or multiple fleshy, digitiform processes at their distal tips (Vari \&
Ferraris, 2006; Peixoto \& Wosiacki, 2010). Additionally, nuptial male Tetranematichthys lack the characteristic sharp recurved bony hooks on the maxillary barbel present in Tympanopleura and Ageneiosus, and the swimbladder in Tetranematichthys has a large anterior chamber with posterior diverticula enlarged and fused, unlike the structure in Tympanopleura (Birindelli et al., 2012).

Description. Tympanopleura comprises species of small to medium sized auchenipterids, ranging in maximum size from about $50 \mathrm{~mm} \mathrm{SL} \mathrm{(T.} \mathrm{piperata)} \mathrm{to} 160 \mathrm{~mm} \mathrm{SL} \mathrm{(T.}$ rondoni). Body widest at pectoral-fin origin, moderately to strongly compressed posteriorly. Dorsal and ventral aspects of body gently tapered posteriorly, greatest body depth at base of dorsal fin. Head moderately depressed, dorsal profile gently sloping upward to anterior margin of supraoccipital, inflected more acutely to dorsal-fin origin. Mouth inferior to nearly terminal (T. piperata). Eye size variable between species but relatively large (8-36\% HL), displaced laterally and visible in both dorsal and ventral views, lacking circumorbital sulcus, covered with thick epidermis continuous with that on side of head. Large opercular opening, gill membranes broadly fused to isthmus. Premaxilla and dentary with relatively few irregular rows of small, unicuspid teeth; premaxilla not greatly expanded anteromedially. Salient aspects of head osteology as listed under Diagnosis.

Single pair of maxillary barbels, diminutive, filiform and fleshy for most of length in all but nuptial males, lying in small groove above upper lip. Maxillary barbel of nuptial male elongated, ossified entire length; at peak development with sharp, antrorse, tooth-like hooks on dorsomedial and ventromedial surfaces. Mandibular barbels absent in adults; small juveniles occasionally with 1-2 pair of minute chin barbels that become resorbed with growth.

Lateral-line canal extending from dorsomedial margin of posttemporal midlaterally along trunk to base of caudal fin, sinusoidal, with several short dorsal and ventral rami obliquely directed posteriorly, each branch passing to the surface and ending in a small pore. Lateral-line bifurcated at base of caudal fin with a short, branched ramus extending posteriorly a short distance on each fin lobe.

Suspensorium large but not greatly elongated and oriented in moderately oblique dorso-ventral plane. Quadrate with dorsomedial lamina extending between and broadly sutured to hyomandibular and metapterygoid, the latter bone laminar, roughly quadrangular, articulating synchondrally with quadrate near posteroventral corner. Hyomandibular articulates synchondrally with sphenotic by short anterodorsal process. Suprapreopercle small, rod-like, investing short section of preopercular latero-sensory canal anteroventral to exit from pterotic. Preopercle moderately large blade, smooth on all margins, sutured anteroventrally with quadrate. Preopercular latero-sensory canal with posterior and ventral branches exiting at anteroventral corner. Small bone, presumed mesopterygoid (but see 
Walsh, 1990) anterior to metapterygoid, superficially contacting vomer anteromedially, medial to palatine.

Hyoid arch consisting of unpaired urohyal, and paired hypohyal, ceratohyal, interhyal, epihyal, and branchiostegal bones. Urohyal broadly rounded anteriorly, with long, laminar projection posteriorly and a vertical extension between hypohyals anteromedially. Ceratohyal sutured anteriorly to ventral ossification of the hypohyal along its ventromedial surface; posteriorly, ceratohyal articulated suturally and synchondrally with interhyal. Total of 7-10 branchiostegal rays, first 6-7 supported by ceratohyal, remaining ones supported by interhyals. Second and third basibranchials ossified. First two hypobranchials ossified, obliquely concave on anterior margin, with medial cartilaginous flange anterior to lateral edge. Five ossified epibranchials and ceratobranchials; posterior ceratobranchial pair expanded posteromedially and supporting large pharyngeal tooth plates, each with short, conical teeth. Relatively large gill rakers on medial and lateral margins of epibranchials and ceratobranchials, numbering 4-10 on epibranchial, 9-24 on ceratobranchial. Pair of relatively large oval pharyngeal tooth plates supported by infrapharyngobranchials and posterior tips of ossified third and fourth epibranchials. Anteromedial tip of first epibranchial broadly flared and overlapping medial tip of second epibranchial.

Complex centrum formed by first six vertebrae, combined with modifications of posterior neurocranium and supporting elements of dorsal fin to form Weberian apparatus, the entire complex modified to form an elastic spring apparatus. Müllerian ramus large, discoidal, apposed anterodorsally to gas bladder tunica. Gas bladder enlarged, unencapsulated in bone, cordiform or longitudinally elongated, with a pair of short posterior terminal diverticula (except $T$. piperata). Large pseudotympanum formed by hiatus of epaxial musculature and lateral contact of gas bladder with body wall.

Pleural ribs 4-8, the first articulating with transverse process of sixth vertebra. Free vertebrae posterior to complex centrum 31-36. Preural (PU1) and ural (U1) centra fused. Parhypural fused with lower caudal plate formed by first and second hypurals, third and fourth hypurals fused; fusion pattern $\mathrm{PH}+1+2 ; 3+4,5$ (after Lundberg \& Baskin, 1969). Caudal fin strongly forked, principal caudal-fin rays typically i,7-8,i, 16-26 upper and 14-18 lower procurrent rays.

Dorsal fin with single small spinelet, large spine, six thin branched rays, five proximal pterygiophores, entire base of fin short. Dorsal spine pungent, typically with crenulate anterior margin and series of small, sharp or conical retrorse serrae on posterior margin in juveniles, females, and nonbreeding males. Nuptial males with highly modified dorsalfin spine, lengthened and thickened, anterior margin with sharp, antrorse serrae, typically in two rows basally, single row distally, aligned along or oblique to midsagittal plane; rear margin of spine smooth. Adipose fin small, posterior margin forming a free flap.
Cleithrum broadly fused to coracoid along entire anteroventral margin; coracoids broadly sutured at midline. Postcleithral process absent or reduced to a small conical projection. Pectoral fin with single pungent spine and 6-13 branched rays supported by three ossified radials, the last radial expanded posteriorly and supporting multiple rays. Anterior margin of pectoral-fin spine weakly to moderately crenulate or rugose, dorsal and ventral margins with shallow grooves to nearly smooth, posterior margin with 12-37 retrorse serrae extending along entire shaft, usually in single row, occasionally bifurcated or split into two rows proximally. Posterior margin of fin straight or slightly falcate, anterior rays longest.

Pelvic fin abdominal, with single unbranched and 6 branched rays, unbranched ray thickened. First branched ray longest, medial rays progressively shorter, distal margin of fin straight to slightly rounded.

Anal fin long, 23-42 rays. First pterygiophore typically with a small ray-like splint of bone anteriorly (occasionally two), and a single well-developed unbranched ray. Last pterygiophore with slightly expanded dorsal lamina and supporting two short-branched rays. Distal margin of fin straight to slightly convex; anterior rays longest, progressively shorter posteriorly. Anal fin sexually dimorphic; in prenuptial and nuptial males the fin forms an intromittent organ, with the first 5-6 rays thickened and elongated, and progressive development of a tube-like canal anteriorly and displacement of the urogenital pore to near the distal tip of the first fin ray.

Pigmentation on head, body, and fins relatively drab, consisting of nearly uniform brown to gray countershading and light to unpigmented areas on venter ( $T$. brevis, T. cryptica, T. longipinna), or with distinctive pattern consisting of prominent large blotches, irregular spots, or stippling (T. atronasus, $T$. piperata, and $T$. rondoni).

Remarks on the distinction between Tympanopleura and Ageneiosus. Although Tympanopleura and Ageneiosus are distinguished from all other auchenipterids in lacking mandibular barbels, this character state requires qualification in that it applies only to adult specimens, a condition that has not been cited in the literature. Walsh (1990) found one to two pairs of minute barbels on the chins of several juvenile specimens of two species of Tympanopleura and at least three species of Ageneiosus; barbels were described as short, fleshy, and apparently derived from superficial integument. We did not exhaustively examine all specimens used in this study for this character, but we were able to confirm the presence of chin barbels in at least a dozen specimens of T. atronasus as well as some specimens of T. piperata. Walsh (1990) described an apparent heterochronic process whereby mandibular barbels may appear early in development and are resorbed with growth, similar to a situation in some species of Pangasiidae (Karamchandani \& Motwani, 1956; Fumihito, 1989). As noted by Fox (1999), the lability of 
barbels in siluriforms and cypriniforms necessitates that caution be exercised when making comparisons between taxa, and that phylogenetic inferences on the basis of presence or absence of barbels, their structure, number, and location may be of value, but within a framework of additional corroborative morphological characters. There is a general lack of information regarding structure and function of mandibular barbels in siluriforms (Diogo \& Chardon, 2000), and a study of their embryological development and ontogenetic fate in Tympanopleura and Ageneiosus could be informative.

Species of Tympanopleura exhibit variation in the presence of a postcleithral process on the pectoral girdle. A small or rudimentary postcleithral process is typically present in $T$. brevis, T. cryptica, T. piperata, and $T$. rondoni. The postcleithral process appears to be uniformly absent in other species of Tympanopleura and in all species of Ageneiosus. The primitive condition for catfishes in general is the presence of a moderately developed, unornamented postcleithral process. However, there is considerable variation among siluriforms in size and ornamentation of the postcleithral process, and the structure has been independently reduced or lost in several lineages (Stewart, 1986). At the opposite extreme from Tympanopleura and Ageneiosus, most other auchenipterids have a well-developed postcleithral process, and in doradids it is generally prominent and in many species conspicuously ornamented with grooves and ridges (among auchenipterids, the postcleithral process is also reduced in Tetranematichthys and Pseudepapterus hasemani). Stewart (1986) noted a positive correlation between relative size of the postcleithral process and strength of the pectoral-fin spine and locking mechanism in pimelodids. A similar condition appears to exist in doradoids, and within Tympanopleura, those species with the most robust pectoral-fin spines (T. brevis and T. rondoni) have the most prominent postcleithral process, whereas the other species with weak pectoral-fin spines have the process reduced (rudimentary in T. cryptica and T. piperata) or absent altogether. Moreover, we noted considerable variation among species of Tympanopleura in which the postcleithral process is present; in some cases specimens either exhibited or lacked the postcleithral process (even within a single lot), and occasional individuals were observed to have the process variably developed bilaterally.

The unique structure of the doradoid gas bladder has long been of keen interest from a taxonomic, anatomical, and functional perspective (e.g., Bridge \& Haddon, 1889, 1892, 1893; Eigenmann, 1925; Chardon, 1968; Birindelli et al., 2009, 2012). Early authors considered a gas bladder greatly reduced in size and encapsulated in a bony capsule associated with the complex centrum and Weberian apparatus to be a diagnostic feature of Ageneiosus. In the original description of Ageneiosus (=Tetranematichthys) quadrifilis, Kner (1858) illustrated the unusal globular, bipartite gas bladder of this species, which may have subsequently led to some confusion about its taxonomic relationship relative to species that were considered at the time as congeners. The taxonomic scope of an Ageneiosus group and the known morphological variation of the gas bladder by species represented therein was expanded when Eigenmann (1912) described the genus Tympanopleura, for the type species T. piperata, based on the salient feature of the "air bladder projecting into the abdominal cavity, naked laterally, the skin over it forming a large pseudotympanum". This was further elaborated by Eigenmann \& Myers (in Myers, 1928) and by Eigenmann \& Allen (1942) with subsequent descriptions of the nominal species $T$. alta and T. nigricollis.

In a detailed comparative analysis of gas bladder morphology among auchenipterid genera, Birindelli et al. (2012) found a suite of characters of value for inference of phylogenetic relationships within the family. Most species of auchenipterids have relatively simple gas bladders, characterized as cordiform with smooth walls, internal T-shaped septa, and with the modified and expanded parapophyses of the fourth vertebrae (Müllerian rami) attached to the anterodorsal margins of the gas bladder. Together the Müllerian rami and protractor muscles form an elastic spring apparatus, a synapomorphy shared by auchenipterids and doradids (and also present in mochokids, ariids, malapterurids, and pangasiids), that is used in sound production (Fine \& Ladich, 2003; Kaatz \& Stewart, 2012). In their study, Birindelli et al. (2012) proposed eight characters and alternate states of each to construct a hypothesized phylogeny of the Auchenipteridae. Therein, the authors proposed an Ageneiosus group characterized by the shared presence of a gas bladder with posterior, short, thin terminal diverticula. Within their Ageneiosus group, the authors proposed two independent lineages, one consisting of species with a reduced, diminutive gas bladder and pseudotympanum, and a lineage with an unreduced gas bladder and large pseudotympanum, comprised of A. atronasus, A. brevis, and A. piperatus (herein placed in Tympanopleura). Recognition of distinct clades represented by species with an enlarged gas bladder and pseudotympanum versus those with reduced, variably ossified gas bladders was independently corroborated by Ribeiro (2011), in combination with other characters supporting a presumably monophyletic Tympanopleura lineage.

Given the prevailing evidence provided by recent and historic investigations, we formally recognize Tympanopleura as a valid genus and restrict Ageneiosus to related species that share a reduced gas bladder and pseudotympanum, and larger maximum adult body size. Nonetheless, considerable variation exists in gas bladder morphology, especially concerning its relative size, the ossification process (where present), and development (or secondary loss) of diverticula, such that much remains to be explored. Britski (1972) and Walsh (1990) found evidence of allometric and ontogenetic changes in size and degree of 
ossification in some species, and there appear to be possible homoplasies in gas bladder morphology among some species of Ageneiosus and Tympanopleura. Ageneiosus pardalis, a trans-Andean species, retains a large gas bladder, and $A$. militaris and A. magoi have only a partially reduced gas bladder, yet these species are postulated to be related to those taxa with greatly reduced, encapsulated gas bladders (Britski, 1972; Walsh, 1990; Ribeiro, 2011). Conversely, $T$. piperata, with a large gas bladder lacking diverticula, exhibits partial ossification of the tunica externa and internal longitudinal septum in adults. In summary, species of Tympanopleura are diagnosed by the shared condition of a prominent pseudotympanum (Fig. 5) and a large, cordiform or slightly elongate gas bladder (Fig. 6). In contrast, most species of Ageneiosus have, as adults, a greatly reduced gas bladder that is partially to fully encased in bone as a result of progressive ossification involving the complex centrum, and, possibly, ossification of the tunica itself (Fig. 7).

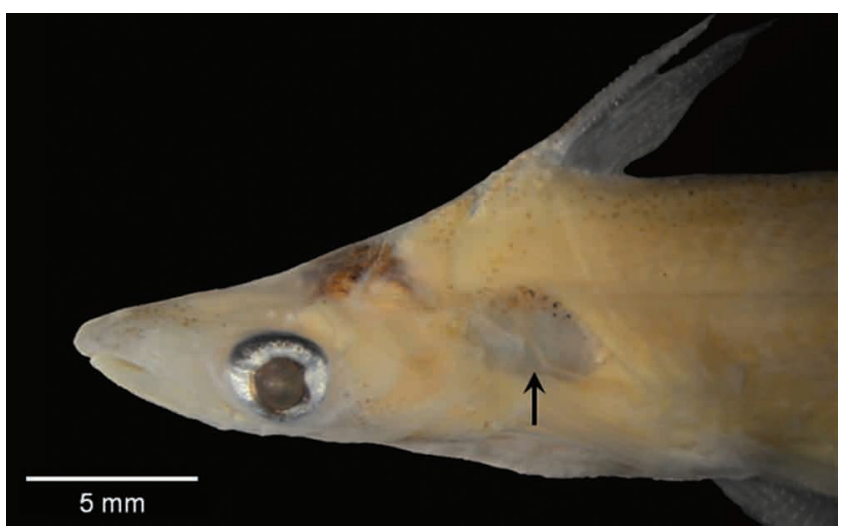

Fig. 5. Pseudotympanum (arrow) in Tympanopleura piperata, INHS 36738 (41.5 mm SL).

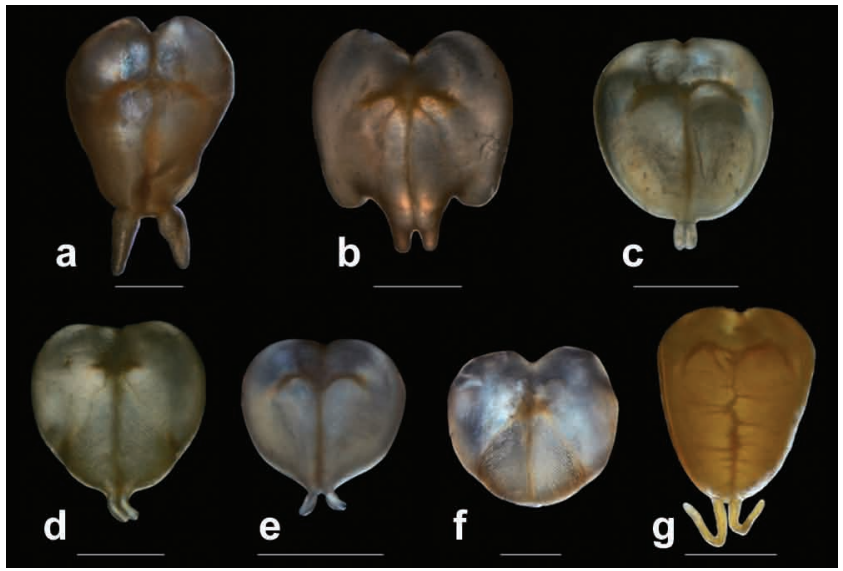

Fig. 6. Gas bladders of species of Tympanopleura in ventral view: (a) T. atronasus, INHS 106400 (79.9 mm SL); (b) T. atronasus, FMNH 93488 (107.3 mm SL); (c) T. brevis, SIUC 39913 (59.4 mm SL); (d) T. cryptica, INHS 40163 (60.5 mm SL); (e) T. longipinna, MZUSP 34417 (50.5 mm SL); (f) T. piperata, ANSP 194019 (42.5 mm SL); (g) $T$. rondoni. MZUSP $7862(117.6 \mathrm{~mm} \mathrm{SL})$. Scale bars: a-e $=5$ $\mathrm{mm} ; \mathrm{f}=2 \mathrm{~mm} ; \mathrm{g}=10 \mathrm{~mm}$.

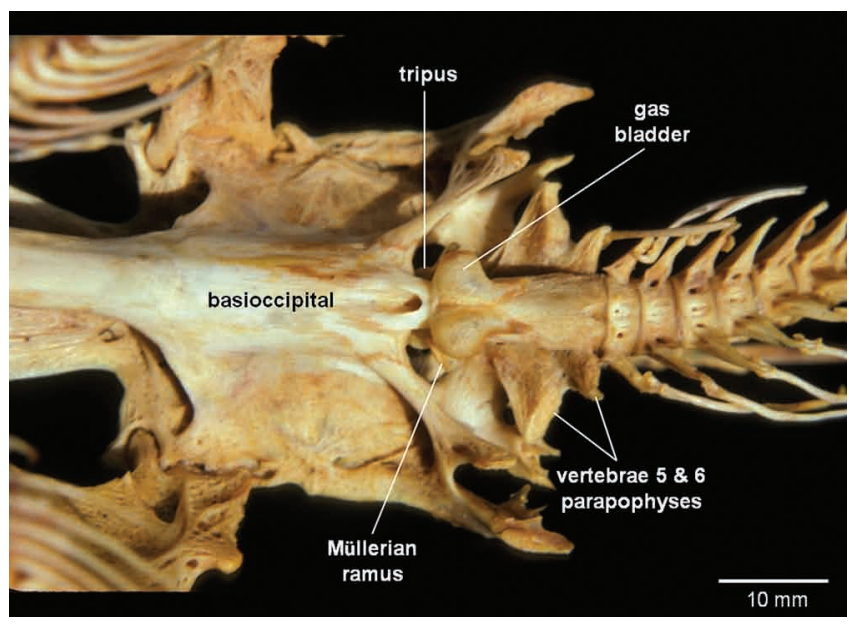

Fig. 7. Posterior neurocranium and anterior axial skeleton of Ageneiosus inermis, UMMZ 207464 (345 mm SL) in ventral view.

\section{Statistical analyses}

Meristics. Species of Tympanopleura, including the two described herein (T. cryptica and T. longipinna), are distinguished by a combination of counts of anal-fin rays, pectoral-fin rays, gill rakers on the anterolateral margin of the first arch, preanal and total vertebrae, and pleural ribs (Tables 1-6). Mean number of anal-fin rays for all species differed significantly in pair-wise comparisons (KruskalWallis ANOVA; $p<0.01$; Table 1$)$. The fewest anal fin rays are found in T. atronasus (23-30, mode 27), and the greatest are present in $T$. longipinna (32-42, mode 37). Modal pectoral-fin ray counts are fewest (9) in T. atronasus, $T$. cryptica, and T. piperata, and greatest (11) in T. brevis, $T$. longipinna, and T. rondoni (Table 2). Among all species, T. atronasus has the lowest total gill raker count (14-23, mode 16 , mean $=16.4), T$. rondoni has the highest (2433, mode 29-30, mean=28.3), and the other species are intermediate, with $T$. piperata differing significantly from all in having the second lowest modal and mean count (19; Table 3). Tympanopleura atronasus is distinctive in having the highest number of preanal vertebrae (16-19, mode 17), whereas the other species have mean and/or modal counts of 14-15 (Table 4). Likewise, there is considerable overlap in total number of vertebrae among all species (Table 5); $T$. longipinna and T. atronasus have a more elongated body and the highest count of total vertebrae (39-43), and T. cryptica has the fewest (38). Tympanopleura atronasus has more pleural ribs (7-8) than the other species (4-6; Table 6).

Morphometrics. A principal component analysis (PCA) of Tympanopleura species resulted in complete separation of $T$. longipinna and T. piperata along sheared principal component III (PC3) from a combination of $T$. atronasus, T. brevis, T. cryptica, and T. rondoni (Fig. 8a). The latter four species were generally separated from each other along sheared principal component II (PC2) with marginal 
overlap among groupings of two species each. In the multispecies comparison variable loadings on the first principal component were positive and indicative of principal component I (PC1) as a general size factor (Bookstein et al., 1985). PC1 accounted for $93.0 \%$ of the total variance in the complete covariance matrix, with sheared $\mathrm{PC} 2$ and sheared PC3 accounting for $3.0 \%$ and $1.6 \%$, respectively, thus totaling $97.6 \%$ for the first three principal components (Table 7). Variables that loaded most heavily with positive values along sheared PC2 were: eye diameter (0.36), caudal peduncle depth (0.31), caudal peduncle length (0.29), and pelvic-fin origin to adipose-fin origin (0.20). Variables that loaded most heavily with negative values along sheared PC2 were anterior internarial distance $(-0.31)$, snout length $(-0.29)$, upper jaw length $(-0.25)$, and gape width $(-0.23)$.
Along sheared PC3, heaviest positive loadings were for anal-fin base length (0.45), pelvic-fin origin to adipose-fin origin (0.33), and dorsal-fin origin to adipose-fin origin (0.22); greatest negative loading along this axis was for eye diameter $(-0.63)$. Not unexpectedly and corresponding to their greater anal-fin ray counts, $T$. longipinna and $T$. piperata stand apart from the other species in having relatively longer anal-fin base lengths; likewise, rank order of mean values of this measurement for the other species trended with the anal-fin ray counts of each species. As a proportion of SL, T. longipinna and T. piperata have greater distances from the pelvic-fin origin to dorsal-fin origin, and the dorsal-fin origin to adipose-fin origin in comparison to the other species. Relative to head length, T. piperata has the largest eye size, whereas $T$. rondoni has the smallest.

Table 1. Frequency distribution of anal-fin rays among species of Tympanopleura. Sample mean values with different letter superscripts are significantly different $(\mathrm{p} \leq 0.01) ; \mathrm{SD}=$ standard deviation.

\begin{tabular}{|c|c|c|c|c|c|c|c|c|c|c|c|c|c|c|c|c|c|c|c|c|c|c|c|}
\hline \multicolumn{24}{|c|}{ Anal-fin rays } \\
\hline & 23 & 24 & 25 & 26 & 27 & 28 & 29 & 30 & 31 & 32 & 33 & 34 & 35 & 36 & 37 & 38 & 39 & 40 & 41 & 42 & $\mathrm{~N}$ & mean & $\mathrm{SD}$ \\
\hline T. atronasus & 1 & 1 & 4 & 17 & 40 & 20 & 13 & 1 & & & & & & & & & & & & & 97 & $27.2^{\mathrm{a}}$ & 1.2 \\
\hline T. cryptica & 1 & & 1 & 1 & 4 & 11 & 19 & 2 & & & & & & & & & & & & & 39 & $28.2^{\mathrm{c}}$ & 1.3 \\
\hline T. longipinna & & & & & & & & & & 1 & & 2 & 7 & 18 & 21 & 11 & 10 & 2 & 1 & 1 & 74 & $37.0^{\mathrm{d}}$ & 1.7 \\
\hline T. rondoni & & & & & & 6 & 8 & 10 & 16 & 9 & 4 & 1 & 3 & 4 & 2 & & & & & & 63 & $31.3^{\mathrm{f}}$ & 2.4 \\
\hline
\end{tabular}

Table 2. Frequency distribution of pectoral-fin rays among species of Tympanopleura. Sample mean values with different letter superscripts are significantly different $(\mathrm{p} \leq 0.01)$; $\mathrm{SD}=$ standard deviation.

\begin{tabular}{|c|c|c|c|c|c|c|c|c|c|c|c|}
\hline \multicolumn{12}{|c|}{ Pectoral-fin rays } \\
\hline & 6 & 7 & 8 & 9 & 10 & 11 & 12 & 13 & $\mathrm{~N}$ & mean & SD \\
\hline T. atronasus & & 1 & 23 & 76 & & & & & 100 & $8.8^{\mathrm{a}}$ & 0.5 \\
\hline T. brevis & & & & & 4 & 32 & 10 & & 46 & $11.1^{\mathrm{b}}$ & 0.5 \\
\hline T. cryptica & & & 2 & 32 & 4 & & & & 38 & $9.1^{\mathrm{c}}$ & 0.4 \\
\hline T. longipinna & & & & & 5 & 52 & 16 & 3 & 76 & $11.2^{\mathrm{b}}$ & 0.6 \\
\hline T. piperata & 1 & 3 & 15 & 50 & 4 & & & & 73 & $8.7^{\mathrm{a}, \mathrm{c}}$ & 0.7 \\
\hline T. rondoni & & & & & 11 & 38 & 9 & 1 & 59 & $11.0^{\mathrm{b}}$ & 0.6 \\
\hline
\end{tabular}

Table 3. Frequency distribution of total gill rakers on anterolateral margin of first arch among species of Tympanopleura. Sample mean values with different letter superscripts are significantly different $(\mathrm{p} \leq 0.01) ; \mathrm{SD}=$ standard deviation.

\begin{tabular}{|c|c|c|c|c|c|c|c|c|c|c|c|c|c|c|c|c|c|c|c|c|c|c|c|}
\hline \multicolumn{24}{|c|}{ Total gill rakers } \\
\hline & 14 & 15 & 16 & 17 & 18 & 19 & 20 & 21 & 22 & 23 & 24 & 25 & 26 & 27 & 28 & 29 & 30 & 31 & 32 & 33 & $\mathrm{~N}$ & mean & SD \\
\hline T. atronasus & 3 & 6 & 8 & 6 & 3 & & & 1 & & 1 & & & & & & & & & & & 28 & $16.4^{\mathrm{a}}$ & 2.0 \\
\hline T. brevis & & & & & & & 1 & 6 & 8 & 10 & 3 & & & & & & & & & & 28 & $22.3^{\mathrm{b}}$ & 1.0 \\
\hline T. cryptica & & & & & & & & 5 & 7 & 5 & 3 & 2 & 1 & & & & & & & & 23 & $22.7^{\mathrm{b}}$ & 1.4 \\
\hline T. longipinna & & & & & & 1 & 1 & 3 & 3 & 13 & 2 & 6 & & & & & & & & & 29 & $22.9^{\mathrm{b}}$ & 1.5 \\
\hline T. piperata & & & 2 & 5 & 5 & 7 & 2 & 4 & 1 & 2 & & & & & & & & & & & 28 & $19.0^{c}$ & 1.9 \\
\hline T. rondoni & & & & & & & & & & & 1 & 4 & 6 & 7 & 4 & 10 & 10 & 1 & 3 & 1 & 47 & $28.3^{\mathrm{d}}$ & 2.1 \\
\hline
\end{tabular}


Table 4. Frequency distribution of number of preanal vertebrae among species of Tympanopleura. Sample mean values with different letter superscripts are significantly different $(\mathrm{p} \leq 0.01) ; \mathrm{SD}=$ standard deviation.

\begin{tabular}{|c|c|c|c|c|c|c|c|c|c|c|}
\hline \multicolumn{11}{|c|}{ Preanal vertebrae } \\
\hline & 13 & 14 & 15 & 16 & 17 & 18 & 19 & $\mathrm{~N}$ & mean & SD \\
\hline T. atronasus & & & & 2 & 20 & 16 & 2 & 40 & $17.5^{\mathrm{a}}$ & 0.7 \\
\hline T. brevis & & 7 & 5 & & & & & 12 & $14.4^{\mathrm{b}}$ & 0.5 \\
\hline T. cryptica & & 1 & 31 & & & & & 32 & $15.0^{\mathrm{b}, \mathrm{c}}$ & 0.2 \\
\hline T. longipinna & 3 & 22 & 3 & & & & & 28 & $14.0^{\mathrm{b}, \mathrm{d}}$ & 0.5 \\
\hline T. piperata & & 4 & 33 & 6 & & & & 31 & $15.0^{\mathrm{b}, \mathrm{c}}$ & 0.5 \\
\hline T. rondoni & & 10 & 32 & 5 & & & & 47 & $14.9^{\mathrm{b}, \mathrm{c}}$ & 0.6 \\
\hline
\end{tabular}

Table 5. Frequency distribution of total number of vertebrae among species of Tympanopleura. Sample mean values with different letter superscripts are significantly different $(\mathrm{p} \leq 0.01) ; \mathrm{SD}=$ standard deviation.

\begin{tabular}{|c|c|c|c|c|c|c|c|c|c|}
\hline \multicolumn{10}{|c|}{ Total vertebrae } \\
\hline & 38 & 39 & 40 & 41 & 42 & 43 & $\mathrm{~N}$ & mean & SD \\
\hline T. atronasus & & 5 & 5 & 22 & 10 & 1 & 43 & $40.9^{\mathrm{a}}$ & 1.0 \\
\hline T. brevis & 1 & 1 & 9 & 1 & & & 12 & $39.8^{\mathrm{b}}$ & 0.7 \\
\hline T. cryptica & 31 & & & 1 & & & 32 & $38.1^{\mathrm{c}}$ & 0.5 \\
\hline T. longipinna & & & 2 & 6 & 6 & 14 & 28 & $42.1^{\mathrm{d}}$ & 1.0 \\
\hline T. piperata & & 10 & 16 & 5 & & & 31 & $39.8^{\mathrm{b}}$ & 0.7 \\
\hline T. rondoni & 1 & 3 & 31 & 10 & 1 & & 46 & $40.2^{\mathrm{b}}$ & 0.7 \\
\hline
\end{tabular}

Table 6. Frequency distribution of pairs of pleural ribs among species of Tympanopleura. Sample mean values with different letter superscripts are significantly different $(\mathrm{p} \leq 0.01) ; \mathrm{SD}=$ standard deviation.

\begin{tabular}{|c|c|c|c|c|c|c|c|c|}
\hline \multicolumn{9}{|c|}{ Pairs of pleural ribs } \\
\hline & 4 & 5 & 6 & 7 & 8 & $\mathrm{~N}$ & mean & SD \\
\hline T. atronasus & & & & 26 & 11 & 37 & $7.3^{\mathrm{a}}$ & 0.5 \\
\hline T. brevis & & 10 & & & & 10 & $5.0^{\mathrm{b}}$ & 0.0 \\
\hline T. cryptica & 2 & 15 & & & & 17 & $4.9^{\mathrm{b}, \mathrm{c}}$ & 0.3 \\
\hline T. longipinna & 10 & 15 & & & & 25 & $4.6^{\mathrm{cd} d}$ & 0.5 \\
\hline T. piperata & 21 & 7 & & & & 28 & $4.3^{\mathrm{d}}$ & 0.4 \\
\hline T. rondoni & 2 & 5 & 32 & & & 39 & $5.8^{\mathrm{e}}$ & 0.5 \\
\hline
\end{tabular}

In order to evaluate shape differences between $T$. atronasus, T. brevis, T. cryptica, and T. rondoni, additional principal component analyses were made between combinations of two species each, with the exceptions of T. atronasus and T. brevis, T. atronasus and T. rondoni, and T. cryptica and T. rondoni, each combination of which showed no overlap in the plot of principal component scores in the multi-species comparison. In each dualspecies comparison, plots of principal component scores resulted in complete separation along the sheared PC2 axis (Figs. 8b-d).

In the PCA between T. atronasus and T. cryptica (Fig. $8 \mathrm{~b}), \mathrm{PC} 1$ accounted for $92.8 \%$ of the variance for the total covariance matrix, with $96.6 \%$ of the cumulative variance attributed to the first three principal components.
Measurements with greatest positive loadings along sheared PC2 were body depth at dorsal-fin origin $(0.42)$, pectoral spine length (0.29), adipose-fin origin to anal-fin insertion (0.25), and pectoral-fin origin to dorsal-fin origin (0.23), proportional values of which were all greater in $T$. cryptica. Greatest negative loadings along sheared PC2 were for caudal peduncle length $(-0.40)$, preanal length $(-0.27)$, prepelvic length $(-0.25)$, and eye diameter $(-0.25)$, proportional values of which were all slightly greater in T. atronasus. Additionally, mean ratios that were slightly greater in $T$. cryptica than in $T$. atronasus included predorsal length, prepectoral length, body width at pelvicfin origin, and head length. As reflected in number of analfin rays, the anal-fin base length of T. atronasus is shorter than that of T. cryptica. 
Table 7. Variable loadings for within-group size factor and sheared principal components representing 29 morphometric variables from a principal component analysis (PCA) of six Tympanopleura species combined.

\begin{tabular}{|c|c|c|c|}
\hline Measurement & Size & Sheared PC2 & Sheared PC3 \\
\hline Standard length & 0.17 & 0.09 & 0.05 \\
\hline Preadipose length & 0.17 & 0.10 & 0.07 \\
\hline Preanal length & 0.20 & 0.06 & -0.13 \\
\hline Predorsal length & 0.19 & -0.10 & -0.18 \\
\hline Prepelvic length & 0.19 & 0.05 & -0.17 \\
\hline Prepectoral length & 0.19 & -0.17 & -0.10 \\
\hline Pectoral-fin origin to dorsal-fin origin & 0.18 & -0.18 & 0.05 \\
\hline Pelvic-fin origin to dorsal-fin origin & 0.19 & 0.12 & 0.02 \\
\hline Pelvic-fin origin to adipose-fin origin & 0.14 & 0.20 & 0.33 \\
\hline Dorsal-fin origin to adipose-fin origin & 0.16 & 0.26 & 0.22 \\
\hline Adipose-fin origin to anal-fin insertion & 0.15 & 0.10 & 0.13 \\
\hline Body depth at dorsal-fin origin & 0.17 & -0.02 & 0.07 \\
\hline Caudal peduncle depth & 0.18 & 0.31 & -0.05 \\
\hline Caudal peduncle length & 0.18 & 0.29 & -0.05 \\
\hline Body width at pectoral-fin origin & 0.18 & -0.17 & 0.17 \\
\hline Body width at pelvic-fin origin & 0.19 & 0.16 & 0.03 \\
\hline Pectoral spine length & 0.19 & -0.08 & -0.04 \\
\hline Anal-fin base length & 0.10 & 0.11 & 0.45 \\
\hline Head length & 0.20 & -0.17 & -0.11 \\
\hline Head depth at occiput & 0.17 & -0.03 & -0.02 \\
\hline Head width at postorbitals & 0.20 & -0.09 & -0.03 \\
\hline Dorsal interopercular width & 0.19 & 0.02 & 0.04 \\
\hline Anterior internarial distance & 0.22 & -0.31 & 0.04 \\
\hline Preisthmus length & 0.20 & -0.08 & -0.05 \\
\hline Snout length & 0.23 & -0.29 & 0.04 \\
\hline Gape width & 0.22 & -0.23 & 0.00 \\
\hline Upper jaw length & 0.22 & -0.25 & -0.17 \\
\hline Lower jaw length & 0.22 & -0.19 & -0.17 \\
\hline Eye diameter & 0.14 & 0.36 & -0.63 \\
\hline$\%$ Variance & 93.0 & 3.0 & 1.6 \\
\hline Cumulative\% & & 96.0 & 97.6 \\
\hline
\end{tabular}

In the PCA between T. brevis and T. cryptica (Fig. $8 \mathrm{c})$, cumulative variance totaled $94.3 \%$ for the first three principal components with $87.2 \%$ of that attributed to PC1. Measurements with greatest positive loadings along sheared PC2 were caudal peduncle depth (0.48), caudal peduncle length (0.31), adipose-fin origin to anal-fin insertion (0.23), and body width at pelvic-fin origin (0.21); mean ratios of these variables relative to SL were all greater in T. cryptica than in T. brevis. Measurements with greatest negative loadings along sheared PC2 were snout length $(-0.37)$, upper jaw length (-0.32), lower jaw length $(-0.22)$, and prepectoral length (-0.21). Relative to T. cryptica, T. brevis has a shorter, more slender caudal peduncle, and a more spatulate shaped head and inferior mouth. 
In the PCA between T. brevis and T. rondoni (Fig. 8d), proportion of variance for the first principal component and cumulatively for the first three principal components totaled $95.0 \%$ and $98.0 \%$, respectively. Greatest positive loadings along sheared PC2 were for eye diameter (0.44), anal-fin base length (0.32), pelvic-fin origin to adiposefin origin (0.30), and pectoral spine length (0.28), mean proportional values of which were all greater for T. brevis. Measurements with greatest negative loadings along
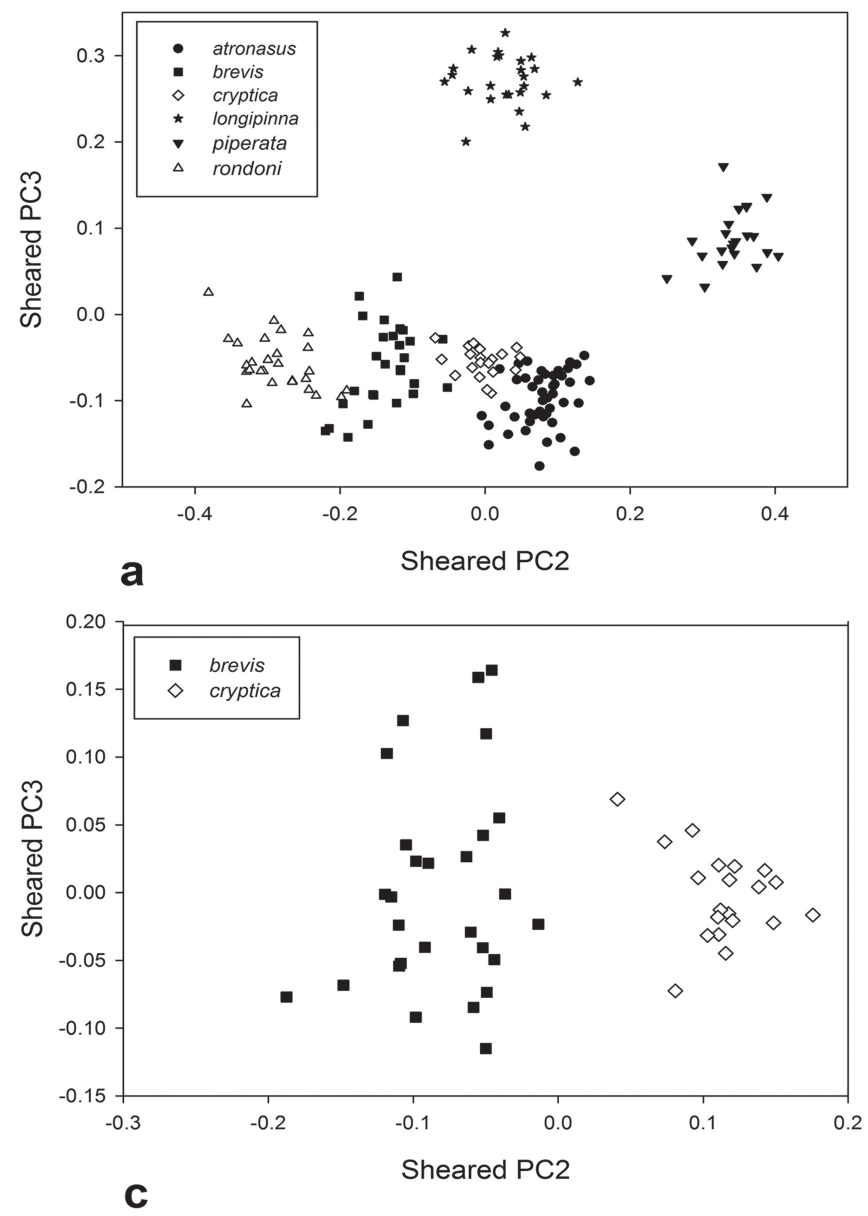

sheared PC2 were anterior internarial distance $(-0.29)$, gape width $(-0.28)$, head depth at supraoccipital $(-0.27)$, and head width at postorbitals $(-0.26)$, mean ratios of which were all greater for $T$. rondoni. Among others, measurements with slightly higher mean proportional values in $T$. rondoni in comparison to $T$. brevis included preanal length, prepectoral length, and head length. In essence, $T$. rondoni has a slightly more robust body and head shape than T. brevis.
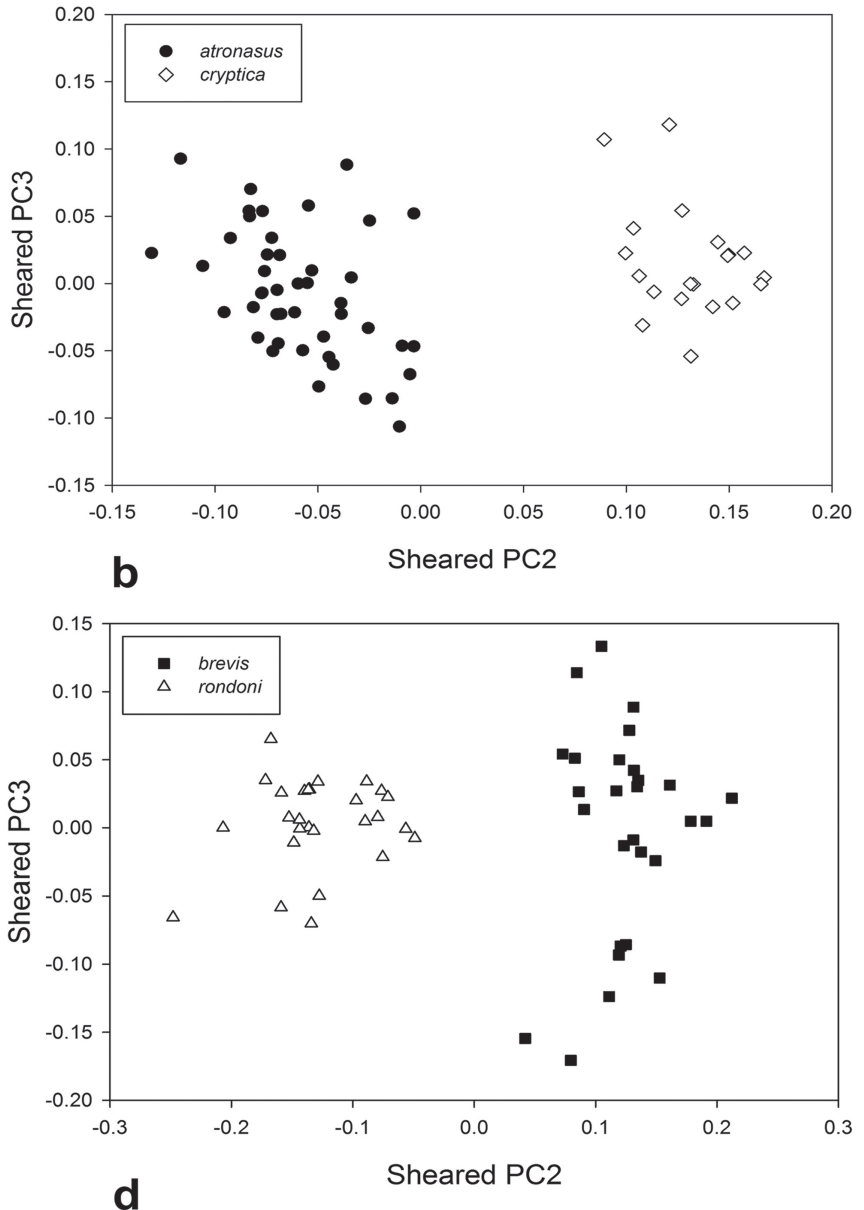

Fig. 8. Scatter plots of principal component scores from sheared principal component analysis of 29 morphometric variables for: (a) all species of Tympanopleura combined, and two-way comparisons of (b) T. atronasus and T. cryptica, (c) T. brevis and T. cryptica, and (d) T. brevis and T. rondoni.

\section{Species accounts}

\section{Tympanopleura atronasus}

(Eigenmann \& Eigenmann, 1888)

Figs. 1a, 3, 4, 6a-b, 9

Ageneiosus atronasus Eigenmann \& Eigenmann, 1888: 119, 149150 [type-locality: South America, exact locality unknown, presumably Brazil; holotype MCZ 27270]. -Eigenmann \& Eigenmann, 1890: 300, 302-303 [in key; description after Eigenmann \& Eigenmann, 1888; comparison with Ageneiosus brevis]. -Eigenmann \& Eigenmann, 1891: 35 [checklist]. -Eigenmann, 1910: 397 [checklist]. -Miranda Ribeiro, 1911: 402 [brief description; comparison with A. brevis; distinction from latter in footnote of key erroneously based on "barbilhâo espinhoso"]. -Gosline, 1945: 24 [checklist]. -Fowler, 1951: 451 [checklist; literature compilation]. -Burgess, 1989: 286 [checklist]. -Ferraris, 2003: 471 [checklist; synonymy after Walsh, 1990; typelocality; holotype; general distribution; common name after Ortega \& Vari, 1986 (in Peru, as T. nigricollis)]. -GranadoLorencio et al., 2005: 518 [occurrence in Amazonian floodplain lakes; in tables; identification not verified]. -Hardman, 2005: 710, 715 [molecular phylogeny]. -Mojica 
et al., 2005: 204 [checklist; Colombian Amazon; ICNMHN cataloged lots $(4464,5977,6386,6574)$; identifications not verified]. -Bogotá-Gregory \& Maldonado-Ocampo, 2006: 82 [checklist; Colombian Amazon, after Mojica et al., 2005]. -Akama \& Sarmento-Soares, 2007: 116 [checklist; middle and upper Amazon River basin]. -Ferraris, 2007: 68, 550, 556 [type checklist; synonymy after Walsh, 1990 and Ferraris, 2003; holotype; distribution in middle and upper Amazon River basin]. -Granado-Lorencio et al., 2007: 689 [in table; see Granado-Lorencio et. al., 2005]. -Hercos et al., 2007: 46 [in list of material cataloged into IDSM collection; collection locality not given; identification(s) not verified]. -Anjos et al., 2008: 202, 209 [in table; upper Purus River basin, occurrence in Caeté River; photograph (INPA 28507)]. -Maldonado-Ocampo et al., 2008: 208 [checklist; Colombian Amazon, after Mojica et al., 2005, BogotáGregory \& Maldonado-Ocampo, 2006; identification(s) not verified]. -Barriga-Salazar, 2012: 115 [checklist; Ecuador, Napo-Pastaza "ichthyohydrographic" zone]. -Birindelli et al., 2012: 655-656, 658-660, figs. 6a, 9 [gas bladder morphology; phylogenetic hypothesis; in material examined (MZUSP 52620\{2\}, MZUSP 85285\{1\}; photograph of gas bladder; identifications not verified]. -Birindelli, 2014: 543 [phylogeny of Doradoidea; in material examined (MZUSP $52620\{22,2 \mathrm{c} / \mathrm{s}\}$, MZUSP $63629\{1, \mathrm{c} / \mathrm{s}\}$, MZUSP 74483\{2\}].

Ageneiosus melanopogon Miranda Ribeiro, 1917: 51-52 [typelocality: Brazil, fluvio Solimões; disposition of type(s) unknown]. -Gosline, 1945: 25 [checklist]. -Fowler, 1951: 453 [checklist; literature compilation]. Burgess, 1989: 286 [checklist]. -Ferraris, 2003: 471 [checklist; as synonym of A. atronasus after Walsh, 1990; type-locality; holotype not found]. -Ferraris, 2007: 68 [type checklist; as synonym of $A$. atronasus after Walsh, 1990; information duplicated from Ferraris, 2003].

Tympanopleura nigricollis Eigenmann \& Allen, 1942: 139; plate 5, figs. 2-3; plate 6, fig. 3 [type-locality: Peru, Iquitos; holotype CAS 57940]. -Fowler, 1945: 67 [checklist]. -Fowler, 1951: 456457, fig. 484 [checklist; literature compilation; alto Amazonas, Peru]. -Gosline, 1945: 26 [checklist]. -Ortega \& Vari, 1986: 14 [checklist; literature compilation, in part; common name (Peru)]. -Burgess, 1989: 286 [checklist]. -Ferraris, 2003: 471 [checklist; as synonym of $A$. atronasus after Walsh, 1990; type-locality; holotype]. -Ferraris, 2007: 68 [type checklist; as synonym of $A$. atronasus after Walsh, 1990].
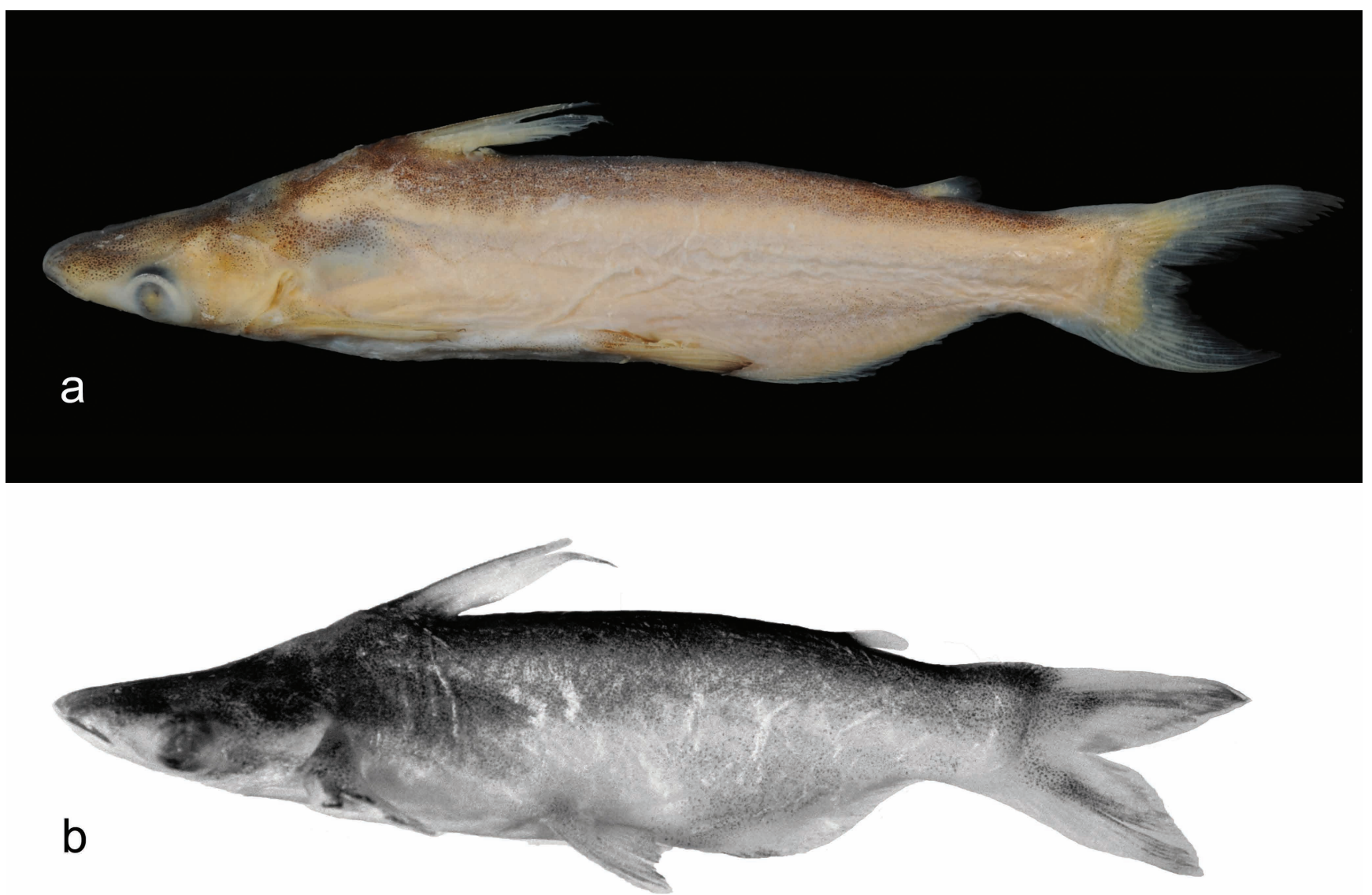

Fig. 9. Tympanopleura atronasus. (a) INHS 106400 (96.4 mm SL), female, Rio Nanay, Loreto Region, Peru; (b) UF 185769 (89.4 mm SL, male), rio Amazonas, Amazonas State, Brazil. 
Diagnosis. Tympanopleura atronasus is unique among congeners in having the greatest number of pleural ribs (7-8 pairs vs. 4-6 in all other species). It can be further distinguished from other species of Tympanopleura by the following combination of characters: a large, dark patch of dense melanophores concentrated on the flank above the anal fin ( $v s$. diffuse pigment or unpigmented), longitudinal black to purplish stripe in each caudal-fin lobe (vs. absent), a broad, black crescent on the chin (vs. diffuse pigment or unpigmented, except T. cryptica). Tympanopleura atronasus differs from $T$. cryptica in having fewer gill rakers (14-23, mode 16 vs. 21-26, mode 22), more preanal vertebrae (16-19 vs. 14-15), more total vertebrae (39-43, mode 41 vs. 38-41, mode 38), and a shorter distance between pectoral- and dorsal-fin origins (15.7-20.9\% SL vs. 21.6$24.3 \%$ SL). Tympanopleura atronasus is distinguished from $T$. brevis in having fewer anal-fin rays (23-30 vs. 3136 ), fewer pectoral-fin rays (7-9 vs. 10-12), fewer gill rakers on the first arch (14-23, mode $16 v s$. 20-24, mode 23), more preanal vertebrae (16-19 vs. 14-15), and shorter distance between pectoral- and dorsal-fin origins (15.7-20.9\% SL vs. 21.4-27.0\% SL). Tympanopleura atronasus differs from $T$. longipinna in having fewer anal-fin rays (23-30 vs. 32-42), fewer pectoral-fin rays (7-9 vs. 10-13), fewer gill rakers (1423 , mode 16 vs. 19-25, mode 23), more preanal vertebrae (16-19 vs. 13-15), fewer total vertebrae (39-43, mode 41 vs. 40-43, mode 43), greater prepelvic length (49.2-55.2\% SL vs. $38.8-48.4 \% \mathrm{SL})$, and a shorter anal-fin base (22.1-27.6\% SL vs. 33.9-39.9\% SL). Tympanopleura atronasus differs from $T$. piperata in having fewer anal-fin rays (23-30 vs. 31-38), fewer gill rakers (14-23, mode 16 vs. 16-23, mode 19), more preanal vertebrae (16-19, mode $17 v s$. 14-16, mode 15), more total vertebrae (39-43, mode 41 vs. 39-41, mode 40), greater prepelvic length (49.2-55.2\% SL vs. 41.3-47.0\% $\mathrm{SL})$, shorter anal-fin base (22.1-27.6\% SL vs. 30.9-39.3\% SL), presence of paired posterior diverticula on the gas bladder (vs. absent), and absence of a transverse, hourglass-shaped bar of pigment on the base of the caudal fin (vs. usually present). Tympanopleura atronasus is distinguished from T. rondoni in having fewer anal-fin rays (23-30, mode 27 vs. $28-37$, mode 31 ), fewer pectoral-fin rays (7-9 vs. 10-13), fewer gill rakers (14-23 vs. 24-33), more preanal vertebrae (16-19, mode 17 vs. 14-16, mode 15), more total vertebrae (39-43, mode 41 vs. 38-42, mode 40), shorter, non-recurved posterior diverticula on gas bladder (Fig. 6a, b), larger eye diameter (16.0-27.8\% HL vs. 8.4-17.0\% HL), and absence of prominent, irregular spots distributed extensively on the head and body (vs. present). Tympanopleura atronasus reaches a considerably larger maximum size (about $116 \mathrm{~mm}$ SL) than T. cryptica, T. longipinna, and T. piperata (all less than about $80 \mathrm{~mm} \mathrm{SL}$ ).

Description. Morphometric data are summarized in Table 8 . Tympanopleura atronasus is a medium-sized auchenipterid. Size range 53.0-139.0 mm SL $(\mathrm{n}=109)$ for specimens of undetermined sex, mature females, and non-nuptial males.
Size range 72.2-109.9 mm SL ( $\mathrm{n}=34)$ for penuptial and nuptial males. Dorsal profile of head weakly convex from tip of snout to dorsal-fin origin. Dorsal profile of body from behind dorsal fin to caudal fin slightly convex to nearly straight. Abdomen convex from cleithrum to anal-fin origin. Ventral contour of body along anal-fin base angled upward in straight line roughly parallel to dorsal profile of head behind eyes. Caudal peduncle relatively deep, 8.2-12.7\% SL. Body not markedly compressed at pectoral- or pelvic-fin base, but rather gradually tapered to base of caudal fin.

Head length $25.3-31.2 \%$ SL. Mouth subterminal, the upper jaw extending anterior to tip of lower jaw approximately the width of the premaxillary tooth band. Snout short, 36.9-49.5\% HL, forming a broad arc in dorsal profile. Posterior edge of lower jaw reaching to just below middle of eye. Premaxillary and dentary tooth bands narrow, teeth small, straight to slightly recurved, not in discrete rows. Eye large, 16.0-27.8\% HL, covered by thick epidermis and invested by opaque subepidermal fat deposits on anterior and posterior margins; eyes lateral, equally visible from ventral and dorsal profile (Fig. 1a). Fontanelle groove short, deep, bounded by relatively high ridges on central portion of frontals. Anterior nares lateral to distal tip of mesethmoid wings and directed forward; posterior nares remote, not bordering lateral margins of frontals, each with very short flap of epidermis surrounding entire margin. Gill membranes broadly fused to isthmus along anterolateral margin of cleithrum; pre-isthmus length 66.4$82.5 \%$ HL. Branchiostegal rays 7-9 (mode 8 ; $\mathrm{n}=51$ ). Total gill rakers on anterolateral margin of first arch 14-23 (mode 16; $\mathrm{n}=28$ ); first epibranchial with 4-8 (mode 5) gill rakers, first ceratobranchial with 9-15 (mode 11). Longest gill rakers near middle of arch thin, flat, and typically crenulate on medial margin; tapering, short, smooth, and more conical gill rakers near ends of each arch.

Maxillary barbels of females and non-nuptial males small, filiform, concealed in premaxillary groove above and extending slightly posterior of upper lip, length 10.823.2\% HL (mean=15.0 $\pm 3.0 \mathrm{SD} ; \mathrm{n}=27$ ). Maxillary barbel of prenuptial males ossified at base with short, fleshy terminus, extending beyond rictus, length $19.7-34.1 \% \mathrm{HL}$ (mean=27.7 $\pm 3.8 \mathrm{SD} ; \mathrm{n}=16$ ). Maxillary barbel of nuptial males greatly thickened and ossified, typically abducted anterolaterally in preserved specimens, length $30.7-34.3 \%$ HL (mean=33.3 $\pm 1.2 \mathrm{SD} ; \mathrm{n}=8$ ). Maxillary barbel of nuptial males also distinguished by having 4-10 (mode $8 ; n=11)$ sharp, recurved, ossified hooks; 4-7 (mode 5) hooks on dorsolateral margin, 1-4 (mode 3) hooks on dorsomedial margin. Single pair of minute mandibular barbels variably present and concealed in shallow epidermal folds in specimens 52-105 $\mathrm{mm}$ SL, vestigial or resorbed in larger individuals; origin of mandibular barbels medial to lateral margins of dentaries and in approximate plane between front margin of eyes.

Dorsal fin rays II,6, consisting of a small spinelet, elongated spine, and branched rays progressively shorter in length from anterior to posterior. Dorsal-fin origin 
slightly posterior to vertical plane through pectoralfin insertion. Dorsal-fin spine relatively long in females and non-reproductive males, length $17.5-24.8 \%$ SL (mean=20.0 $\pm 1.6 \mathrm{SD} ; \mathrm{n}=20$ ). Anterior margin of dorsal-fin spine in non-reproductive specimens weakly crenulated proximally, lacking prominent, sharp serrae; lateral margin of spine with weak longitudinal grooves and ridges; posterior margin with 18-33 small, sharp, retrorse serrae (mean=24.7 $\pm 4.7 \mathrm{SD} ; \mathrm{n}=15$ ) or low-crowned crenulations; serrae or crenulations distributed primarily on distal twothirds to three-fourths length of spine. Dorsal spine of nuptial males (75-110 mm SL) greatly elongated, length 27.6-42.8\% SL (mean=36.8 $\pm 4.4 \mathrm{SD} ; \mathrm{n}=8$ ), slightly inflected anteriorly near midpoint, and with 47-57 (mean $=53 \pm 3.8 \mathrm{SD}$; $\mathrm{n}=8$ ) antrorse serrae along anterior margin; serrae arranged in an alternating, opposing, anterolateral direction along distal portion of spine, serrae shorter and in a single center row on proximal half and embedded within a thick keel of soft tissue; posterior margin of spine smooth or only with a few minute, proximal denticulations. Adipose fin small, posterior margin free.

Anal fin short, base 22.1-27.6\% SL, with 23-30 rays (mode 27; $\mathrm{n}=97$ ); distal margin straight to slightly convex except in nuptial males. Anal-fin pterygiophores 23-27 (mode 25; $\mathrm{n}=19$ ). First 5 anal-fin rays of prenuptial and nuptial males unbranched, elongated, and thickened to form intromittent organ; gonopore located distally on leading edge of anal fin about one-third to one-half distance from base to tip of longest ray in prenuptial specimens, to near the tip of the leading ray in fully nuptial specimens.

Table 8. Morphometric data for specimens of Tympanopleura atronasus. Synoptic material includes the holotype and four paratypes of $T$. nigricollis (CAS 57940, CAS 57941[2], CAS 57942). SD=standard deviation.

\begin{tabular}{|c|c|c|c|c|c|}
\hline & $\mathrm{N}$ & Range & Mean & $\mathrm{SD}$ & Holotype MCZ 27270 \\
\hline Standard length (SL, mm) & 51 & $56.3-116.5$ & --- & --- & 72.2 \\
\hline \multicolumn{6}{|c|}{ Percent of SL } \\
\hline Preadipose length & 50 & $74.3-84.8$ & 81.8 & 1.6 & 82.1 \\
\hline Preanal length & 51 & $55.9-68.3$ & 64.6 & 2.0 & 64.5 \\
\hline Predorsal length & 51 & $29.9-41.2$ & 34.8 & 1.9 & 36.0 \\
\hline Prepelvic length & 51 & $49.2-55.2$ & 51.8 & 1.4 & 53.6 \\
\hline Prepectoral length & 51 & $25.6-30.7$ & 28.4 & 1.2 & 29.6 \\
\hline Pectoral-fin origin to dorsal-fin origin & 51 & $15.7-20.9$ & 19.2 & 0.9 & 18.6 \\
\hline Pelvic-fin origin to dorsal-fin origin & 49 & $21.2-29.1$ & 25.9 & 1.9 & 24.9 \\
\hline Pelvic-fin origin to adipose-fin origin & 49 & $31.2-38.1$ & 34.8 & 1.5 & 32.5 \\
\hline Dorsal-fin origin to adipose-fin origin & 49 & $43.6-52.9$ & 48.6 & 2.2 & 47.9 \\
\hline Adipose-fin origin to anal-fin insertion & 49 & $10.8-16.5$ & 13.6 & 1.3 & 12.9 \\
\hline Body depth at dorsal-fin origin & 51 & $13.6-23.5$ & 19.8 & 1.8 & 18.7 \\
\hline Caudal peduncle depth & 51 & $8.2-12.7$ & 10.6 & 0.9 & 10.2 \\
\hline Caudal peduncle length & 51 & $11.0-15.2$ & 13.1 & 1.0 & 11.4 \\
\hline Body width at pectoral-fin origin & 51 & $17.8-22.9$ & 21.0 & 1.0 & 20.4 \\
\hline Body width at pelvic-fin origin & 51 & $6.4-13.1$ & 11.7 & 1.2 & 11.5 \\
\hline Pectoral spine length & 44 & $13.3-19.0$ & 17.0 & 1.2 & 17.0 \\
\hline Anal-fin base length & 51 & $22.1-27.6$ & 24.5 & 1.3 & 23.3 \\
\hline Head length (HL) & 51 & $25.3-31.2$ & 28.6 & 1.2 & 29.6 \\
\hline \multicolumn{6}{|c|}{ Percent of HL } \\
\hline Head depth at supraoccipital & 51 & $48.2-68.6$ & 55.9 & 3.9 & 53.3 \\
\hline Head width at postorbitals & 50 & $54.3-79.9$ & 70.0 & 5.1 & 72.4 \\
\hline Dorsal interopercular width & 51 & $44.5-59.4$ & 53.4 & 2.8 & 45.8 \\
\hline Anterior internarial distance & 49 & $26.1-33.3$ & 29.8 & 1.7 & 30.4 \\
\hline Preisthmus length & 50 & $66.4-82.5$ & 73.0 & 2.9 & 72.4 \\
\hline Snout length & 51 & $36.9-49.5$ & 44.4 & 2.7 & 42.1 \\
\hline Gape width & 51 & $47.6-58.9$ & 54.5 & 2.7 & 53.3 \\
\hline Upper jaw length & 51 & $30.7-39.5$ & 35.3 & 1.9 & 34.1 \\
\hline Lower jaw length & 51 & $25.8-37.2$ & 32.1 & 1.9 & 32.2 \\
\hline Eye diameter & 51 & $16.0-27.8$ & 21.2 & 2.0 & 24.3 \\
\hline
\end{tabular}


Pectoral-fin spine well developed, short, stout, 13.3$19.0 \% \mathrm{SL}$, not reaching to pelvic-fin origin. Anterior margin of spine rugose but lacking distinct serrae. Dorsal and ventral surfaces of spine with shallow longitudinal grooves. Posterior margin of spine with single series of retrorse serrae along entire length except short proximal section; serrae, counted from both sides in some specimens, ranging from 12-26 (mode 19; mean=19.1 $\pm 2.6 \mathrm{SD} ; \mathrm{n}=112$ ). Pectoral fin with 8-9, rarely 7 branched rays (mode 9; $\mathrm{n}=100$ ), anterior-most pectoral rays longest. Postcleithral process absent.

Pelvic-fin origin about even with or slightly anterior to vertical plane through tip of adpressed dorsal-fin spine, excluding prenuptial and nuptial males; distal margin of fin straight to slightly rounded. Pelvic fin rays i,6; first branched ray longest, subsequent rays progressively shorter.

Caudal fin forked, lobes equal, with $8+9$ principal rays, 16-22 (mode 19; $\mathrm{n}=28$ ) upper, and 14-18 (mode 17) lower procurrent rays.

Preanal vertebrae 16-19 (mode $17 ; \mathrm{n}=40$ ). Total vertebrae $39-43$ (mode $41 ; n=43$ ). Pairs of pleural ribs 7-8 (mode $7 ; \mathrm{n}=37$ ).

Gas bladder of adult large, bulbous anterior margin, tunica smooth over entire surface, moderately turgid and thickened where internal septae contact interior walls, with two relatively short tubular posterior diverticula (Figs. 6a, b; see Remarks). Large, rugose Müllerian ramus (Fig. 4) forming expanded discoidal plate, impinging on anterodorsal face of gas bladder.

Color in alcohol. Overall ground color of body light tan to cream colored. Top of head and dorsum with a dense cast of slate-gray, dark brown, or black melanophores, diminishing sublaterally. Intensity and extent of pigmentation variable, but never appearing mottled or spotted. Freshly preserved specimens usually with dense patches of dusky specks on chin, flanks above anal fin, and an elongate streak in each caudal lobe extending from base of hypural plate to midpoint of longest caudal rays or beyond (Fig. 9). Pigment on chin (Fig. 1a) ranges from a full semicircle of dense specks extending from lower lip to rear margins of orbits, to a faint crescent overlying dentaries, and usually represented by at least traces of subcutaneous flecks scattered between symphysis of the dentaries; in some specimens, especially live or freshly preserved, the chin pigmentation appears as two large, bilateral, intense dark patches. Upper lip and margin of opercular flap with thin streaks of intense black pigment. Pigment on flanks above anal fin variable, usually consisting of relatively light, diffuse, minute melanophores (often obscure or faded in preserved specimens), occasionally consisting of a large dark patch formed by aggregated melanophores. Pigment in upper caudal lobe usually more extensive than in lower caudal lobe; in some specimens, pigmentation at caudalfin base diffuse. Darkly pigmented specimens with a patch of melanophores extending laterally on body posteriorly from top margin of opercular opening onto dorsal half of pseudotympanum, and anterior to pelvic-fin origin. Dorsal fin generally lacking pigment except along anterior margin of fin spine. Adipose fin hyaline except for small patch of melanophores extending from midline onto anterior base of fin. Pectoral, pelvic, anal, and caudal fins with thin bands of black pigment along distal margins.

Distribution. Tympanopleura atronasus is distributed throughout the middle and upper Amazon River basin, including the río Ucayali in Peru, río Mamoré in Bolivia, and mainstem and major tributaries of the rio Solimões and upper rio Amazonas in Brazil (Fig. 10). The species has been taken principally from large main channels and sloughs associated with lowland lotic habitats throughout its range.

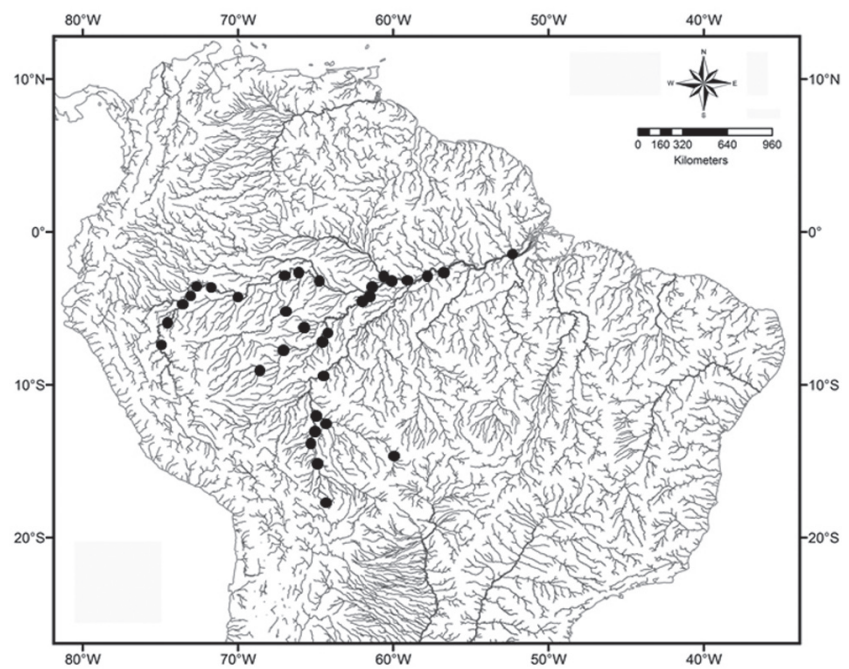

Fig. 10. Distribution of Tympanopleura atronasus based on material examined. Type-locality unknown. Some symbols represent more than one lot or locality.

Ecology. Little is known about the life-history or general ecology of T. atronasus. In the material examined, at least 34 prenuptial or nuptial males and 26 gravid females were identified. Based on these specimens, the reproductive period for this species occurs between mid-to-late October and the end of March. The extended period during which reproductive specimens were available presumably represents broad temporal (including interannual) and spatial variability in the rainy season and local conditions across the upper to middle portion of the Amazon River basin where the species is predominately distributed. Males exhibited peak nuptial barbel and dorsal-fin dimorphism from mid December through March. Reproductive males ranged from 72.2-109.9 $\mathrm{mm} \mathrm{SL}$ (mean=91.0; $\mathrm{n}=34$ ), and ripe females ranged from 60.4-115.7 $\mathrm{mm} \mathrm{SL}$ (mean=89.7; $\mathrm{n}=26$ ). Cursory examination of gut contents of a few specimens revealed the presence of small macroinvertebrates and fish remains. 
Remarks. Tympanopleura atronasus apparently exhibits some variation in gas bladder morphology, although we did not examine many specimens or conduct a detailed study of variation. Paired posterior (terminal) diverticula separated at their bases, as in Fig. 6a, were observed in other specimens examined by Walsh (1990:94, fig. 20d; UF 44926) and Birindelli et al. (2012:656, fig. 6a; MZUSP 85285 , but note apparent error in figure legend), in contrast to more robust, horn-like diverticula, fused at their bases, observed for one specimen illustrated herein (Fig. 6b). Additionally, a specimen (MEPN 302) from the río Yasuni, Ecuador, examined by D. Stewart and R. Barriga-Salazar (pers. comm.), exhibited an anamolous fusion of the posterior ends of paired terminal diverticula, separated at their bases, forming a loop. All of the above specimens were of adult size (79.9-107.3 mm SL), thus observed variation was presumed not to be due to differences in developmental stage. A comprehensive study is needed to fully examine the extent of variation in gas bladder morphology in this species, as well as congeners, to determine if there are trends across ontogenetic or size stages, geographic areas, or possible differences between the sexes.

Etymology of the specific epithet is derived from the Latin ater (neuter atrum), meaning black, and nasus, the nose, in reference to the intense black pigmentation on the tip of the snout and lips in live and freshly preserved specimens. We consider the name to be a noun in apposition and therefore follow Article 34.2.1 of the International Code of Zoological Nomenclature (ICZN, 1999) in retaining the original spelling.

Material examined. Holotype of Ageneiosus atronasus. MCZ 27270, $72.2 \mathrm{~mm} \mathrm{SL}$, male, South America, exact locality unknown. CAS 57940 (ex IU 15788), 1 (88.8 mm SL, male), holotype of $T$. nigricollis, Peru, Iquitos, Sep 1920, W. R. Allen; CAS 57941 (ex IU 15788b-d), 2 (95.9 mm SL, male; $91.5 \mathrm{~mm} \mathrm{SL}$, female), paratypes of T. nigricollis (smallest specimen in original lot of $3=T$. longipinna), Peru, Iquitos, Sep 1920, W. R. Allen; CAS 57942 (ex IU 15789), 1 (79.2 $\mathrm{mm} \mathrm{SL}$, female [?]), paratype of T. nigricollis, Peru, río Ucayali near Orellana, Aug 1920, W. R. Allen.

Non-type material. 211 specimens (46.2-146.8 mm SL). Bolivia. Beni: AMNH 56070, 2 (56.3-58.3 mm SL), río Mamoré $5 \mathrm{~km} \mathrm{SE}$ of Limoquije, 6 Aug 1965, W.P. MacLean; FMNH 58137, 1 (93.0 mm SL), río Mamoré, Berlin, 15 Sep 1909, J.D. Haseman; FMNH 58138, 1 (94.4 mm SL), San Joaquin, 5 Sep 1909, J.D. Haseman; FMNH 58139, 1 (69.2 mm SL), rio Guaporé, 19 Sep 1909, J.D. Haseman; INPA 651, 7 (96.1-113.0 mm SL), río Mamoré, Trinidad, Laguna Capital, 30 Sep 1983, G. Loubens \& L. Lauzanne; INPA 654, 2 (105.1-107.5 mm SL), same data as INPA 651; MZUSP 27804, 3 (102.9-107.1 mm SL), Laguna San José, Trinidad, 3 Mar 1982, Convênio ORSTOM-UTB. Brazil. Acre: INPA 28507, 1 (84.1 mm SL), rio Purus, Sena Madureira, rio Caeté, c. 0903'43”S 684'24”'W, 24 Oct 2004, H. dos Anjos. Amapá: MZUSP 101875, 1 (120.9 mm SL), rio Jarí, Laranjal do Jarí downriver of Cachoeira

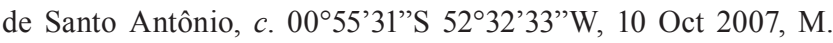

Carvalho et al. Amazonas: INPA 13392, 1 (103.7 mm SL), rio Solimões, Ilha da Marchantaria, 18 Feb 1993, P. Petry \& R. Sotero; INPA 16598, 1 (74.3 mm SL), rio Amazonas, Manaus, Costa da Terra Nova, 30 Nov 2000, J. Zuanon et al.; INPA 17176, 1 (91.1 $\mathrm{mm}$ SL), rio Purus, Sacado de Santa Luzia, c. 04²'48"S 62²3'54”'W, 4 Jun 2007, L.H. Rapp Py-Daniel et al.; INPA 18557, 9 (74.8-112.3 mm SL), rio Purus, Berurí, Paraná do Lago Samaúma, tributary of rio Abufari, 8 Dec 2000, L.H. Rapp PyDaniel et al.; INPA 18985, 1 (112.0 mm SL), rio Japurá, Tefé, on the edge of the Mamirauá Reserve, 1 Oct 1998, W.G.R. Crampton; INPA 18988, 8 (81.6-93.0 mm SL), Tefé, Lago Mamirauá, 19 Aug 1999, W.G.R. Crampton; INPA 18996, 7 (65.8-91.7 mm SL), rio Solimões, Tefé, Ilha de Içé, Jan 2001, W.G.R. Crampton; INPA 33857, 1 ( $86.3 \mathrm{~mm}$ SL), rio Juruá, Carauarí, mouth of Igarapé Xué, 27 Nov 2008, R. Frederico \& L. Queiroz; INPA 35101, 4 (54.5$63.4 \mathrm{~mm}$ SL), rio Purus, Berurí, community of Carapanã, collected with bottom trawl, c. 0430'19'S 62³'50”W, 19 Oct 2009, C. Duarte \& L.H. Rapp Py-Daniel; INPA 35110, 10 (46.5-74.3 mm SL), rio Purus, Berurí, collected with bottom trawl near shore at

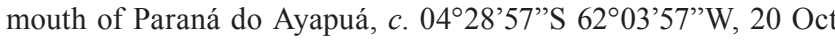
2009, C. Duarte \& L.H. Rapp Py-Daniel; MCZ 52582, 4 (88.2$116.5 \mathrm{~mm} \mathrm{SL})$, Parana do Janauaca, c. $03^{\circ} 25^{\prime} \mathrm{S} 61^{\circ} 21^{\prime} \mathrm{W}, 7-12 \mathrm{Dec}$ 1976, W.L. Fink; MCZ 52583, 7 (84.7-107.6 mm SL), Parana do Janauaca, $c .03^{\circ} 25^{\prime} \mathrm{S} 61^{\circ} 21^{\prime} \mathrm{W}, 7-12$ Dec 1976, W.L. Fink; MNHN 99-204, 1 (74.6 mm SL), Amazon River at Manaus, 1899(?), d'Anthonay; MNHN 99-205, 1 (57.7 mm SL), Amazon River at Manaus, 1899(?), d'Anthonay; MPEG 1.444, 3 (68.7-82.1 mm SL), rio Solimões, Ponta do Catalão, 5 Apr 1983, R. Barthem \& P. Stockman; MZUSP 5920, 1 (77.6 mm SL), Lago Jacaré, right margin of rio Solimões, above Manacapuru, 29-31 Mar 1967, Expedição Permanente da Amazônia (EPA); MZUSP 6338, 1 (109.6 mm SL), Lago Castro, mouth of rio Purus, 7-8 Nov 1967, EPA; MZUSP 6581, 3 (86.9-90.1 mm SL), Lago Manacapuru, 1213 Nov 1967, EPA; MZUSP 6997, 2 (92.0-93.6 mm SL), rio Madeira $25 \mathrm{~km}$ below Nova Olinda, 27 Nov 1967, EPA; MZUSP 7546, 3 (75.8-79.5 mm SL), Paraná do Urucará, municipality of Urucará, 9 Dec 1967, EPA; MZUSP 9283, 1 (89.9 mm SL), rio Solimões, Fonte Boa, 6 Oct 1968, EPA; MZUSP 9284, 1 (88.5 mm SL), same collection data as MZUSP 9283; MZUSP 9286, 1 (93.0 $\mathrm{mm} \mathrm{SL}$ ), rio Solimões, proximity of Ilha Barurua, above mouth of rio Jutaí, 15 Oct 1968, EPA; MZUSP 9287, 1 (96.8 mm SL), Santo Antônio do Ica, mouth of rio Iça, 17 Dec 1968, EPA; MZUSP 26937, 1 (89.5 mm SL), rio Solimões, Lago Janauacá and vicinity, Nov-Dec 1976, Alpha Helix expedition; MZUSP 27627, 9 (88.9$90.5 \mathrm{~mm} \mathrm{SL}$ ), Costa Japão, lower rio Japurá, municipality of Tefé, 23 Oct 1982, L.P.S. Portugal; MZUSP 27630, 1 (78.4 mm SL), rio Solimões, mouth of rio Purus, Codajás, 25 Oct 1982, L.P.S. Portugal; MZUSP 52620, 22 (52.8-103.7 mm SL), Beruri, rio Purus, 12-13 Jan 1975, P.E. Vanzolini; MZUSP 63596, 1 (105.7 mm SL), rio Purus, Santa Luzia, 11 Jan 1975, P.E. Vanzolini; MZUSP 63624, 1 (61.0 mm SL), rio Solimões, Lago Janauaca and vicinity, Sep 1976-Jan 1977, Alpha Helix expedition; MZUSP 63626, 2 (84.1-91.3 mm SL), same data as MZUSP 63624; MZUSP 63629, 8 (77.8-115.2 mm SL), mouth of rio Pauini, 11-14 Dec 1974, P.E. Vanzolini; MZUSP 63630, 7 (75.2-111.5 mm SL), Pauini, 1519 Dec 1974, P.E. Vanzolini; MZUSP 63631, 1 (103.2 mm SL), rio 
Preto da Eva, Manaus, Três Bocas, 13-28 Jan 1972, A. Abe; MZUSP 63632, 1 (88.7 mm SL), Canutama, 29 Dec 1974, P.E. Vanzolini; MZUSP 63634, 1 (79.2 mm SL), Benjamin Constant, 25-27 Nov 1962, K. Lenko; MZUSP 63635, 1 (86.0 mm SL), mouth of rio Paciá, 23 Dec 1974, P.E. Vanzolini; MZUSP 74483, 2 (84.2$87.3 \mathrm{~mm}$ SL), rio Solimões, lagoon along Lago Janauacá channel, 10 Jan 1977, Alpha Helix expedition; UF 181565, 1 (104.2, c/s, disarticulated), same data as MCZ 52582; UF 185769 (ex SIUC uncat.), 3 (89.4-112.5 mm SL, $1 \mathrm{c} / \mathrm{s}$ ), slough of rio Amazonas 10 km E of Manaus, 9 Oct 1985, T. Shepard \& M. Barton; UMMZ 217886, 3 (83.0-104.0 mm SL), Lago do Reis, Ilha do Reis, Jan 1983, W.L. Fink \& local fishermen; USNM 309166, 1 (unmeasured), Parana de Janauaca entrada do Lago do Castanho, 26 Oct 1977, P. Bayley; USNM 309167, 1 (unmeasured), Lago Terra Preta, Janauari, 3 Mar 1977, P. Bayley; USNM 309168, 1 (unmeasured), vicinity of Manaus, 1977 to 1979, P. Bayley. Pará: MZUSP 7861, 1 (83.1 mm SL), rio Nhamundá, Paraná do Jacaré, municipality of Faro, 13 Dec 1967, EPA; MZUSP 9285, 1 (109.0 mm SL), Itapiranga, Paraná de Urucará, 9-12 Sep 1968, EPA; UF 44926, 2 (90.1-105.3 mm SL), rio Maica just below mouth of rios Tapajos \& Santarem 0240’S 54³0’W, 8 Dec 1986, L.G. Nico. Rondônia: INPA 10955, 2 (93.3-101.1 mm SL), rio Madeira, rio Jaci Paraná, Jaci Paraná, 28 Aug 1993, João Paulo Viana; INPA 35928, 3 (91.9-

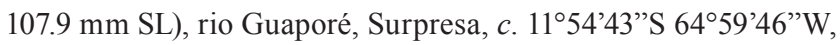
16 Jul 1984, G. Santos; INPA 35929, 3 (123.3-146.8 mm SL), rio Guaporé, Surpresa, c. 12²6’42”S 64¹3’38”W, 21 Nov 1983, G. Santos; MZUSP 113999 (ex MZUSP 34417), 1 (55.5 mm SL), rio Madeira, Calama, Praia do Caraparu, 13 Dec 1980, M. Goulding. Peru. Loreto: ANSP 178257, 2 (74.4-105.0 mm SL), río Amazonas, main channel along $\mathrm{W}$ bank, 30-45 min upriver from inlet to Iquitos (mouth of río Itaya), S of Iquitos, 3 Aug 2001, M.H. Sabaj Pérez et al.; ANSP 178307, 4 (46.2-74.7 mm SL), río Amazonas, main channel along $\mathrm{W}$ bank, 30-45 min upriver from inlet to Iquitos (mouth of río Itaya), S of Iquitos, 13 Aug 2001, M.H. Sabaj Pérez et al.; ANSP 182620, 1 (93.3 mm SL), río Nanay, large left bank upriver from mouth, N of Iquitos, c. 0342'49"S 73¹6'43" W, 15 Aug 2005, M.H. Sabaj Pérez et al.; ANSP 182731, 2 (56.7$60.5 \mathrm{~mm} \mathrm{SL}$ ), río Amazonas, vicinity of Iquitos, upriver and downriver of mouth of río Itaya, 8 Aug 2005, M.H. Sabaj Pérez et al.; BMNH 1977.3.10:229, 1 (87.6 mm SL), Peruvian Amazon near Iquitos, Bueno Caño Amazonas, 30 May 1974, purch. M. Chapman; CAS 58835 (ex IU 15911), 1 (95.3 mm SL), Pevas (=Pebas), W.G. Scherer; INHS 40164, 3 (89.1-139.0 mm SL), río Orosa, mouth of Tonche Cano, Madre Selva II field station, 69.4 mi E of Iquitos, c. 0347'26”'S 73¹4'50”'W, 12-13 Aug 1996), M.H. Sabaj Pérez et al; INHS 44109, 2 (73.5-75.1 mm SL), río Napo \& stream, Mazan, $33.3 \mathrm{~km}$ NE Iquitos, c. 03²9’32.5”S $73^{\circ} 5$ 11.9”W, 29-30 Jul 1997, M.H. Sabaj Pérez et al.; INHS 44112, 1 (74.2 mm SL), same locality as INHS 44109, 2 Aug 1997, M.H. Sabaj Pérez et al.; INHS 106399 (ex INHS 40163), 1 (76.2 mm SL), same locality and date as INHS 40164; INHS 106400 (ex INHS 44198), 5 (79.9-96.4 mm SL), río Nanay, upriver from Santa Clara at Mizplaya, 13.9 km W Iquitos, 29-30 Jul 1997, M.H. Sabaj Pérez et al:; SU 34216, 1 (74.7 mm SL), Ampiyacu River near Pevas (=Pebas), 6 Mar 1937, W.G. Scherer; SU 34217, 1 (97.0 mm SL), same locality as SU 34216, 1937, W.G. Scherer; SU 34218, 1 (104.7 mm SL), same locality as SU 34216, 1937, W.G. Scherer; USNM 284858, 1 (80 mm SL), caño entering río Nanay NE of Iquitos, $c$. 0349'S 73¹1'W, 18 Aug 1986, R.P. Vari et al.; USNM 284867, 1 (83.0 mm SL), río Nanay at Nanay Beach W of Iquitos, c. 0350'S 73¹'W, 17 Aug 1986, R.P. Vari et al. Ucayali: BMNH 1977.3.10.230, 1 (93.3 mm SL), Peruvian Amazon, Lago Yarinacocho, Ucayali River, 27 Mar 1974, purch. M. Chapman; FMNH 93488, 3 (100.8-109.9 mm SL), Yarinococha, Jan 1977, P. Hocking et al.; MZUSP 113998 (ex MZUSP 25972), 1 (75.9 mm SL), río Ucayali, Masisea, Province Coronel Portillo, 6 Oct 1975, H. Ortega; USNM 261396, 2 (72.0-85.5 mm SL), río Ucayali, Masisea, 31 May 1973, H. Ortega. Locality unknown. UMMZ 56135, 2 (72.4-102.3 mm SL), specific locality unknown, W.J. Beal \& J.B. Steere.

\section{Tympanopleura brevis (Steindachner, 1881)}

Figs. 1b, 6c, 11

Ageneiosus brevis Steindachner, 1881: 16-17 [type-locality: Amazonenstrom bei Coary (=Coari) und aus dem Hyavary (=Javari), collection date unknown, F. Steindachner; syntypes NMW 47801, 2]. -Eigenmann \& Eigenmann, 1888: 149 [checklist]. -Eigenmann \& Eigenmann, 1890: 300-302 [in key; citations; description]. -Eigenmann \& Eigenmann, 1891: 35 [checklist]. -Eigenmann, 1910: 397 [checklist]. -Miranda Ribeiro, 1911: 402-404 [in key; description]. -Gosline, 1945: 24 [checklist]. -Fowler, 1951: 452 [checklist; citations]. -Burgess, 1989: 286 [checklist]. -Pacheco et al., 2001: 33 [habitat and community assemblage; trophic category; in table; identification not verified]. -Ferraris, 2003: 471 [checklist; synonymy after Walsh, 1990; type-locality; syntypes]. -Pouilly et al., 2003: 1143, 1154 [diet; identification not verified]. -Pouilly \& Rodriguez, 2004: 251 [in table; habitat occurrence and abundance in floodplain lakes of Mamoré River, Bolivia; diet, zooplanktivory; identification not verified]. -Pouilly et al., 2004: 251 [in table; río Mamoré; floodplain lakes and edge; identification not verified]. -Granado-Lorencio et al., 2005: 518 [occurrence in Amazonian floodplain lakes; in tables; identification not verified]. -Mojica et al., 2005: 204 [checklist; Colombian Amazon; ICNMHN cataloged lots $(4465,8500)$; identifications not verified]. -Bogotá-Gregory \& MaldonadoOcampo, 2006: 82 [checklist; Colombian Amazon, after Mojica et al., 2005]. -Ortega et al., 2006: 107 [checklist; source, Duque \& Patiño, 2000; common name; Putumayo River basin, Colombia and Peru]. -Akama \& Sarmento-Soares, 2007: 116 [checklist; type-locality; distribution]. -Ferraris, 2007: 69, 550, 561 [type checklist; information duplicated from Ferraris, 2003]. -Granado-Lorencio et al., 2007: 687 [in table; see Granado-Lorencio et. al., 2005]. -Hercos et al., 2007: 46 [in list of material cataloged into IDSM collection; collection locality not given; identification(s) not verified]. -Lucinda et al., 2007: 81 [in table; rio Tocantins; influence of hydroelectric reservoir; identification not verified]. -Maldonado-Ocampo et al., 2008: 208 [checklist; Colombian Amazon, after Mojica et al., 2005, Bogotá-Gregory \& Maldonado-Ocampo, 2006, Ortega et al., 2006; identification(s) not verified]. -Barriga- 
Salazar, 2012: 115 [checklist (as A. cf. brevis); Ecuador, Napo-Pastaza "ichthyohydrographic" zone; identification not verified]. -Birindelli et al., 2012: 5-6, 8-10, fig. 6 [MZUSP 52620, 1 specimen in material examined, identification not verified, but 2 specimens listed in material examined for $A$. atronasus cited with same catalog number, and most of lot identified as $T$. atronasus in our study; photographs of gas bladder of MZUSP 34417 identified as A. brevis presumed erroneous and based on T. longipinna; MZUSP 48966 in material examined, identification not verified]. -Birindelli, 2014: 543 [phylogeny of Doradoidea; MZUSP 34417 in material examined presumed erroneous and based on $T$. longipinna; MZUSP 56660 in material examined presumed erroneous and based on $T$. rondoni].
Tympanopleura alta Eigenmann \& Myers in Myers, 1928: 85 [type-locality: Peru, río Marañon; type IU 15790 (=CAS 58258)]. -Fowler, 1941: 470 [checklist]. -Eigenmann \& Allen, 1942: 139-140, plate 6, fig. 4 [types listed; redescription; no coeca (=terminal diverticula) on gas bladder noted, presumably an erroneous observation]. -Fowler, 1945: 67 [checklist; citations]. -Gosline, 1945: 26 [checklist]. -Fowler, 1951: 456, fig. 483 [checklist; citations; distribution]. -Ortega \& Vari, 1986: 14 [checklist; citations; common name (Peru)]. -Burgess, 1989: 285-286 [checklist; illustration after Fowler, 1951]. -Ferraris, 2003: 471 [checklist; as synonym of $A$. brevis after Walsh, 1990; type-locality; holotype]. -Ferraris, 2007: 68 [type checklist; as synonym of $A$. brevis after Walsh, 1990; information duplicated from Ferraris, 2003].

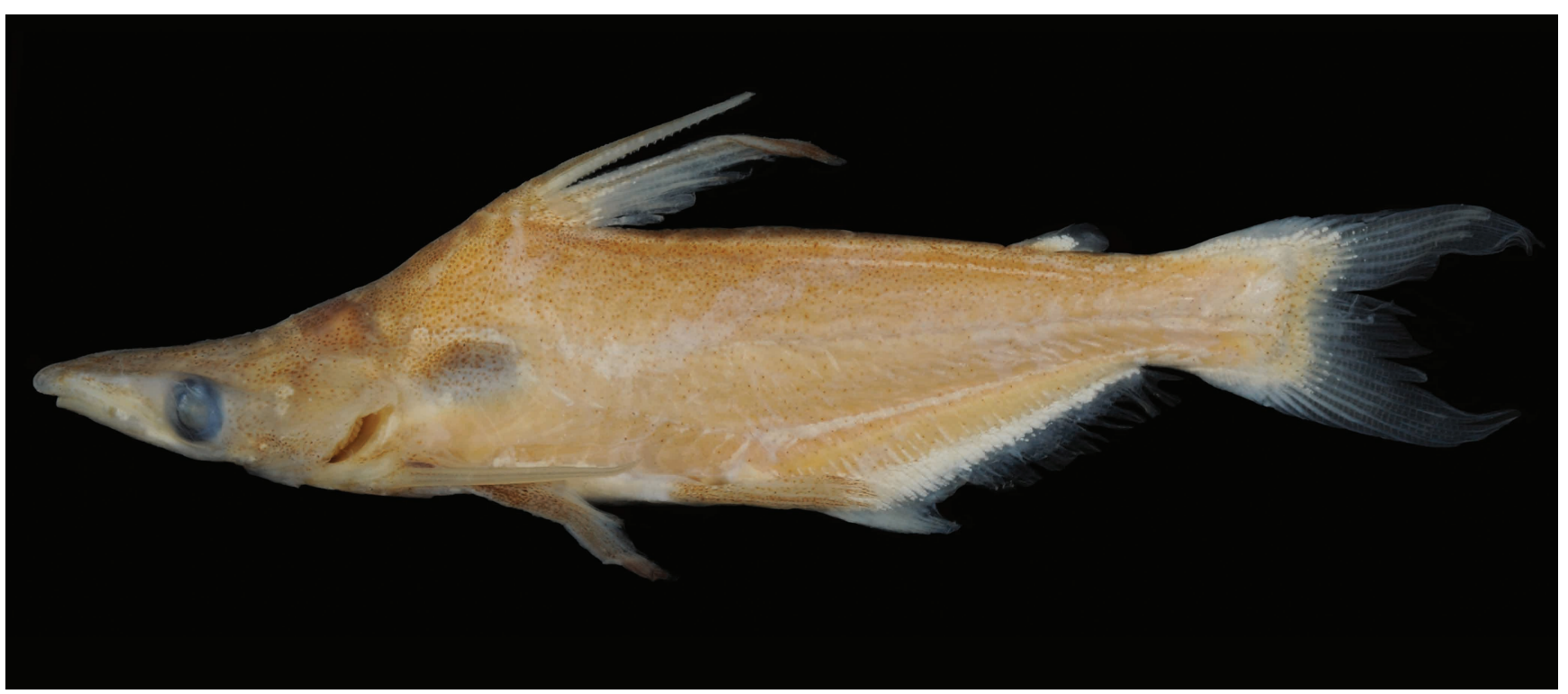

Fig. 11. Tympanopleura brevis, ANSP 194010 (68.5 mm SL), prenuptial male, rio Jutai, Amazonas State, Brazil.

Diagnosis. Tympanopleura brevis is distinguished from congeners by having a greatly flattened snout with an acute, upwardly inflected dorsal profile of the head, and the usual presence of a robust, triangular, and rugose postcleithral process ( $v s$. absent or very weakly developed). Tympanopleura brevis further differs from T. atronasus in having a greater number of anal-fin rays (31-36 vs. 23-30), pectoral-fin rays (10-12 vs. 7-9), and gill rakers on the first arch (20-24 vs. 14-18), fewer preanal vertebrae (14-15 vs. 1619), fewer pairs of pleural ribs (5 vs. 7-8), greater distance between pectoral- and dorsal-fin origins (21.4-27.0\% SL vs. $15.7-20.9 \% \mathrm{SL}$ ), and generally diffuse pigmentation over the head and body, lacking the distinctive dark concentration of melanophores usually present in T. atronasus on the chin, flanks above the anal fin, and streaks in each lobe of the caudal fin. Tympanopleura brevis differs from $T$. cryptica in having a greater number of anal-fin rays (3136 vs. 23-30), pectoral-fin rays (10-12, mode 11 vs. 8-10, mode 9), and more total vertebrae (38-41, mode 40 vs. 38). Tympanopleura brevis differs from $T$. longipinna in having fewer anal-fin rays (31-36, mode 33 vs. 32-42, mode 37) and total vertebrae (38-41, mode 40 vs. 40-43, mode 43), a longer pectoral-fin spine (19.1-24.4\% SL vs. 15.9-18.2\% SL), shorter anal-fin base (26.6-33.9\% SL vs. 33.9-39.9\% SL), and shallower head depth at midpoint of the supraoccipital (43.0-55.6\% HL vs. 53.0-74.1\% HL). Tympanopleura brevis differs from $T$. piperata in having fewer anal-fin rays (31-36, mode 33 vs. 31-38, mode 35), greater number of pectoral-fin rays (10-12, mode 11 vs. 6-10, mode 9), gill rakers on the first arch (20-24, mode 23 vs. 16-23, mode 19), and pleural rib pairs (5 vs. 4-5, mode 4), greater predorsal length (35.144.0\% SL vs. 28.8-34.4\% SL), prepelvic length (47.4-53.9\% vs. $41.3-47.0 \%$ SL), prepectoral length $(27.9-35.6 \%$ SL vs. 23.6-28.3\% SL), distance between pectoral- and dorsal-fin origin (21.4-27.0\% SL vs. 15.2-20.9\% SL), and body width at the pectoral-fin origin (20.5-26.6\% SL vs. $16.8-20.0 \%$ SL), a longer pectoral-fin spine (19.1-24.4\% SL vs. 13.9-18.1\% SL), longer head (29.7-35.6\% SL vs. 22.2-27.8\% SL), shallower head depth at midpoint of the supraoccipital (43.0-55.6\% HL vs. 54.3-69.7\% HL), greater gape width (44.9-57.5\% HL 
vs. $34.8-53.6 \% \mathrm{HL})$, smaller eye diameter $(13.8-21.0 \% \mathrm{HL}$ vs. $24.3-35.7 \% \mathrm{HL}$ ), presence of short posterior diverticula on the gas bladder (vs. diverticula absent), and lack of an hourglass-shaped transverse bar of pigmentation usually present at the base of the caudal fin in T. piperata. The relatively uniform pigmentation pattern on the head and body of $T$. brevis distinguishes it from $T$. rondoni, which characteristically has a pigmentation pattern consisting of discrete, irregular, large spots distributed over the head, body, and fins. Tympanopleura brevis further differs from T. rondoni in having more anal-fin rays (31-36, mode $33 \mathrm{vs.}$ 28-37, mode 31), fewer gill rakers (20-24, mode 23 vs. 2433 , mode 29-30) more pleural rib pairs (5 vs. 4-6, mode 6), a larger eye diameter (13.8-21.0\% HL vs. 8.4-17.0\% HL), and a cordiform gas bladder with shorter posterior diverticula (vs. gas bladder elongated antero-posteriorly and with two longer, recurved posterior diverticula).
Description. Morphometric data are provided in Table 9. Tympanopleura brevis is a relatively small auchenipterid, most specimens not exceeding $100 \mathrm{~mm}$ SL; largest specimen examined $109.0 \mathrm{~mm}$ SL (holotype of $T$. alta). Size range 43.5-109.0 $\mathrm{mm}$ SL $(\mathrm{n}=64)$ for specimens of undetermined sex, mature females, and non-nuptial males. Size range 58.4-82.0 mm SL $(n=5)$ for prenuptial and nuptial males. Body short, head spatulate. Dorsal profile of head greatly depressed anterior to eyes, acutely angled upward from rear margin of fontanelle to dorsal origin, concave, especially in nuptial males. Body moderately broad at pectoral-fin base, markedly compressed posteriorly to caudal peduncle. Body depth at dorsal fin origin 19.6-23.3\% SL. Dorsal contour from dorsal fin to caudal fin nearly straight to weakly convex. Ventral profile from snout to anal-fin origin weakly convex. Caudal peduncle shallow, maximum depth $6.6-10.2 \% \mathrm{SL}$.

Table 9. Morphometric data for specimens of Tympanopleura brevis. Synoptic material includes the lectotype and paralectotype of Ageneiosus brevis (NMW 47801[2]) and holotype and paratype of T. alta (CAS 58258, CAS 58259). $\mathrm{SD}=$ standard deviation.

\begin{tabular}{|c|c|c|c|c|c|}
\hline & $\mathrm{N}$ & Range & Mean & SD & Lectotype NMW 47801(1) \\
\hline Standard length (SL, mm) & 30 & $48.3-109.0$ & --- & --- & 104 \\
\hline \multicolumn{6}{|c|}{ Percent of SL } \\
\hline Preadipose length & 30 & $78.8-84.3$ & 81.4 & 1.4 & 81.5 \\
\hline Preanal length & 30 & $56.1-65.6$ & 62.2 & 2.0 & 63.3 \\
\hline Predorsal length & 30 & $35.1-44.0$ & 39.8 & 2.0 & 39.5 \\
\hline Prepelvic length & 30 & $47.4-53.9$ & 51.1 & 1.6 & 50.0 \\
\hline Prepectoral length & 30 & $27.9-35.6$ & 33.4 & 1.6 & 32.0 \\
\hline Pectoral-fin origin to dorsal-fin origin & 30 & $21.4-27.0$ & 23.9 & 1.2 & 23.2 \\
\hline Pelvic-fin origin to dorsal-fin origin & 30 & $21.4-26.5$ & 24.1 & 1.2 & 23.8 \\
\hline Pelvic-fin origin to adipose-fin origin & 30 & $31.2-38.3$ & 35.4 & 1.5 & 38.3 \\
\hline Dorsal-fin origin to adipose-fin origin & 30 & $40.7-49.2$ & 43.4 & 1.7 & 46.3 \\
\hline Adipose-fin origin to anal-fin insertion & 30 & $10.7-15.1$ & 13.3 & 1.1 & 13.0 \\
\hline Body depth at dorsal-fin origin & 30 & $19.6-23.3$ & 21.8 & 1.0 & 20.7 \\
\hline Caudal peduncle depth & 30 & $6.6-10.2$ & 8.5 & 0.9 & 8.5 \\
\hline Caudal peduncle length & 30 & $8.7-12.4$ & 10.6 & 0.9 & 11.3 \\
\hline Body width at pectoral-fin origin & 30 & $20.5-26.6$ & 23.5 & 1.6 & 22.6 \\
\hline Body width at pelvic-fin origin & 30 & $8.2-11.6$ & 10.5 & 0.7 & 11.1 \\
\hline Pectoral spine length & 30 & $19.1-24.4$ & 21.7 & 1.1 & 21.9 \\
\hline Anal-fin base length & 30 & $26.6-33.9$ & 29.2 & 2.1 & 29.9 \\
\hline Head length (HL) & 30 & $29.7-35.6$ & 32.7 & 1.5 & 31.3 \\
\hline \multicolumn{6}{|c|}{ Percent of HL } \\
\hline Head depth at supraoccipital & 30 & $43.0-55.6$ & 48.5 & 3.6 & 48.8 \\
\hline Head width at postorbitals & 30 & $52.4-72.8$ & 62.0 & 4.6 & 64.4 \\
\hline Dorsal interopercular width & 30 & $39.0-51.8$ & 43.7 & 2.8 & 43.6 \\
\hline Anterior internarial distance & 30 & $25.0-37.1$ & 30.5 & 2.6 & 33.7 \\
\hline Preisthmus length & 30 & $49.5-75.3$ & 66.5 & 5.4 & 62.9 \\
\hline Snout length & 30 & $39.3-57.9$ & 47.8 & 3.3 & 50.6 \\
\hline Gape width & 30 & $44.9-57.5$ & 51.5 & 2.7 & 53.7 \\
\hline Upper jaw length & 30 & $32.6-42.8$ & 38.0 & 2.9 & 39.6 \\
\hline Lower jaw length & 30 & $27.6-37.7$ & 32.5 & 2.7 & 34.7 \\
\hline Eye diameter & 30 & $13.8-21.0$ & 17.4 & 1.4 & 17.5 \\
\hline
\end{tabular}


Head large, length $29.7-35.6 \%$ SL, greatly depressed and spatulate anterior to eyes. Dorsal surface of frontals and supraoccipital rugose. Snout long, broadly rounded or squared off anteriorly in dorsal profile. Mouth distinctly inferior, most of premaxillary tooth patch exposed when mouth is closed. Premaxillary and dentary tooth bands relatively broad at midline, teeth sharp, recurved, not in discrete rows. Premaxillary teeth in a series of about 4-5 irregular rows at midline, tapering to 2-3 rows posterolaterally. Dentary tooth patch in a series of 3-4 irregular rows, not tapered laterally. Eye intermediate in size relative to congeners, $13.8-21.0 \% \mathrm{HL}$; eyes lateral, slightly more visible from dorsal than ventral profile, covered with thin, translucent skin (Fig. 1b). Fontanelle groove moderate in length, approximately equal to or slightly greater than eye diameter, deep, bounded by relatively high ridges on central portion of frontals. Anterior nares lateral to distal tips of mesethmoid wings and directed forward; posterior nares remote, not bordering lateral margins of frontals, each with very short flap of skin surrounding entire margin. Posterior edge of lower jaw reaching to just below middle of eye. Gill membranes broadly connected to isthmus; preisthmus length $49.5-75.3 \%$ HL. Branchiostegal rays 8-9 (mode 9; $\mathrm{n}=26$ ). Total gill rakers on anterolateral margin of first arch 20-24 (mode 23; n=28); first epibranchial with 7-9 (mode 8) and first ceratobranchial with 13-16 (mode 15) gill rakers. Gill rakers long, crenulate.

Maxillary barbel short and filiform, concealed in premaxillary groove in females and non-reproductive males, 7.2-21.6\% HL (mean=13.9 $\pm 3.7 \mathrm{SD} ; \mathrm{n}=24$ ) in nonnuptial individuals. Prenuptial males with maxillary barbel elongated and ossified, 24.8-31.8\% HL (mean=30.0 \pm 3.5 SD; $n=4$ ). A fully nuptial male (ANSP 193973) measured $82.0 \mathrm{~mm} \mathrm{SL}$; the left maxillary barbel was $31.9 \% \mathrm{HL}$ with 9 anterodorsal hooks, right barbel with 7 hooks, not fully developed.

Dorsal fin rays II,6, consisting of a small spinelet, elongated spine, and branched rays; first ray longest, extending posterior to or beyond midpoint between dorsalfin origin and adipose-fin origin when fin is adpressed. Dorsal-fin origin slightly posterior to vertical plane passing through pectoral-fin insertion. Length of dorsal-fin spine $15.5-23.2 \%$ HL (mean=20.1 $\pm 2.0 \mathrm{SD} ; \mathrm{n}=22$ ) in juveniles, adult females, and non-nuptial adult males. Length of dorsal-fin spine in prenuptial and nuptial males 20.7-33.7\% $\mathrm{SL}$ (mean=28.0 $\pm 5.0 \mathrm{SD} ; \mathrm{n}=5$ ). Dorsal-fin spine in juveniles and adult females straight and pungent, longitudinal ridges on lateral margins, rugose on anterior margin with 2631 (mean=28.7 $\pm 1.6 \mathrm{SD} ; \mathrm{n}=7$ ) small, low-crowned knobs. Posterior margin of dorsal-fin spine with 13-29 (mode 14; mean $=18.7 \pm 4.6 \mathrm{SD} ; \mathrm{n}=27$ ) sharp, retrorse serrae, not quite to base. The single nuptial male examined (ANSP 193973) had 44 antrorse serrae on the anterior margin of the dorsalfin spine, arranged in a single serial row and most closely spaced together proximally. Adipose fin small, posterior margin free.
Anal fin moderate in length, base $26.6-33.9 \%$ SL, with $31-36$ (mode $33 ; n=45$ ) rays; distal margin straight to gently rounded in all but nuptial males. Anal-fin pterygiophores 28-34 (mode 32; $n=12$ ). First 5-6 anal-fin rays of prenuptial and nuptial males thickened and coalesced to form intromittent organ.

Pectoral-fin spine well developed and pungent, long, 19.1-24.4\% SL, reaching past origin of pelvic fin when depressed. Anterior margin of spine rugose with single series of low-crowned knobs, most pronounced proximally. Dorsal and ventral surfaces of spine with 2-3 shallow, longitudinal grooves extending the length of the spine. Posterior margin of spine with 14-37 (mode 19; mean=23.5 $\pm 6.0 \mathrm{SD}$; $\mathrm{n}=33$ ) sharp, unicuspid retrorse serrae, arranged in single row, or bicuspid or in two distinct parallel rows proximally. Combined, five specimens, the types of T. brevis (NMW 47801), T. alta (CAS 58258 and CAS 58259), and one other specimen (MCZ 36190) had noticeably more posterior pectoral-spine serrations (30-37; mean $=33.4$; both fins) than all other specimens examined (14-31; mean=21.7; $\mathrm{n}=28$; left fin only); size range of the former group was $93.5-109.0 \mathrm{~mm} \mathrm{SL}$, and the latter group ranged in size from $43.5-82.0 \mathrm{~mm}$ SL. This difference in posterior pectoral-spine serrations is provisionally attributed to a possible ontogenetic difference, with larger specimens having a greater number, but the possibility of geographic or inter-population variation cannot be precluded. Pectoral fin with 10-12 (mode 11) branched rays, posterior margin of fin falcate with anterior rays longest. Postcleithral process typically present and moderately robust, short, conical.

Pelvic-fin origin anterior to vertical plane through tip of adpressed dorsal-fin spine; distal margin of fin straight to slightly convex. Pelvic fin rays i,6; first branched ray longest, subsequent rays progressively shorter.

Caudal fin forked, lobes equal, with $8+9$ principal rays, 16-24 (mode 22) upper, and 13-17 (mode 15; $\mathrm{n}=16$ ) lower procurrent rays.

Preanal vertebrae 14-15 (mode 14; $\mathrm{n}=12$ ). Total vertebrae 38-41 (mode 40;n=12). Pairs of pleural ribs 5 $(\mathrm{n}=10)$.

Gas bladder of adult large, cordiform with rounded posterior margin, tunica smooth and thin over entire surface, with two short terminal diverticula joined or closely proximate at their bases (Fig. 6c).

Color in alcohol. Background coloration tan to yellowishbrown, lighter on venter than on dorsum. Upper sides of body, dorsum, and head peppered with diffuse, small brown specks; melanophores darkest and most densely distributed dorsolaterally. Lower half of sides below lateral line variable, typically lightly speckled. Underside of head and body generally with very little or no pigmentation. Concentrations of melanophores on upper half of opercle and in wedge-shaped areas posterior to eyes along sublateral margin of head. Top of head nearly uniformly 
pigmented, but with lighter areas surrounding orbits, above fontanelle, and around nares. Top of supraoccipital solid dark brown, extending onto anterior margin of dorsal spine. Base of dorsal fin with brown specks, extending outward along first soft ray; tip of fin dark brown to black. Adipose fin hyaline or opaque. Caudal peduncle with dense concentration of melanophores forming weak crescentic bar; caudal-fin rays generally unpigmented except near base. Anal fin hyaline or only lightly speckled except for occasional thin dark brown or black margin. Pectoral and pelvic fins similarly pigmented, black posterior margin and stripe extending along top of first 3-4 rays, darkest near tips of rays, lightly speckled along ray margins and near base of remaining fin rays.

Distribution. Tympanopleura brevis is distributed throughout the middle and upper Amazon River basin, with most records from the State of Amazonas in Brazil and the Loreto Region of Peru (Fig. 12).

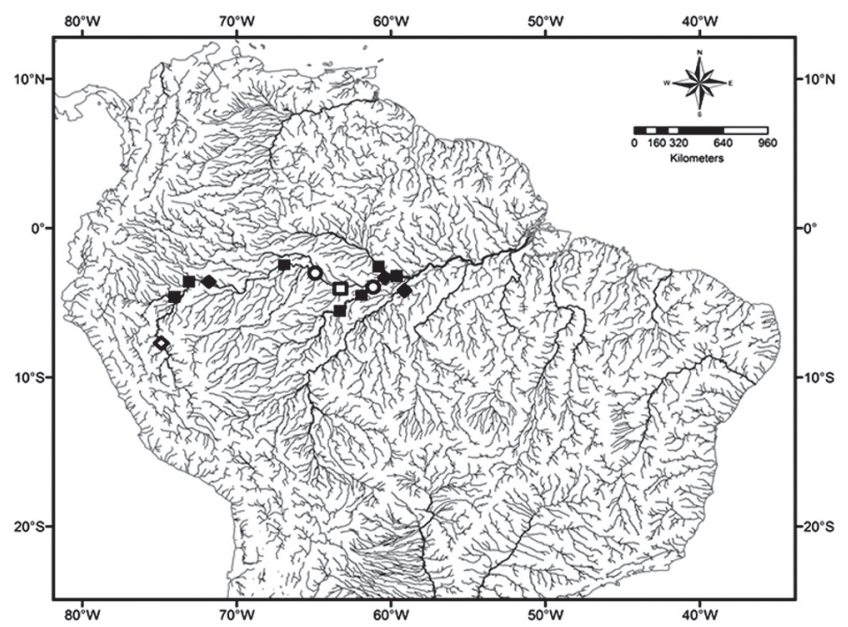

Fig. 12. Distribution of Tympanopleura brevis based on material examined (squares; open square represents typelocality), T. cryptica (diamonds; open diamond represents type-locality), and both species in sympatry (open circles). Some symbols represent more than one lot or locality.

Ecology. Pouilly et al. (2003, 2004) and Pouilly \& Rodriguez (2004) reported Tympanopleura brevis (as Ageneiosus brevis), together with an unidentified species listed as Tympanopleura sp., from floodplain lakes of the río Mamoré, Bolivia. These authors examined species assemblages, habitat characteristics, and diet composition of species in the fish communities, and reported Tympanopleura as occurring in three lake types: oxbow lakes immediately adjacent to the río Mamoré mainstem, forested floodplain lakes ( $>1 \mathrm{~km}$ from the mainstem river), and floodplain edge lakes ( $>4 \mathrm{~km}$ from the mainstem). Based on diet composition and breadth, these investigators scored T. brevis as a zooplanktivore (diet comprised primarily of rotifers and microcrustaceans), with aquatic invertebrates as secondary in importance (Pouilly et al., 2004, Table
2), and stated "Ageneiosus brevis appears to be the only species that is highly specialized in the consumption of zooplankton" (Pouilly et al., 2003, p. 1143). In their tabular summaries, T. brevis was assigned an abbreviation of "AGEMA" whereas Ageneiosus inermis was assigned a species code of "AGEBR," but diet composition was not reported for the latter. Diet classification for "AGEBR" (as a piscivore/carnivore) was derived from bibliographic references (Santos, 1991; Marrero \& Taphorn, 1991). We suspect that there may have been transposition of data regarding species codes and/or diet composition as reported by these authors. A few gut contents of specimens of different species of Tympanopleura examined by the senior author all contained prey items larger than microcrustaceans, primarily aquatic macroinvertebrates (especially decapods) and fish remains. We did not examine any auchenipterid specimens obtained in the río Mamoré study (Pouilly et al., 2003, 2004; Pouilly \& Rodriguez, 2004), and thus cannot confirm the identity of specimens assigned to "A. brevis" or the diets of specimens attributed to this species in their study.

Remarks. Tympanopleura brevis was described by Steindachner (1881) from four specimens ranging in length from 4 to 4.5 in $(10.2-11.4 \mathrm{~cm})$, presumably TL. Only two specimens from the original type series were located (NMW 47801), and we determined that both of these specimens represent the same species. We hereby select the larger specimen of this lot, a $104.0 \mathrm{~mm} \mathrm{SL}$ presumed female, based on size of the maxillary barbel, as a lectotype. The current disposition of the other two specimens from the type series is unknown.

A single specimen (IU 15790, $135 \mathrm{~mm}$, presumably TL) was designated as the type in the original description of T. alta (Eigenmann \& Myers, in Myers, 1928), and the collection locality was listed as "Iquitos, Rio Marañon Peru." Subsequently, Eigenmann \& Allen (1942) redescribed T. alta and listed as the type IU 15790, 132 $\mathrm{mm}$, and as a paratype IU 15977, $128 \mathrm{~mm}$, both from Iquitos. The city of Iquitos is not on the río Marañon proper, however, and the precise locality from where these specimens were collected is unknown.

Lucinda et al. (2007) reported Ageneiosus brevis in a list of species from a survey of fishes in the vicinity of the Lajeado Hydroelectric Reservoir on the rio Tocantins, State of Tocantins, Brazil. No specimens of T. brevis were represented from the rio Tocantins or other major tributaries of the lower Amazon River basin in the material examined herein. Thus, we conclude that the specimens reported as A. brevis by Lucinda et al. (2007) were either misidentified or represent a significant range extension of T. brevis as currently documented.

Etymology of the specific epithet is from the Latin brevis, meaning short, possibly in reference to the relatively short head in comparison to Ageneiosus inermis, to which Steindachner (1915) compared this species. 
However, meaning of the specific epithet in the original description and subsequent publications by Steindachner was not explicitly stated and can be considered ambiguous. Therefore, we treat the name as a noun in apposition and follow Article 31.2.2 of the International Code of Zoological Nomenclature (ICZN, 1999) in retaining the original spelling.

Material examined. Syntypes. NMW 47801, 2 (95.4-104.0 $\mathrm{mm}$ SL, both presumed female), Brazil, rio Amazonas at Coary (=Coari) and from the rio Hyavary (=Rio Javari), F. Steindachner. The larger specimen is here designated a lectotype and the smaller specimen is designated a paralectotype (see Remarks); CAS 58258 (ex IU 15790), 1 (109.0 mm SL, female), holotype of Tympanopleura alta, Peru, río Marañon, vicinity of Iquitos, 1920, W.R. Allen; CAS 58259 (ex IU 15977), 1 (104.8 mm SL, female), paratype of T. alta, Peru, Iquitos, 1922, P.S. Morris.

Non-type material. 136 specimens (26.2-93.5 mm SL). Brazil. Amazonas: ANSP 193972, 1 (56.2 mm SL), rio Negro 10.2 $\mathrm{km}$ downriver of Santa Maria, $19.4 \mathrm{~km}$ upriver of Leprosario, c. $03^{\circ} 01^{\prime} 02.0^{\prime \prime} \mathrm{S} 60^{\circ} 25^{\prime} 12.5^{\prime \prime} \mathrm{W}, 13$ Dec 1993, J.G. Lundberg et al.; ANSP 193973, 1 (82.0 mm SL), rio Jutaí downriver of Porto Antunes, upriver of Copatana, c. 02 ${ }^{\circ} 52^{\prime} 36.7^{\prime \prime} \mathrm{S} 66^{\circ} 58^{\prime} 25.6^{\prime \prime} \mathrm{W}$, 16 Nov 1993, O.T. Oyakawa et al.; ANSP 194005, $1(73.8 \mathrm{~mm}$ $\mathrm{SL}$ ), rio Jutaí downriver of Porto Antunes, upriver of Copatana, c. 0258'1.7'S 67000'43.6”W, 16 Nov 1993, O.T. Oyakawa et al.; ANSP 194006, 2 (53.3-57.0 mm SL), rio Japurá downriver of Nova Betania, $29.4 \mathrm{~km}$ upriver of Serraria, c. 02 $54^{\circ} 41.5^{\prime \prime} \mathrm{S}$ $64^{\circ} 51^{\prime} 53.5^{\prime}$ 'W, 2 Nov 1993, S.L. Jewett et al.; ANSP 194010, 25 (53.8-74.3 mm SL, $1 \mathrm{c} / \mathrm{s}$ ), rio Jutaí downriver of Porto Antunes, upriver of Copatana, c. $02^{\circ} 56^{\prime} 41.7^{\prime} \mathrm{S} 67^{\circ} 00^{\prime} 52.6^{\prime \prime} \mathrm{W}, 16 \mathrm{Nov}$ 1993, O.T. Oyakawa et al.; ANSP 194012, 1 (55.1 mm SL), rio Negro $10.6 \mathrm{~km}$ downriver of Leprosario, $14.8 \mathrm{~km}$ upriver of Manaus, c. $03^{\circ} 05^{\prime} 47.7^{\prime \prime} \mathrm{S} 60^{\circ} 09^{\prime} 49.7^{\prime \prime} \mathrm{W}, 10$ Oct 1994, J.G. Lundberg et al.; CAL unk., 1 (60.8 mm SL), rio Purus downriver

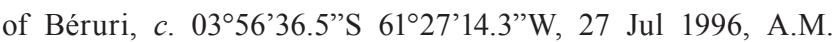
Zanata et al. (AMZ-96-073); CAL unk., 2 (49.9-51.2 mm SL), rio Jutaí downriver of Porto Antunes, upriver of Foz do Jutaí, c. $02^{\circ} 53^{\prime} 8.0^{\prime}$ 'S 67000'25.9'W, 16 Nov 1993, J.G. Lundberg et al. (JGL-93-067); CAL unk., 2 (58.1-68.0 mm SL), rio Negro 10.5 $\mathrm{km}$ upriver of Manaus, $10.6 \mathrm{~km}$ below tributary Tacuma-acu, 9.0

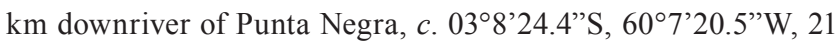
Oct 1993, J.G. Lundberg et al. (JGL-93-002); CAL unk., 2 (70.6$77.6 \mathrm{~mm} \mathrm{SL}$ ), rio Jutaí downriver of Porto Antunes, upriver of Foz do Jutaí, c. 0252’49.9”'S 6659’37.8”W, 13 Nov 1993, J.P. Friel et al. (JPF-93-063); INPA 10311, 16 (40.1-77.3 mm SL, 1 $\mathrm{c} / \mathrm{s}$ ), rio Negro, Novo Airão, Lago do Prato, collected with bottom trawl, c. $02^{\circ} 37^{\prime}$ S $60^{\circ} 56^{\prime} \mathrm{W}, 18$ Sep 1991, M. Garcia; INPA 11326, 3 (60.3-76.0 mm SL), same locality as INPA 10311, 17 Mar 1991, M. Garcia; INPA 12348, 2 (26.2-44.5 mm SL), same collection data as INPA 10311; INPA 12688, 1 (51.4 mm SL), rio Negro, rio Jaú, Uruá meander, c. $02^{\circ} 37^{\prime} \mathrm{S} 60^{\circ} 56^{\circ} \mathrm{W}, 7$ Nov 1994, M. Garcia; INPA 18528, 17 (44.2-60.8 mm SL, $2 \mathrm{c} / \mathrm{s})$, rio Purus, beach at Abufari, c. $05^{\circ} 25^{\prime} \mathrm{S} 63^{\circ} 00^{\prime} \mathrm{W}, 8$ Dec 2000, L.H. Rapp Py-Daniel et al.; INPA 34082, 1 (68.8 mm SL), rio Negro, Catalão, collected with bottom trawl, c. 0309'34'S 59 54'44'”'W, 30 Oct 2007, L.H. Rapp Py-Daniel et al.; INPA 35102, 6 (59.5-85.5 mm SL), rio Purus, Berurí, above the community of Capanã, collected with bottom trawl, c. 0430'19'"S 62 03'50'W, 19 Oct 2009, C. Duarte \& L.H. Rapp Py-Daniel; INPA 35112, 6 (55.6-57.4 mm SL), rio Purus, Berurí, beach in front of mouth of Paraná do Ayapuá, collected with bottom trawl, c. $04^{\circ} 28^{\prime} 57^{\prime}$ 'S $62^{\circ} 03^{\prime} 52^{\prime}$ 'W, 20 Oct 2009 , C. Duarte \& L.H. Rapp Py-Daniel; INPA 4419, 2 (49.3-50.7 mm SL), rio Negro, proximity of Manaus, Dec 1990, J.G. Lundberg \& L. Chao; INPA 4656, 1 (54.0 mm SL), rio Negro, Manaus, collected with bottom trawl, c. $03^{\circ} 06^{\prime} \mathrm{S} 60^{\circ} 01^{\prime} \mathrm{W}, 28 \mathrm{Nov} 1990$, J. Lundberg \& L. Chao; INPA 9591, 3 (42.4-60.5 mm SL), rio Negro, rio Jaú, Novo Airão, lake in front of Igarapé Preto, collected with bottom trawl, c. 02 $2^{\circ} 37^{\prime} \mathrm{S} 60^{\circ} 56^{\prime} \mathrm{W}, 25$ Jun 1994, M. Garcia \& J. Zuanon; INPA 9598, 10 (unmeasured), rio Negro, rio Jaú, rio Uruazinho, collected with bottom trawl, c. 02 ${ }^{\circ} 37^{\prime} \mathrm{S} 60^{\circ} 56^{\prime} \mathrm{W}, 25$ Jun 1994 , M. Garcia \& J. Zuanon; MCP 30617, 3 (49.8-65.9 mm SL), rio Solimões, near Tefé, north shore of Ilha Cuera, c. 03²2'19's 64'38'28'W, 19 Jan 2001, W.G.R. Crampton; MCZ 36190, 1 (93.5 mm SL), same locality as MCZ 7733, received 1866, Thayer Expedition; MCZ 7733, 1 (74.8 mm SL), Lago do Coari on rio Solimões, at Coari, 13 Sep 1865, Thayer Expedition (L. Agassiz et al.); MZUSP 56655, 1 (46.2 mm SL), rio Purus, collected with bottom trawl, c. 0351'09”S 6123'25”W, 26 Jul 1996, M. Toledo-Piza et al. Peru. Loreto: ANSP 182476, 1 (85.0 mm SL), río Nanay, downriver half of large beach (left bank) at village of Pampa Chica, $4.54 \mathrm{~km} \mathrm{~W}$ of Iquitos, c. $03^{\circ} 45^{\prime} 09^{\prime \prime} \mathrm{S} 73^{\circ} 17^{\prime} 00^{\prime \prime} \mathrm{W}$, 7 Aug 2005, M. Sabaj Pérez et al.; SIUC 39913, 13 (43.5-55.0 mm SL), río Tamshiyacu, c. $04^{\circ} 1.688^{\prime} \mathrm{S} 73^{\circ} 8.754^{\prime} \mathrm{W}, 28$ Jul 1999, J.G. Stewart et al.; UF 185770, 10 (46.4-60.9 mm SL), same data as SIUC 39913.

\section{Tympanopleura cryptica, new species}

urn:1sid:zoobank.org:act:BF66586A-0B47-47CE-B8125B7B809D3430

Figs. 1c, 6d, 13

Holotype. MUSM 47102 (ex INHS 40163), 84.9 mm SL, prenuptial male, Peru, Loreto, río Solimões drainage, río Orosa, mouth of Tonche Cano, $69.4 \mathrm{mi} \mathrm{E}$ of Iquitos c. $3^{\circ} 47^{\prime} 26^{\prime \prime}$ S 73¹4'50”W, 12-13 August 1996, M.H. Sabaj Pérez, J.W. Armbruster \& M. Hardman.

Paratypes. 40 specimens (54.1-78.2 mm SL). Brazil. Amazonas: INPA 12609, $1(67.5 \mathrm{~mm} \mathrm{SL})$, Ilha da Marchantaria, Lago Camaleão, 4 Feb 1981, INPA ichthyology team; INPA 18986, 1 (66.9 mm SL), Tefé, rio Japurá, margin of Mamirauá Sustainable Development Reserve, 19 Jan 1999, W.G.R. Crampton; INPA 25112, 1 (78.2 mm SL), rio Madeira, Cachoeirinha, 19 Sep 2004, D. Pimpão; INPA 35926, 4 (54.1-72.0 mm SL, 1 c/s), rio Purus, Lago Samaúma, tributary of rio Abufari, Berurí, 8 Dec 2000, L.H. Rapp Py-Daniel et al. Peru. Loreto: ANSP 139065, $1(59.0 \mathrm{~mm} \mathrm{SL})$, vicinity of Iquitos, río Nanay opposite naval base, backwater pools $1 \& 2$, above Amazon, 12 Oct 
1955, C.G. Chaplin et al. (Catherwood Expedition); ANSP 194024, 2 (65.5-66.0 mm SL), collected with holotype; CAS 158750, 1 (63.0 mm SL), Yahnas Yacu, proximity of Pevas (=Pebas), 24 Jul 1941, W.G. Scherer; INHS 40163, 15 (56.2-67.1 mm SL), collected with holotype; INHS 44032, 1 (67.6 mm SL), río Nanay, Pampa Chica 4.54 km W center of Iquitos c. 345'8.8'S $73^{\circ} 17^{\prime} 0.1^{\prime \prime} \mathrm{W}, 22$ Jul 1997, M.H. Sabaj Pérez \& J.W. Armbruster; INHS 44198, 1 (68.3 $\mathrm{mm} \mathrm{SL}$ ), río Nanay upriver from Santa Clara at Mizplaya, $13.9 \mathrm{~km}$ W of Iquitos c. 346'54.6”S 73²1'49.6”W, 29-30 Jul 1997, M.H. Sabaj Pérez et al.; MHNG 2394.39, 3 (56.5$61.0 \mathrm{~mm} \mathrm{SL}$ ), río Calleria, vers. Embouchure, dans le río Ucayali Cocha Tachsitea, 3 Oct 1984, P. de Rham \& H.
Ortega; MUSM 47103, 3 (62.6-65.8 mm SL), collected with holotype; MZUSP 115005, 2 (60.9-64.5 mm SL), collected with holotype; UF 185771, 2 (62.3-67.3 mm SL), collected with holotype; USNM 270812, 2 (56.4-72.2 mm SL), río Ucayali, Pucallpa, Tacshitea, 3 Oct 1984, H. Ortega.

Non-type material. 3 specimens (35.0-39.5 mm SL). Peru. Loreto: UF 128851, 1 (39.5 mm SL), Caño Yarina, río Pacaya in Reserva Nacional Pacay Samiria c. 5'17’39.5”S 74²9'53.1'W, 12 May 2003, J.S. Albert \& W.G.R. Crampton; UF 129190, 2 (35.0-37.0 mm SL), same general locality as UF 128851 c. 5²4'37.3'S 74³0'15.18'W, 14 May 2003, J.S. Albert \& W.G.R. Crampton.

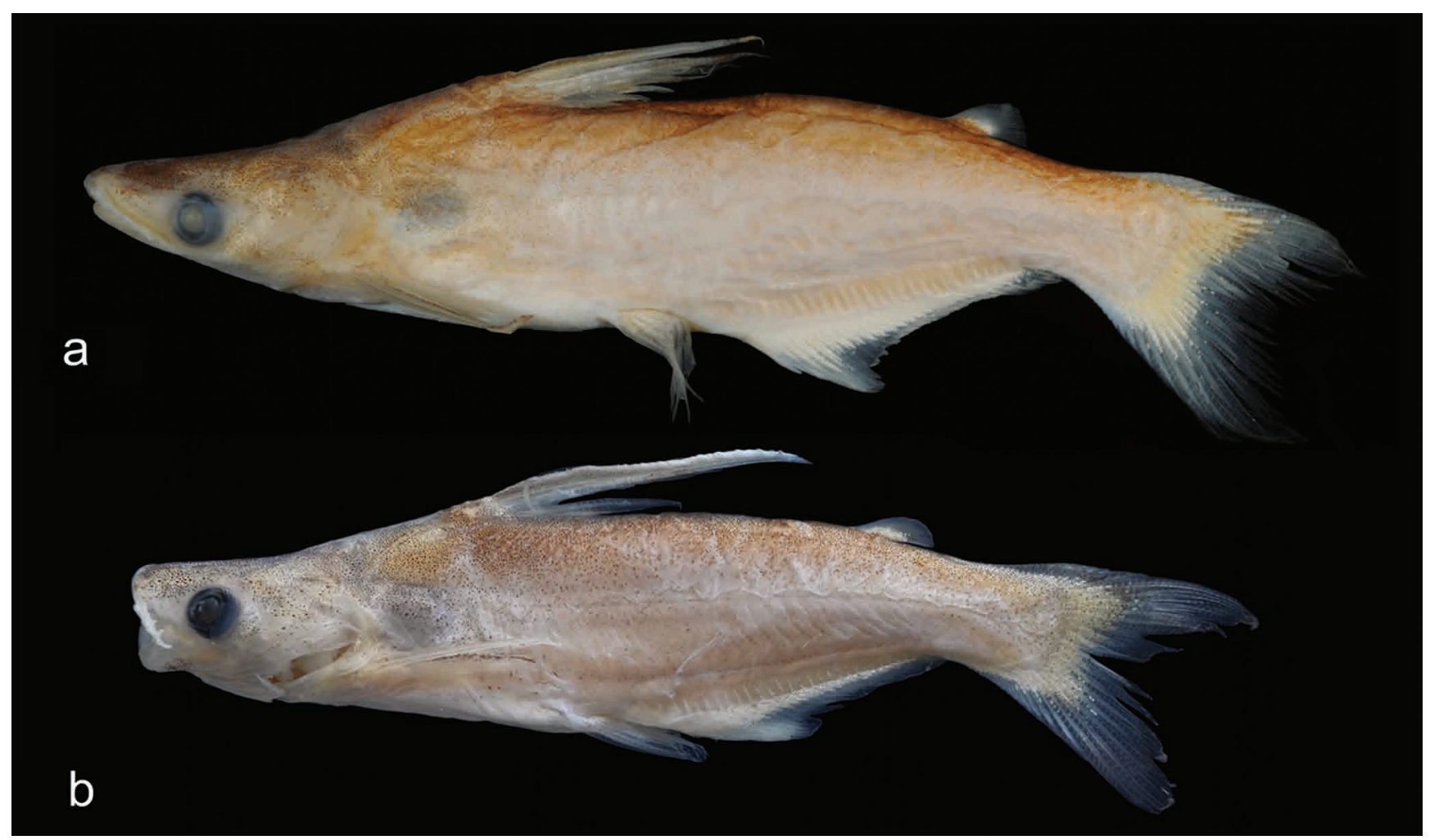

Fig. 13. Tympanopleura cryptica, new species. (a) holotype, MUSM 47102 (84.9 mm SL), pre-nuptial male, río Orosa, Loreto Region, Peru; (b) paratype, INPA 35926 (65.3 mm SL), nuptial male, rio Purus, Amazonas State, Brazil.

Diagnosis. Tympanopleura cryptica is distinguished from congeners on the basis of a unique combination of characters. Tympanopleura cryptica differs from $T$. atronasus in having more gill rakers on the first arch (2126, mode 22 vs. 14-23, mode 16), fewer preanal vertebrae (14-15 vs. 16-19), fewer total vertebrae (38-41, mode 38 vs. 39-43, mode 41), fewer pleural rib pairs (4-5 vs. 7-8), greater distance between pectoral- and dorsal-fin origin (21.6-24.3\% SL vs. 15.7-20.9\% SL), and a uniform body coloration that does not include a dark blotch of melanophores on the flank above the anal-fin base or streaks in the caudal fin, as is typically present in T. atronasus. Tympanopleura cryptica differs from $T$. brevis in having fewer anal-fin rays (23-30 vs. 31-36), fewer pectoral-fin rays (8-10, mode 9 vs. 10-12, mode 11), and fewer total vertebrae (38 vs. 38-41, mode 40). Tympanopleura cryptica differs from $T$. longipinna in having fewer anal-fin rays (23-30 vs. 32-42), fewer pectoral-fin rays (8-10, mode $9 v s$. 10-13, mode 11), more preanal vertebrae (14-15, mode 15 vs. 13-15, mode 14), fewer total vertebrae (38-41, mode 38 vs. 40-43, mode 43), greater preanal length (59.6-66.0\% SL vs. 49.7-57.6\% SL), shorter distance between dorsaland adipose-fin origin (33.9-46.7\% SL vs. $46.5-54.0 \%$ SL), shorter anal-fin base (24.4-30.3\% SL vs. 33.9-39.9\% $\mathrm{SL}$ ), and a slightly larger eye diameter (16.7-25.6\% HL $v s$. 11.6-18.5\% HL). Tympanopleura cryptica differs from $T$. piperata in having fewer anal-fin rays (23-30 vs. 31-38), more gill rakers on the first arch (21-26, mode 22 vs. 16- 
23 , mode 19), fewer total vertebrae (38-41, mode $38 v s$. $39-41$, mode 40 ), greater prepelvic length (48.4-53.6\% SL vs. $41.3-47.0 \% \mathrm{SL})$, greater prepectoral length $(29.7-33.8 \%$ SL vs. 23.6-28.3\% SL), greater distance between pectoraland dorsal-fin origin (21.6-24.3\% SL vs. $15.2-20.9 \%$ SL), shorter distance between dorsal- and adipose-fin origin (33.9-46.7\% SL vs. 45.9-55.4\% SL), shorter anal-fin base (24.4-30.3\% SL vs. 30.9-39.3\% SL), a slightly smaller eye diameter (16.7-25.6\% HL vs. 24.3-35.7\% HL), presence of two small posterior diverticula on gas bladder ( $v s$. diverticula absent), and base of the caudal fin without a characteristic dark, hourglass-shaped transverse bar usually present in $T$. piperata. Tympanopleura cryptica differs from $T$. rondoni in having fewer anal-fin rays (2330 , mode 29 vs. 28-37, mode 31), fewer pectoral-fin rays (8-10, mode 9 vs. 10-13, mode 11), fewer gill rakers on the first arch (21-26, mode 22 vs. 24-33, mode 29-30), fewer total vertebrae (38-41, mode $38 v s$. 38-42, mode 40), fewer pleural rib pairs (4-5, mode 5 vs. 4-6, mode 6), a larger eye diameter (16.7-25.6\% HL vs. 8.4-17.0\% HL), gas bladder cordiform and with two short posterior diverticula ( $v s$. gas bladder elongated antero-posteriorly and with two longer, recurved diverticula), and pigmentation on the head and body diffuse and relatively uniform in appearance, in contrast to the prominent spotted pattern of $T$. rondoni.

Description. Tympanopleura cryptica is a small-sized auchenipterid. Specimens of undetermined sex, mature females, and non-nuptial males ranged in size from 35.0$78.2 \mathrm{~mm} \mathrm{SL}(\mathrm{n}=29)$. Prenuptial and nuptial males ranged in size from 57.5-84.9 mm SL ( $\mathrm{n}=15)$. Morphometric data are summarized in Table 10. Dorsal profile of head nearly straight or weakly convex to dorsal-fin origin. Dorsal profile of body from behind dorsal fin to caudal fin slightly convex to nearly straight. Body relatively short, depth at base of dorsal fin approximately equal to or slightly greater than body width at origin of pectoral fin. Ventral profile of head flat, ventral profile of body from isthmus to anal-fin origin straight or gently rounded, angled upward posteriorly along anal-fin base. Caudal peduncle deep, $8.3-11.4 \%$ SL. Body not markedly compressed at pectoralor pelvic-fin base, but rather gradually tapered to base of caudal fin.

Head length 25.9-33.0\% SL. Mouth only weakly inferior, upper jaw projecting anterior to tip of lower jaw a distance approximately equal to width of the premaxillary tooth band and less than half of eye diameter. Corners of mouth approximately in line with transverse plane extending between posterior nares; posterior edge of lower jaw extending to a point approaching a plane through middle of the eye. Snout short, 40.4-51.3\% HL, forming a broad arc or squared off in dorsal and ventral view. Jaw teeth small, conical, slightly recurved, barely extending through epidermal tissue. Center of premaxillary tooth plate partially to fully exposed in ventral view, fully exposed posterolaterally, with about 3-6 irregular rows of teeth at midline, tapering to 1-2 rows posterolaterally. Dentary teeth small, thin, conical, distributed in about 3-4 uneven rows and slightly exposed laterally. Eye relatively large, horizontal diameter $16.7-25.6 \% \mathrm{HL}$, covered by thick epidermis; eyes lateral, equally visible in dorsal and ventral view (Fig. 1c). Cranial fontanelle relatively elongate, open from posterior margin of mesethmoid along anteromedial half of frontals to a point just anterior to a plane passing through posterior margins of the eyes. Anterior nares lateral to distal tips of mesethmoid wings and directed anterodorsally; posterior nares remote, about equidistant between anterior nares and anterior margin of orbit, encircled by short ridge of epidermis. Gill membranes broadly fused to isthmus along a plane falling posterior to rear margin of orbit, pre-isthmus length about 62.5-82.8\% HL. Branchiostegal rays 7-8 (mode 8; $\mathrm{n}=19$ ). Total gill rakers on anterolateral margin of first arch 2126 (mode 22; $\mathrm{n}=23$ ); first epibranchial with 6-10 (mode 8) and first ceratobranchial with 13-20 (mode 14) gill rakers. Longest gill rakers near middle of arch thin and crenulate on medial margin; tapering, short, and pointed near distal ends of each arch.

Maxillary barbel of females and non-nuptial males small, filamentous, concealed in premaxillary groove, length $13.9-15.8 \% \quad$ HL $\quad$ (mean=15.1 $\pm 0.8 \quad \mathrm{SD} ; \mathrm{n}=6$ ). Maxillary barbel of prenuptial males ossified and slightly thickened over approximately proximal one-half to threefourths, with fleshy terminus, extending slightly beyond rictus, lacking well-developed hooks, length 21.2-29.6\% HL (mean=24.1 $\pm 2.7 \mathrm{SD} ; \mathrm{n}=11$ ). Structure of nuptial male maxillary barbel unknown, as no peak nuptial males were available in material examined.

Dorsal fin rays II,6, consisting of a small spinelet, elongated spine, and branched rays; first ray longest, extending anterior to or about equal to midpoint between dorsal-fin origin and adipose-fin origin when fin is adpressed. Dorsal-fin spine short, relatively thin and weak in females and non-nuptial males, depressed spine reaching less than midpoint between dorsal-fin origin and adiposefin origin, length of spine $16.8-22.3 \%$ SL (mean $=20.2 \pm 1.6$ $\mathrm{SD} ; \mathrm{n}=10$ ). Dorsal-fin spine elongated in prenuptial and nuptial males, $18.6-34.9 \%$ SL (mean=23.5 $\pm 4.6 \mathrm{SD}$; $\mathrm{n}=13$ ). Serration of spine variable. In females and nonnuptial males, anterior margin of spine weakly to strongly crenulated with single row of low-crowned serrae (range 12-33; mean=22.9 $\pm 6.1 \mathrm{SD} ; \mathrm{n}=15)$, crowded together proximally and forming a low embedded keel, more distantly separated distally, or absent altogether over distal half or more. Dorsal, ventral, and lateral margins of spine with well developed longitudinal grooves and ridges. Posterior margin of spine in females and non-nuptial males with 13-24 weak serrae (mode 20; mean $=18.7 \pm 3.0$ $\mathrm{SD}$; $\mathrm{n}=18$ ); serrae short, relatively blunt, absent near base, displaced to ventrolateral edge of spine in some specimens, and occasionally nearly absent on entire posterior margin. Detailed structure of dorsal-fin spine of nuptial males 
unknown; one prenuptial male examined (USNM 270812; $72.2 \mathrm{~mm} \mathrm{SL}$ ) with entire anterior margin of dorsal-fin spine crenulated, denticulations longest and most closely spaced proximally, but lacking well developed serrae; posterior margin weakly crenulated proximally and smooth distally. Longest dorsal-fin rays reaching well beyond tip of spine in all but prenuptial and nuptial males. Adipose fin small, posterior margin free.

Anal fin relatively short, base $24.4-30.3 \%$ SL, with 23-30 rays (mode 29; $\mathrm{n}=39$ ); distal margin gently convex in juveniles, females, and non-nuptial males. Anal-fin pterygiophores 25-28 (mode 27; $\mathrm{n}=25$ ) in specimens examined with $\geq 27$ anal rays. First 5 anal-fin rays of prenuptial males unbranched, elongated, and thickened to form intromittent organ; gonopore located distally on leading edge of anal fin about one-third to one-half distance from base to tip of longest ray, presumably displaced toward distal end in fully nuptial male.

Pectoral-fin spine well developed, relatively short, stout, $14.2-22.7 \% \mathrm{SL}$, not reaching to pelvic-fin origin. Anterior margin nearly smooth or weakly rugose proximally, lacking distinct serrae. Dorsal and ventral surfaces of spine with shallow longitudinal grooves. Posterior margin of spine with single series of retrorse serrae along entire length except short proximal section; serrae range from 16-25 (mode 18; mean=17.7 $\pm 1.7 \mathrm{SD} ; \mathrm{n}=22$ ). Pectoral fin with 9-10 (mode 9; $\mathrm{n}=38$ ) branched rays; anterior-most pectoral rays longest. Postcleithral process typically present, short, conical.

Table 10. Morphometric data for specimens of Tympanopleura cryptica. SD=standard deviation.

\begin{tabular}{|c|c|c|c|c|c|}
\hline & $\mathrm{N}$ & Range & Mean & $\mathrm{SD}$ & Holotype MUSM 47102 \\
\hline Standard length (SL, mm) & 26 & $56.4-78.2$ & --- & --- & 84.9 \\
\hline \multicolumn{6}{|c|}{ Percent of SL } \\
\hline Preadipose length & 19 & $78.6-82.9$ & 80.9 & 1.1 & 80.9 \\
\hline Preanal length & 26 & $59.6-66.0$ & 62.5 & 1.4 & 63.7 \\
\hline Predorsal length & 26 & $31.9-41.6$ & 37.1 & 2.1 & 37.3 \\
\hline Prepelvic length & 26 & $48.3-53.6$ & 50.5 & 1.2 & 51.6 \\
\hline Prepectoral length & 20 & $29.7-33.8$ & 30.9 & 1.0 & 29.7 \\
\hline Pectoral-fin origin to dorsal-fin origin & 20 & $21.6-24.3$ & 23.3 & 0.7 & 21.6 \\
\hline Pelvic-fin origin to dorsal-fin origin & 20 & $23.0-28.2$ & 25.8 & 1.2 & 26.1 \\
\hline Pelvic-fin origin to adipose-fin origin & 25 & $18.7-39.7$ & 33.2 & 6.2 & 36.0 \\
\hline Dorsal-fin origin to adipose-fin origin & 26 & $33.9-46.7$ & 43.0 & 3.7 & 45.2 \\
\hline Adipose-fin origin to anal-fin insertion & 20 & $12.9-15.6$ & 14.8 & 0.6 & 15.4 \\
\hline Body depth at dorsal-fin origin & 26 & $17.8-24.2$ & 22.7 & 1.7 & 22.1 \\
\hline Caudal peduncle depth & 26 & $8.3-11.4$ & 10.6 & 0.7 & 10.2 \\
\hline Caudal peduncle length & 26 & $10.5-14.7$ & 12.6 & 1.1 & 11.2 \\
\hline Body width at pectoral-fin origin & 26 & $15.9-25.0$ & 21.8 & 2.9 & 22.6 \\
\hline Body width at pelvic-fin origin & 20 & $9.5-13.2$ & 11.7 & 0.8 & 11.9 \\
\hline Pectoral spine length & 25 & $14.2-22.7$ & 19.7 & 2.2 & 19.6 \\
\hline Anal-fin base length & 26 & 24.4-30.3 & 27.7 & 1.3 & 27.4 \\
\hline Head length (HL) & 26 & 25.9-33.0 & 29.8 & 2.0 & 29.4 \\
\hline \multicolumn{6}{|c|}{ Percent of HL } \\
\hline Head depth at supraoccipital & 25 & $47.7-68.6$ & 58.6 & 4.0 & 59.6 \\
\hline Head width at postorbitals & 26 & $62.8-80.6$ & 72.1 & 4.7 & 73.6 \\
\hline Dorsal interopercular width & 20 & $45.8-58.4$ & 51.0 & 2.6 & 50.0 \\
\hline Anterior internarial distance & 26 & $25.6-44.0$ & 32.9 & 3.7 & 44.0 \\
\hline Preisthmus length & 20 & $62.5-82.8$ & 71.1 & 4.7 & 74.8 \\
\hline Snout length & 26 & $40.4-51.3$ & 44.0 & 2.7 & 47.6 \\
\hline Gape width & 26 & $47.5-60.6$ & 55.0 & 3.6 & 57.2 \\
\hline Upper jaw length & 20 & $31.4-40.1$ & 35.8 & 2.2 & 37.2 \\
\hline Lower jaw length & 20 & $26.3-36.5$ & 32.0 & 2.3 & 33.2 \\
\hline Eye diameter & 26 & $16.7-25.6$ & 20.9 & 2.1 & 19.6 \\
\hline
\end{tabular}


Pelvic-fin origin posterior to tips of longest adpressed pectoral-fin rays; distal margin of fin straight to slightly convex. Pelvic fin rays i,6; first branched ray longest, subsequent rays progressively shorter.

Caudal fin forked, lobes equal, with $8+9$ principal rays, 17-22 (mode 19; $\mathrm{n}=12$ ) upper, and 13-15 (mode 15) lower procurrent rays.

Preanal vertebrae $14-15$ (mode $15 ; n=32$ ). Total vertebrae 38-41 (mode 38; $\mathrm{n}=32$ ). Pairs of pleural ribs 4-5 (mode 5; $\mathrm{n}=17$ ). Little variation was observed in vertebral and rib counts in the material examined, with very few specimens having counts different than the modes (Tables 4-6).

Gas bladder of adults large, cordiform, posterior margin blunt, tunica smooth and thin over dorsal, lateral, and anteroventral surfaces. Exterior posteroventral surface of tunica thickened, with weak, irregular, posterolaterally radiating ridges as in $T$. piperata. Two short terminal diverticula joined or weakly proximate at their bases (Fig. $6 d)$.

Color in alcohol. Base color of head and body dark brown, gray, or tan with pigmentation generally of relatively uniform shading. Top and sides of head, dorsum, upper half of sides of body with dense pigmentation consisting of small brown to black melanophores, darkest on head, anterolaterally, and dorsally. Pigment on sides of head extends anterior to eye, on membrane over eye, and on opercular skin slightly posteroventrally to eye. Lower half of sides of body with pigment less intense, but extending to base of anal fin and most concentrated anteriorly, especially over pseudotymanum and above pectoral-fin base. Pigment never appearing mottled or spotted. Chin in some specimens with an intense crescent or half-moon shaped patch of dark, concentrated brown melanophores, similar to T. atronasus. Streaks of brown pigment in dorsal and pectoral fins, most intense along leading edge of anterior-most ray; dorsal-fin spine and pectoral-fin spines with flecks scattered along anterior and lateral margins in the former, and anterior and top margins in the latter. Brown pigment extending from sides of body onto base of caudal fin, forming a broad, weakly defined vertical patch, somewhat darker and slightly crescent shaped in upper lobe. Adipose fin with melanophores scattered throughout. Anal and pelvic fins generally hyaline, but the latter with a small patch of melanophores above base of the anterior rays.

Distribution. Tympanopleura cryptica is known from relatively few records in the middle and upper Amazon River basin, State of Amazonas in Brazil and the Loreto Region of Peru (Fig. 12).

Etymology. The specific epithet cryptica is derived from the transliterated Greek kryptos, meaning hidden or concealed, in reference to the close morphological and pigmentation similarities of this species to congeners and its previously unrecognized taxonomic distinctiveness. Gender feminine.

\section{Tympanopleura longipinna, new species}

urn:1sid:zoobank.org:act:55FB056C-8849-4A87-9B841605F5E38747

Figs. 1d, 6e, 14

Ageneiosus brevis (non Steindachner, 1881). -Birindelli et al., 2012: 655-656, 658-660, figs. 6b,c, 9 [MZUSP 34417, 1; presumed misidentification based on majority of specimens in lot; gas bladder morphology; phylogenetic hypothesis; in material examined].

Holotype. MZUSP 114000 (ex MZUSP 34417), 73.0 mm SL, female, Brazil, Rondônia, rio Madeira, Calama, Praia do Caraparu, 13 Dec 1980, M. Goulding.

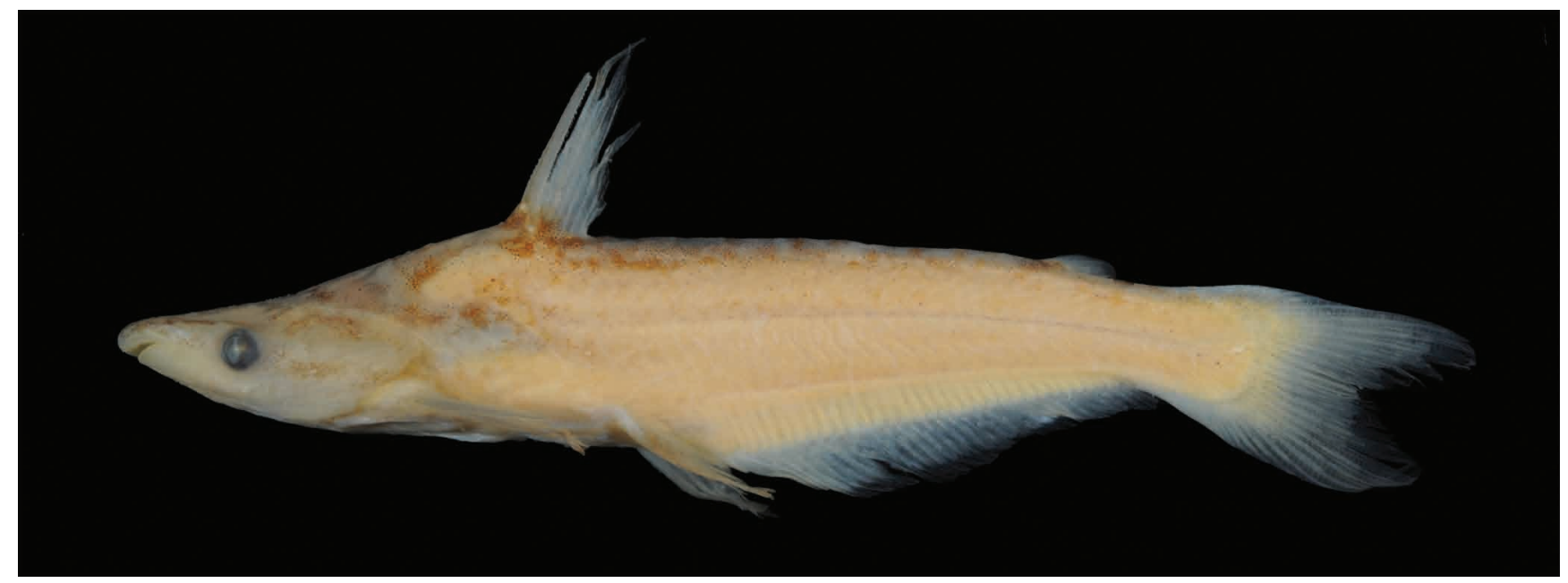

Fig. 14. Tympanopleura longipinna, new species. Holotype, MZUSP 114000 (73.0 mm SL), female, rio Madeira, Rondônia State, Brazil. 
Paratypes. 352 specimens (34.2-81.3 mm SL). Bolivia. Beni: AMNH 56069, 1 (63.2 mm SL), río Mamoré, Puerto Siles, 4 Dec 1965, S. Anderson. Brazil. Amazonas: ANSP 193974, 5 (52.1-65.9 mm SL), rio Japurá downriver from Nova Betania, $29.4 \mathrm{~km}$ upriver from Serraria, $c$. 02 54 '41.5”S 64'51'53.5”W, 2 Nov 1993, S.L. Jewett et al.; ANSP 194004, 18 (57.5-75.5 mm SL), rio Madeira, $c$. 03³3'37.5”'S 58 54'42.4”'W, 15 Oct 1994, J.G. Lundberg et al.; ANSP 194008, 6 (46.1-52.6 mm SL, 3 unmeasured), rio Solimões upriver of Nova Oriente, c. $03^{\circ} 13^{\prime} 37.1^{\prime \prime} \mathrm{S}$ 59 03'34.6"W, 11 Aug 1996, A.M. Zanata et al.; ANSP 194140, 8 (2, 55.9-57.9 mm SL, 6 unmeasured), rio Solimões, above mouth of rio Purus, downriver of Anori, c. $03^{\circ} 45^{\prime} 27.3^{\prime}$ 'S 61'34'51.7' W, 30 Jul 1996, A.M. Zanata et al. INPA 17319, 1 (34.2 mm SL), rio Purus, collected with bottom trawl, c. 045'47.1''S 62 54'51.3' W, 6 Jun 2001, L.H. Rapp Py-Daniel \& C. de Deus; INPA 34077, 6 (50.0$68.6 \mathrm{~mm} \mathrm{SL}, 2 \mathrm{c} / \mathrm{s})$, rio Solimões, collected with bottom trawl near confluence of rio Solimões and rio Negro, $c$. 0309'14'S 5954'17'W, 17 Aug 2007, A. Carvajal et al.; INPA 34078, 3 (44.3-55.0 mm SL), rio Solimões, collected with bottom trawl near shoreline of Lago Catalão, $c$. 0309'43"S 5954'39"W, 7 Aug 2008, A. Ribeiro; INPA 35109, 222 (43.9-79.8 mm SL), rio Purus, Berurí, above the community of Carapanã, 19 Oct 2009, C. Duarte \& L.H. Rapp Py-Daniel; MCP 29602, 1 (68.0 mm SL), rio Solimões, Alvarães, opposite community of Caborini and mouth of Lago Mamirauá, confluence of rio Solimões and rio Japurá, c. 0309'34' 'S 6446'35' 'W, 10 Feb 2001, W.G.R. Crampton; MCP 29603, 1 (67.8 mm SL), rio Solimões, Alvarães, Ilha do Içé, c. $03^{\circ} 16^{\prime} 36^{\prime \prime} S$ 64 41'01'W, Jan 2001, W.G.R. Crampton; MCP 29605, 1 (81.3 mm SL), rio Solimões, Tefé, c. $03^{\circ} 15^{\prime} 37^{\prime \prime}$ S 64²'30'”W, 30 Jan 2001, W.G.R. Crampton; MZUSP 57348, 2 (38.5-47.6 mm SL), rio Amazonas, collected with bottom trawl near mouth of rio Madeira, c. 0313'46"S 5903'59”W, 11 Aug 1996, A.M. Zanata et al.; MZUSP 58309, 2 (45.9-46.2 mm SL), rio Solimões, $7 \mathrm{~km}$ below Paraná do Iranduba, c. 03¹3'34"S $59^{\circ} 56^{\prime} 25^{\prime} \mathrm{W}, 24$ Oct 1993, S.L. Jewett et al. MZUSP 56644, 2 (44.9-54.6 mm SL), rio Madeira, collected with bottom trawl, c. $03^{\circ} 38^{\prime} 26^{\prime \prime} \mathrm{S} 59^{\circ} 02^{\prime} 45^{\prime \prime} \mathrm{W}, 7$ Aug 1996, M.T. Piza et al.; MZUSP 56646, 2 (35.6-40.6 mm SL), rio Purus,

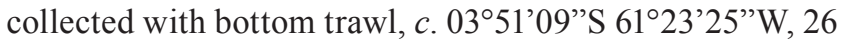
Jul 1996, M.T. Piza et al.; MZUSP 56725, 2 (58.0-59.5 mm $\mathrm{SL})$, rio Japurá, collected with bottom trawl $11 \mathrm{~km}$ below Lago Paupixuna, c. 02³9'24”S 6547'40"W, 7 Nov 1993, O. Oyakawa et al.; MZUSP 63595, 2 (54.1-62.3 mm SL), rio Purus, Campina, 10 Jan 1975, P.E. Vanzolini; MZUSP 63597, 3 (47.5-49.8 mm SL), rio Purus, Cassiã, 3 Jan 1975, P.E. Vanzolini; MZUSP 114002, 2 (63.6-66.0 mm SL), mouth of rio Ituxi, 22 Dec 1974, P.E. Vanzolini; MZUSP 114004, 15 (57.5-75.5 mm SL), same data as ANSP 194004; UF 185773, 2 (63.2-65.4 mm SL), same data as MZUSP 114002. Rondônia: MZUSP 34418, 4 (68.4-75.7 mm SL), rio Madeira, Calama, Paraná do Flechal, 2 Feb 1981, M. Goulding; MZUSP 114001 (ex MZUSP 34417), 12 (47.5-
$67.0 \mathrm{~mm} \mathrm{SL}, 2 \mathrm{c} / \mathrm{s})$, collected with holotype; UF 185772 (ex MZUSP 34417), 11 (56.1-77.3 mm SL), collected with holotype. Peru. Loreto: ANSP 178310, 11 (43.1-76.9 mm $\mathrm{SL}$ ), río Amazonas main channel along $\mathrm{W}$ bank, 30-45 min upriver from inlet to Iquitos (mouth of río Itaya), $\mathrm{S}$ of Iquitos, 13 Sep 2001, M.H. Sabaj Pérez et al; USNM 124918, 3 (64.3-68.2 mm SL), Shansho Cano, 4 Dec 1935, W.G. Scherer. Ucayali: MZUSP 25972, 4 (41.5-65.3 mm SL), río Ucayali, Masisea, Province Coronel Portillo, 6 Oct 1975, H. Ortega.

Non-type material . 593 specimens (40.9-78.7 mm SL). Brazil. Amazonas: ANSP 194007, 4 (40.9-58.1 mm SL), rio Madeira upriver of Itacoatiara, c. 03030'29.3”'S 58 53'17.4'N, 6 Aug 1996, C.C. Fernandes et al.; ANSP 194009, 1 (57.2 mm SL), rio Jurua upriver of rio Meneroa, c. $02^{\circ} 42^{\prime} 24.3^{\prime}$ 'S $65^{\circ} 47^{\prime} 24.8^{\prime}$ N, 9 Nov 1993, M. Garcia et al.; ANSP 194011, 1 (61.1 mm SL), rio Madeira $35 \mathrm{~km}$ upriver of Santa Maria, $1 \mathrm{~km}$ downriver Vila Urucurituba, c. $\left.03^{\circ} 32^{\prime} 46.0^{\prime \prime S} 58^{\circ} 55^{\prime} 09.3^{\prime \prime} \mathrm{N}\right), 15$ Oct 1994, J.G. Lundberg et al.; CAL unk., 1 (55.4 mm SL), rio Solimões upriver of Itacoatiara, c. $03^{\circ} 19^{\prime} 58.4^{\prime \prime} \mathrm{S}, 58^{\circ} 35^{\prime} 53.4^{\prime \prime} \mathrm{W}, 8$ Aug 1996, M. Toledo-Piza et al. (MTP 96.135); CAL unk., 1 (56.4 mm SL), rio Solimões upriver of Itacoatiara, c. 03 20'01.7”S 58 36'01.3”'W, 9 Aug 1996, C.C. Fernandes et al. (CCF 96.102); CAL unk., 1 (60.6 mm SL), rio Solimões, $c$. 0348'19.0"S 61³8'29.9”W, 29 Jul 1996, A.M. Zanata et al. (AMZ 96.97); CAL unk., 1 (61.8 mm SL), rio Solimões, c. $03^{\circ} 36^{\prime} 10.4^{\prime \prime} \mathrm{S} 61^{\circ} 17^{\prime} 45.5^{\prime \prime} \mathrm{W}, 28 \mathrm{Jul} 1996$, A.M. Zanata et al. (AMZ 96.83); CAL unk., 1 (66.0 mm SL), rio Madeira $31.1 \mathrm{~km}$ downriver of Santa Antônia, $25 \mathrm{~km}$ upriver of Itacoatiara, c. $03^{\circ} 14^{\prime} 13.4^{\prime \prime} \mathrm{S} 53^{\circ} 36^{\prime} 20.9^{\prime \prime} \mathrm{W}, 20$ Oct 1994, F.G. Langeani et al. (FL 94.46); CAL unk., 2 (50.6-54.8

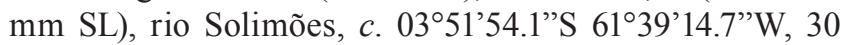
Jul 1996, A.M. Zanata et al. (AMZ 96.102); CAL unk., 4 (54.0-57.6 mm SL), rio Madeira downriver of Nova Olinda do Norte, c. $03^{\circ} 38^{\prime} 35.4^{\prime \prime S} 59^{\circ} 02^{\prime} 49.6^{\prime \prime}$, 7 Aug 1996, M. Toledo-Piza et al. (MTP 96.122); CAL unk., 4 (61.0-78.7 $\mathrm{mm} \mathrm{SL}$ ), rio Madeira $1.4 \mathrm{~km}$ downriver of Nova Rosarinho do Norte, $21.2 \mathrm{~km}$ upriver of Urucurituba, c. 0341'19.1”S $59^{\circ} 05^{\prime} 51.3^{\prime \prime} \mathrm{W}, 16$ Oct 1994, F.G. Langeani et al. (FL 94.32); MCP 29600, 1 (65.5 mm SL), rio Solimões, Tefé,

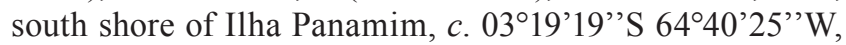
19 Jan 2001, W.G.R. Crampton; MCP 29601, 1 (64.1 mm $\mathrm{SL}$ ), rio Solimões, Tefé, north shore, $1.5 \mathrm{~km} \mathrm{~W}$ entry to Paraná Coxiu Muni, c. 03¹6’36'S 6441'29' W, 17 Jan 2001, W.G.R. Crampton; MCP 29604, 1 (60.7 mm SL), rio Solimões, Alvarães, community of Capivara, c. 03 ${ }^{\circ} 14^{\prime} 07^{\prime \prime} S$ 6441'09' 'W, 13 Jan 2001, W.G.R. Crampton; MZUSP 6998, 1 (59.0 mm SL), rio Madeira $25 \mathrm{~km}$ below Nova Olinda do Norte, 27 Nov 1967, Expedição Permanente da Amazônia (EPA); MZUSP 56076, 1 (unmeasured), rio Juruá, collected with bottom trawl $13.2 \mathrm{~km}$ below Lago Pauapixuna, $c$. 02³9'50.0”S 6548’0.01”'W, 7 Nov 1993, J.P. Friel et al.; MZUSP 56642, 1 (unmeasured), rio Solimões, collected with bottom trawl below mouth of rio Purus, c. $03^{\circ} 36^{\prime} 25^{\prime \prime} \mathrm{S}$ 
61¹9’40”W, 28 Jul 1996, M.T. Piza et al.; MZUSP 56643, 1 (unmeasured), rio Solimões, collected with bottom trawl near mouth of rio Purus, $c$. $03^{\circ} 36^{\prime} 01^{\prime \prime} \mathrm{S} 61^{\circ} 21^{\prime} 21.01^{\prime} \mathrm{W}, 28$ Jul 1996, M.T. Piza et al.; MZUSP 56647, 1 (unmeasured), rio Madeira, collected with bottom trawl, c. 03 $37^{\circ} 41.0^{\prime \prime} \mathrm{S}$ 5901'27.0”'W, 7 Aug 1996, M.T. Piza et al.; MZUSP 56648, 2 (unmeasured mm SL), rio Solimões, collected with bottom trawl near mouth of rio Purus, c. $03^{\circ} 36^{\prime} 08.0^{\prime \prime} \mathrm{S}$ 61 ${ }^{\circ} 17^{\prime} 51.0^{\prime \prime} \mathrm{W}, 28 \mathrm{Jul}$ 1996, M.T. Piza et al.; MZUSP 56650, 1 (unmeasured), rio Solimões, collected with bottom trawl near mouth of rio Purus, c. $03^{\circ} 39^{\prime} 31.0^{\prime \prime} \mathrm{S} 61^{\circ} 28^{\prime} 37.0^{\prime \prime} \mathrm{W}, 30$ Jul 1996, M.T. Piza et al.; MZUSP 56651, 1 (unmeasured), rio Madeira, collected with bottom trawl, c. 03'26'32.0”'S 58 47'57.0"W, 10 Aug 1996, M.T. Piza et al.; MZUSP $56721,1(62.0 \mathrm{~mm} \mathrm{SL})$, rio Solimões, collected with bottom

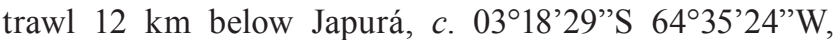
31 Oct 1993, O. Oyakawa et al.; MZUSP 56726, 1 (58.8 $\mathrm{mm} \mathrm{SL}$ ), rio Juruá, collected with bottom trawl between Lago Paupixuna and Lago Meneroa, c. 0246’31's 6549'59"W, 9 Nov 1993, O. Oyakawa et al.; MZUSP 57306, 1 (unmeasured), rio Madeira, near mouth, collected with bottom trawl, c. 03³5'30.0'S 58 57'57.0”W, 6 Aug 1996, A.M. Zanata et al.; MZUSP 57347, 1 (unmeasured), rio Solimões, collected with bottom trawl below mouth of rio Purus, c. 03³6'16.0”S 61²1'12.0”W, 28 Jul 1996, A.M. Zanata et al.; MZUSP 57380, 1 (49.2 mm SL), rio Amazonas, collected with bottom trawl below mouth of rio Negro, c. 03¹0'24”S 59³2'29”'W, 22 Jul 1996, A.M. Zanata et al.; MZUSP 57970, 1 (unmeasured), rio Madeira, collected with bottom trawl $17 \mathrm{~km}$ below Paraná do Canumá, c. 0351'11.0"S 59³'24.0”W, 7 Aug 1996, C. Cox-Fernandes et al.; MZUSP 57977, 1 (unmeasured), rio Madeira, collected with bottom trawl $51 \mathrm{~km}$ below Paraná do Canumá, c. 03³5’09.0”'S 5857’47.0”W, 6 Aug 1996, C. Cox-Fernandes et al.; MZUSP 58124, 1 (unmeasured), rio Amazonas, collected with bottom trawl $21.3 \mathrm{~km}$ below mouth of rio Madeira, c. $03^{\circ} 18^{\prime} 14.0^{\prime \prime} \mathrm{S} 58^{\circ} 36^{\prime} 09.0^{\prime \prime} \mathrm{W}, 20 \mathrm{Oct}$ 1994, M. Westneat et al.; MZUSP 58238, 1 (unmeasured), rio Solimões, collected with bottom trawl $3.9 \mathrm{~km}$ below mouth of rio Japurá, c. $03^{\circ} 12^{\prime} 11.0^{\prime \prime} \mathrm{S} 64^{\circ} 48^{\prime} 01.99^{\prime \prime} \mathrm{W}, 30 \mathrm{Oct}$ 1993, S.L. Jewett et al. MZUSP 58245, 1 (unmeasured), rio Solimões, collected with bottom trawl $10 \mathrm{~km}$ below mouth of rio Japurá, c. $03^{\circ} 19^{\prime} 10.0^{\prime}$ 'S $64^{\circ} 32^{\prime} 02.99^{\prime \prime} \mathrm{W}, 28$ Oct 1993, S.L. Jewett et al.; MZUSP 63598, $1(58.1 \mathrm{~mm}$ SL), mouth of rio Paciá, 23 Dec 1974, P.E. Vanzolini; MZUSP 113997 (ex MZUSP 63630), 1 (68.9 mm SL), Pauini, 15-19 Dec 1974, P.E. Vanzolini; MZUSP 114003, 1 (65.1 mm SL), rio Purus, Santa Luzia, 11 Jan 1975, P.E. Vanzolini. Rondônia: MZUSP 34417, c. 540 (unmeasured), collected with holotype; MZUSP 34418, 4 (68.4-75.7 mm SL), rio Madeira, Calama, Paraná do Flechal, 2 Feb 1981, M. Goulding. Peru. Loreto: CAS 57941, 1, paratype of $T$. nigricollis (52.1 mm SL), Iquitos, Sep 1920, W.R. Allen. Ucayali: MZUSP 114005, 2 (66.2-73.6 mm SL), Pucullpa, Province Coronel Portillo, District Yarinacocha, 9 Aug 1973, H. Ortega.
Diagnosis. Tympanopleura longipinna can be distinguished from $T$. atronasus and T. cryptica on the basis of its much longer anal fin (32-42 anal-fin rays vs. 2330). Tympanopleura longipinna is further distinct from $T$. atronasus in having more pectoral-fin rays (10-13 vs. 7-9), more gill rakers on the first arch (19-25 vs. 14-18), fewer preanal vertebrae (13-15 vs. 16-19), more total vertebrae (40-43, mode 43 vs. 39-43, mode 41), fewer pleural ribs (4-5 vs. 7-8), greater distance from pelvic- to adiposefin origin (37.6-45.1\% SL vs. 31.2-38.1\%), longer anal-fin base (33.9-39.9\% SL vs. 22.1-27.6\% SL), and a generally lighter overall pigmentation pattern on the head, dorsum, and sides of the body, lacking the characteristic dark patches of melanophores concentrated on the flanks above the anal-fin base, the chin, and streaks in each caudalfin lobe usually present in T. atronasus. Tympanopleura longipinna further differs from T. cryptica in having a greater number of pectoral-fin rays (10-13, mode $11 \mathrm{vs}$. 8 -10, mode 9), fewer preanal vertebrae (13-15, mode 14 vs. 14-15, mode 15), more total vertebrae (40-43, mode 43 vs. 38-41, mode 38), shorter preanal length (49.7-57.6\% SL vs. 59.6-66.0\% SL), shorter prepelvic length (38.8-48.4\% SL vs. $48.3-53.6 \% \mathrm{SL}$ ), greater distance from dorsal- to adipose-fin origin $(46.5-54.0 \%$ SL vs. $33.9-46.7 \%$ SL), longer anal-fin base (33.9-39.9\% SL vs. $24.4-30.3 \%$ SL), slightly smaller eye diameter (11.6-18.5\% HL vs. 16.7$25.6 \% \mathrm{HL}$ ), and a generally lighter pigmentation pattern on the head, dorsum, body, and fins. Tympanopleura longipinna differs from $T$. brevis in having an overall greater number of anal-fin rays $(32-42$, mode $37 v s$. 3136 , mode 33$)$ and total vertebrae (40-43, mode 43 vs. 3841 , mode 40 ), greater distance from pelvic- to adipose-fin origin (37.6-45.1\% SL vs. 31.2-38.3\% SL), shorter pectoralfin spine (15.9-18.2\% SL vs. 19.1-24.4\% SL), longer analfin base (33.9-39.9\% SL vs. 26.6-33.9\% SL), shorter head length (25.2-29.7\% SL vs. 29.7-35.6\% SL), and usually lighter pigmentation pattern on the head, dorsum, sides of the body, and fins (vs. diffuse, dark tan to brown pigment extending well below the lateral line and paired fins with dark membranes). Tympanopleura longipinna differs from T. piperata in having a greater number of pectoral-fin rays (10-13, mode 11 vs. 6-10, mode 9), more gill rakers on the first arch (19-25, mode 23 vs. 16-23, mode 19), fewer preanal vertebrae (13-15, mode 14 vs. 14-16, mode 15), more total vertebrae (40-43, mode 43 vs. 39-41, mode 40 ), greater body width at the pectoral-fin origin (21.1$25.7 \%$ SL vs. $16.8-20.0 \%$ SL), smaller eye diameter (11.618.5\% HL vs. $24.3-35.7 \%$ HL), gas bladder with two short posterior diverticula ( $v s$. diverticula absent), and lack of a dense band of pigmentation on the base of the caudal fin. Tympanopleura longipinna differs from $T$. rondoni in having more anal-fin rays (32-42, mode 37 vs. 28-37, mode $31)$, fewer gill rakers on the first arch (19-25, mode $23 v s$. 24-33, mode 29-30), fewer preanal vertebrae (13-15, mode 14 vs. 14-16, mode 15), more total vertebrae (40-43, mode 43 vs. 38-42, mode 40), shorter predorsal length (29.5- 
36.1\% SL vs. 35.2-47.4\% SL), greater distance from dorsalto adipose-fin origin (46.5-54.0\% SL vs. $38.1-46.8 \% \mathrm{SL}$ ), longer anal-fin base (33.9-39.9\% SL vs. $23.1-32.5 \%$ SL), a cordiform gas bladder with two short posterior diverticula (vs. gas bladder elongated antero-posteriorly and with two longer, recurved posterior diverticula), and an overall light pigmentation pattern on the head, dorsum, sides of body, and fins (vs. dark pigmentation over most of body and fins with prominent spots or mottling).

Description. Morphometric data are summarized in Table 11. A small-sized auchenipterid. Size range 34.2-
$81.3 \mathrm{~mm} \mathrm{SL}(\mathrm{n}=108)$ for specimens of undetermined sex, mature females, and non-nuptial males. Size range 50.5-69.2 mm SL $(\mathrm{n}=14)$ for prenuptial and nuptial males. Head moderately depressed, dorsal profile weakly convex to dorsal-fin origin. Dorsal profile of body from behind dorsal fin to caudal fin nearly straight or slightly convex. Isthmus and abdomen flat or slightly convex to pelvicfin origin. Ventral contour of body along anal-fin base angled in a straight line upward to the caudal peduncle. Caudal peduncle relatively shallow, 6.6-9.7\% SL. Body moderately compressed at pectoral-fin insertion, strongly compressed posterior to pelvic-fin base.

Table 11. Morphometric data for specimens of Tympanopleura longipinna. $\mathrm{SD}=$ standard deviation.

\begin{tabular}{|c|c|c|c|c|c|}
\hline & $\mathrm{N}$ & Range & Mean & SD & Holotype MZUSP 114000 \\
\hline Standard length (SL, mm) & 30 & $46.1-78.7$ & --- & --- & 73.0 \\
\hline \multicolumn{6}{|c|}{ Percent of SL } \\
\hline Preadipose length & 30 & $79.2-84.4$ & 81.7 & 1.3 & 80.8 \\
\hline Preanal length & 30 & 49.7-57.6 & 53.6 & 2.0 & 55.3 \\
\hline Predorsal length & 30 & $29.5-36.1$ & 31.6 & 1.5 & 35.5 \\
\hline Prepelvic length & 30 & $38.8-48.4$ & 42.7 & 1.8 & 45.3 \\
\hline Prepectoral length & 30 & 25.1-36.9 & 27.6 & 2.2 & 29.2 \\
\hline Pectoral-fin origin to dorsal-fin origin & 30 & $19.3-23.7$ & 21.2 & 1.0 & 20.5 \\
\hline Pelvic-fin origin to dorsal-fin origin & 30 & $19.5-25.5$ & 23.0 & 1.8 & 20.8 \\
\hline Pelvic-fin origin to adipose-fin origin & 30 & $37.6-45.1$ & 43.0 & 1.8 & 40.1 \\
\hline Dorsal-fin origin to adipose-fin origin & 30 & $46.5-54.0$ & 51.0 & 1.9 & 47.5 \\
\hline Adipose-fin origin to anal-fin insertion & 30 & $9.9-16.5$ & 14.1 & 1.4 & 12.6 \\
\hline Body depth at dorsal-fin origin & 30 & $15.2-23.4$ & 20.4 & 1.9 & 18.9 \\
\hline Caudal peduncle depth & 30 & $6.6-9.7$ & 8.5 & 0.7 & 8.9 \\
\hline Caudal peduncle length & 30 & $9.7-12.9$ & 10.9 & 0.8 & 10.8 \\
\hline Body width at pectoral-fin origin & 30 & $21.1-25.7$ & 23.9 & 1.2 & 23.2 \\
\hline Body width at pelvic-fin origin & 30 & $7.3-12.2$ & 10.3 & 1.0 & 11.6 \\
\hline Pectoral spine length & 30 & $15.9-18.2$ & 17.0 & 0.6 & 16.3 \\
\hline Anal-fin base length & 30 & $33.9-39.9$ & 37.7 & 1.5 & 35.5 \\
\hline Head length (HL) & 30 & $25.2-29.7$ & 26.9 & 1.0 & 27.5 \\
\hline \multicolumn{6}{|c|}{ Percent of HL } \\
\hline Head depth at supraoccipital & 30 & $53.0-74.1$ & 58.3 & 3.8 & 54.2 \\
\hline Head width at postorbitals & 30 & $61.8-78.8$ & 70.8 & 4.0 & 76.6 \\
\hline Dorsal interopercular width & 30 & $48.9-57.8$ & 54.6 & 2.3 & 52.2 \\
\hline Anterior internarial distance & 30 & $28.7-37.7$ & 33.3 & 1.8 & 32.3 \\
\hline Preisthmus length & 30 & $66.0-78.3$ & 73.7 & 2.9 & 78.1 \\
\hline Snout length & 30 & $40.3-57.1$ & 48.0 & 3.8 & 47.8 \\
\hline Gape width & 30 & $51.3-65.3$ & 56.8 & 2.9 & 57.7 \\
\hline Upper jaw length & 30 & $30.1-38.8$ & 34.0 & 2.0 & 38.8 \\
\hline Lower jaw length & 30 & $26.0-37.1$ & 30.5 & 2.2 & 32.3 \\
\hline Eye diameter & 30 & $11.6-18.5$ & 14.5 & 1.7 & 15.9 \\
\hline
\end{tabular}


Head length $25.2-29.7 \%$ SL. Mouth weakly inferior. Snout relatively long, 40.3-57.1\% HL, broadly parabolic in dorsal profile. Premaxillary and dentary tooth bands relatively narrow, teeth minute, conical to weakly recurved, in an irregular series of about 4-5 rows medially on the premaxilla, tapering to 2-3 rows, about 2-3 medially on dentary. Eye moderate in size, 11.6-18.5\% HL, covered by relatively thin layer of epidermis; eyes lateral, equally visible from dorsal and ventral profile (Fig. 1d). Fontanelle groove moderately large, recessed, extending from mesethmoid along most of medial margins of frontals posteriorly to a plane approximately in line with the posterior edges of the orbits. Anterior nares lateral to distal tip of mesethmoid wings and directed forward; posterior nares remote, not bordering lateral margins of frontals, with a low epidermal flap around margin, raised slightly posteriorly. Posterior edge of lower jaw reaching to just below middle of orbit. Gill membranes broadly fused to isthmus behind plane through rear margin of orbit. Branchiostegal rays 8-9 (mode 8; $\mathrm{n}=30$ ). Total gill rakers on anterolateral margin of first arch 19-25 (mode 23; $\mathrm{n}=29$ ); epibranchial with 7-9 (mode 9) and ceratobranchial with 12-17 (mode 14) gill rakers. Longest gill rakers near middle of arch thin and crenulate on medial margin; gill rakers tapering, short, and pointed near ends of each arch.

Maxillary barbels of females and non-nuptial males minute, filiform, concealed in premaxillary groove, length 8.6-28.9\% HL (mean=15.5 $\pm 5.3 \mathrm{SD} ; \mathrm{n}=24$ ). Barbel of prenuptial males thickened, elongated, ossified most of length, with fleshy tip. Barbel of nuptial males ossified entire length, curved inward toward side of head when adducted. Barbel length of prenuptial and nuptial males 35.8-52.1\% HL (mean=45.0 $\pm 5.1 \mathrm{SD} ; \mathrm{n}=8$ ). Barbel of prenuptial and nuptial males with 5-15 (mode 13; $n=8$ ) incipient hooks on anterodorsal and posterolateral surfaces; hooks fully ossified, sharp, recurved in peak nuptial males. Hooks appear to begin development first on the anterodorsal margin, numbering 5-8 in the material examined, with 0-9 on the posterolateral margin.

Dorsal fin rays II,6, consisting of a small spinelet, elongated spine, and branched rays; first ray longest, tip extending anterior to midpoint between dorsal-fin origin and adipose-fin origin when fin is adpressed. Dorsal-fin origin about equal with vertical plane passing through pectoral-fin insertion. Dorsal-fin spine short, relatively thin and weak in females and non-nuptial males, depressed spine reaching about one-third or less the distance between dorsal-fin origin and adipose-fin origin, length of spine $13.5-19.8 \% \mathrm{SL}$ (mean=15.7 $\pm 1.4 \mathrm{SD} ; \mathrm{n}=24$ ). Anterior margin of dorsal-fin spine weakly to moderately crenulated with single row of low-crowned denticulations. Lateral margins of spine with distinct longitudinal grooves and ridges. Entire posterior margin with 16-29 (mean=21.4 $\pm 3.9 \mathrm{SD}$; $\mathrm{n}=16$ ) relatively small, conical, retrorse serrae. Dorsal-fin spine of prenuptial and nuptial males (56.1-69.2 $\mathrm{mm}$ SL) elongated, thin, nearly straight, $18.6-37.8 \%$ SL (mean=29.0 $\pm 6.1 \mathrm{SD} ; \mathrm{n}=8$ ), with 35-56 (mean=46.3 $\pm 9.0 ; n=4)$ sharp, antrorse serrae along anterior margin; serrae arranged in an alternating anterolateral direction on distal half of spine, those on proximal section of the spine in serial row or directed less acutely anterolaterally, irregular and more densely spaced, embedded basally within a ridge of integument. Posterior margin of dorsal-fin spine in nuptial males nearly smooth or with about 18-39 minute, irregularly spaced denticulations. Adipose fin small, posterior margin free.

Anal fin long, base $33.9-39.9 \%$ SL, with $32-42$ rays (mode 37; $\mathrm{n}=74$ ), distal margin straight except in nuptial males. Anal-fin pterygiophores 32-38 (mode 34; n=27). First 5 anal-fin rays of prenuptial and nuptial males unbranched, elongated, and thickened to form intromittent organ; gonopore located distally on leading edge of anal fin about one-third to one-half distance from base to tip of longest ray.

Pectoral-fin spine well developed, short, stout, 15.9$18.2 \% \mathrm{SL}$, not reaching to pelvic-fin origin. Anterior margin of spine rugose but lacking distinct serrae. Dorsal and ventral surfaces of spine with shallow longitudinal grooves. Posterior margin of spine with single series of retrorse serrae along entire length except short proximal section; serrae, counted from both sides in some specimens, range from 13-25 (mode 19; mean=19.3 $\pm 2.8 \mathrm{SD}$; $\mathrm{n}=58$ ). Pectoral fin with 10-13 (mode 11) branched rays, anteriormost rays longest. Postcleithral process often absent; when present, short and rudimentary.

Pelvic-fin origin slightly posterior to tips of longest adpressed pectoral-fin rays; distal margin of fin straight to slightly convex. Pelvic fin rays i,6; first branched ray longest, subsequent rays progressively shorter.

Caudal fin forked, lobes equal and pointed, with $8+9$ principal rays (rarely 6 upper; 8 lower), 17-22 (mode 20; $\mathrm{n}=21$ ) upper and 14-18 (mode 16; $n=22$ ) lower procurrent rays.

Preanal vertebrae $13-15$ (mode $14 ; \mathrm{n}=28)$. Total vertebrae 40-43 (mode 43; $\mathrm{n}=28$ ). Pairs of pleural ribs $4-5$ (mode 5 ; $\mathrm{n}=25$ ).

Pseudotympanum large, triangular, opaque to semitranslucent, weakly to unpigmented on exterior surface. Gas bladder of adult large, cordiform, thin-walled with slightly conical posterior margin, tunica smooth over entire surface, with two short terminal diverticula separated at their bases (Fig. 6e).

Color in alcohol. Overall base color of body light tan to cream colored, pigmentation in most specimens relatively light. Minute, diffuse brown melanophores on top and sides of head, over pseudotympanum, forming a narrow middorsal stripe, and occasionally scattered on sides above lateral line. Concentration of pigmentation greatest over supraoccipital and frontals, around base of dorsal-fin spine, including anterior margin of spine proximally, and middorsal stripe. Pigmentation in some specimens irregular on top of head and mid-dorsally, forming a weakly mottled appearance. Fins, venter, and chin unpigmented. 
Distribution. Tympanopleura longipinna is broadly distributed throughout the upper and middle Amazon River basin in Brazil and Peru (Fig. 15).

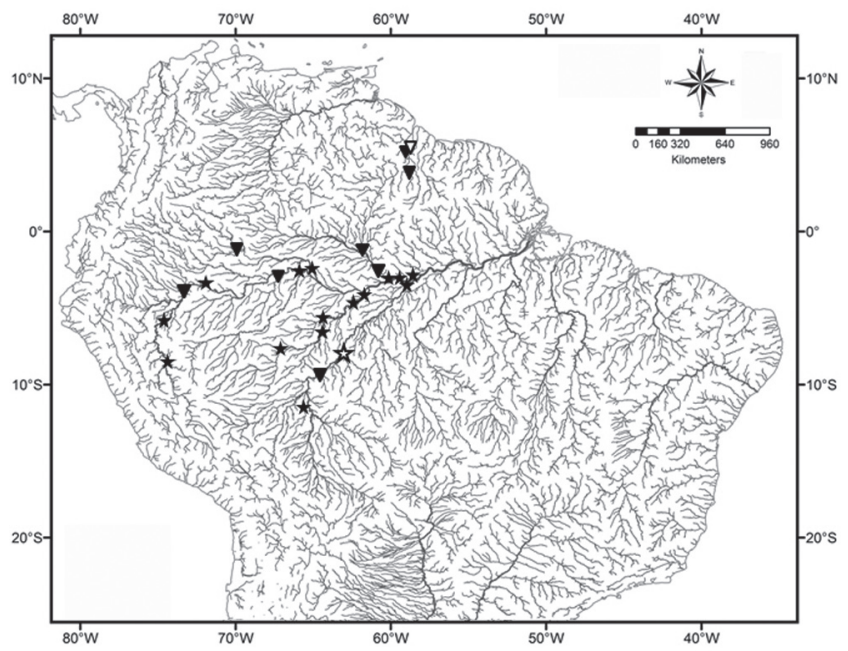

Fig. 15. Distribution of Tympanopleura longipinna (stars) and $T$. piperata (inverted triangles) based on material examined. Open symbols indicate type localities. Some symbols represent more than one lot or locality.

Etymology. The specific epithet longipinna is derived from the Latin longus, meaning long or extended, in combination with the Latin pinna, referring to fin. The name is in reference to the long, multi-rayed anal fin of this species relative to congeners, treated as a noun in apposition. Gender feminine.

Remarks. Tympanopleura longipinna has been misidentified in the past, or its distinctiveness from congeners not readily recognized, based on its superficially similar appearance to other species in pigmentation pattern and general morphology. Walsh (1990) erroneously included specimens of $T$. longipinna, together with specimens of T. rondoni, in his account of T. brevis (as Ageneiosus brevis), although at the time he concluded that there was likely more than one taxon involved. A substantial increase in the amount of available study material in recent years, including many specimens collected during the "Calhamazon" expeditions, has made it possible to evaluate the morphology of this taxon in greater detail. The species is diagnosed on the basis of a combination of relatively subtle characters by which it clearly differs from congeners, e.g., composite bodyshape differences as listed under Diagnosis and revealed by multivariate analysis (Fig. 8a) and high anal-fin ray count.

\section{Tympanopleura piperata Eigenmann, 1912}

Figs. 1e, 5, 6f, 16, 17

Tympanopleura piperata Eigenmann, 1912: 203-204, pl. 20 [typelocality: -British Guiana (=Guyana), Essequibo River at Crab Falls]. -Henn, 1928: 75 [holotype listed]. -Eigenmann \& Myers, in Myers, 1928: 85 [comments on size and comparison with T. alta]. -Eigenmann \& Allen, 1942: 138 [designated type-species of genus]. -Gosline, 1945: 25 [citation]. -Fowler, 1951: 456 [cited as generic type (orthotype)]. -Ibarra \& Stewart, 1987: 84,86 [holotype and paratype listed]. -Burgess, 1989: 286 [checklist]. -Hardman et al., 2002: 235 [checklist; Essequibo and lower Potaro rivers, Guyana]. -Ferraris, 2003: 471 [checklist; as synonym of Ageneiosus piperatus; typelocality; holotype; distribution after Walsh, 1990]. -Ferraris, 2007: 70 [type checklist; as synonym of Ageneiosus piperatus; information duplicated from Ferraris, 2003].

Ageneiosus piperatus. -Rosa \& Menezes, 1996: 657 [in checklist of species of conservation concern, status undetermined]. -Ferraris, 2003: 472 [checklist; see above]. -Watkins et al., 2004: 50 [in list of species from Iwokrama Forest, Guyana; Essequibo and Burro-Burro rivers; identification not verified]. -Mojica et al., 2005: 204 [checklist; Colombian Amazon; ICNMHN cataloged lot (5702); identification not verified]. -Bogotá-Gregory \& Maldonado-Ocampo, 2006: 82 [checklist; Colombian Amazon, after Mojica et al., 2005]. -Akama \& Sarmento-Soares, 2007: 116 [checklist; type-locality; distribution]. -Ferraris, 2007: 70 [type checklist; see above]. -Maldonado-Ocampo et al., 2008: 208 [checklist; Colombian Amazon, after Mojica et al., 2005, Bogotá-Gregory \& Maldonado-Ocampo, 2006; identification(s) not verified]. -Vari et al., 2009: 44 [checklist; Roraima, Brazil]. -Ribeiro \& Rapp Py-Daniel, 2010: 99, 103 [in diagnosis of Ageneiosus uranophthalmus and material examined]. -de Souza et al., 2012: 36 [checklist; Rupununi River, Guyana].

Diagnosis. Tympanopleura piperata is distinguished from congeners by its diminutive size (maximum size less than $50 \mathrm{~mm}$ SL vs. greater than $75 \mathrm{~mm}$ SL in all other species), a large cordiform gas bladder lacking posterior diverticula and with the tunica externa and internal longitudinal septum partially ossified in adults, and unique pigmentation on the caudal fin consisting of a dense patch of melanophores forming an hourglass-shaped band at its base (most visible in live or freshly preserved specimens). Tympanopleura piperata is further distinguished from $T$. atronasus in having a greater number of anal-fin rays (31-38 vs. 23-30), greater number of gill rakers on the first arch (16-23, mode 19 vs. 14-23, mode 16), fewer preanal vertebrae (14-16, mode 15 vs. 16-19, mode 17), fewer total vertebrae (39-41, mode 40 vs. 39-43, mode 41), fewer pleural rib pairs (4-5 vs. 7-8), shorter prepelvic length (41.3-47.0\% SL vs. 49.2$55.2 \% \mathrm{SL}$ ), greater distance from pelvic- to adipose-fin origin (36.7-50.0\% SL vs. 31.2-38.1\% SL), longer anal-fin base (30.9-39.3\% SL vs. 22.1-27.6\% SL), and absence of a dense patch of pigmentation on the flank above the analfin base and elongate streak of pigment in each caudal-fin lobe that is characteristic of T. atronasus. Tympanopleura piperata further differs from $T$. brevis in having fewer pectoral-fin rays (6-10, mode 9 vs. 10-12, mode 11), fewer gill rakers on the first arch (16-23, mode 19 vs. 20-24, mode 23), shorter predorsal length (28.8-34.4\% SL vs. 35.1-44.0\% 
SL), shorter prepelvic length (41.3-47.0\% SL vs. 47.4-53.9\% SL), shorter prepectoral length (23.6-28.3\% SL vs. 27.9$35.6 \% \mathrm{SL}$ ), shorter distance from pectoral- to dorsal-fin origin (15.2-20.9\% SL vs. 21.4-27.0\% SL), narrower body width at pectoral-fin origin (16.8-20.0\% SL vs. $20.5-26.6 \%$ SL), shorter pectoral-fin spine (13.9-18.1\% SL vs. 19.1-24.4\% SL), shorter head length (22.2-27.8\% SL vs. 29.7-35.6\% SL), and a larger eye diameter (24.3-35.7\% HL vs. $13.8-21.0 \%$ HL). Tympanopleura piperata differs from T. cryptica in having more anal-fin rays (31-38 vs. 23-30), fewer gill rakers on the first arch (16-23, mode 19 vs. 21-26, mode 22), greater number of total vertebrae (39-41, mode $40 \mathrm{vs.}$ $38-41$, mode 38$)$, shorter preanal length $(52.5-59.7 \%$ SL $v s$. 59.6-66.0\% SL), shorter prepectoral length (23.6-28.3\% SL vs. $29.7-33.8 \%$ SL), shorter distance from pectoral- to dorsal-fin origin (15.2-20.9\% SL vs. 21.6-24.3\% SL), longer anal-fin base (30.9-39.3\% SL vs. 24.4-30.3\% SL), and a slightly larger eye diameter (24.3-35.7\% HL vs. $16.7-25.6 \%$ HL). Tympanopleura piperata differs from $T$. longipinna in having a slightly shorter anal fin (anal-fin rays 31-38, mode 35 vs. 34-42, mode 37), fewer pectoral-fin rays (6-10, mode 9 vs. 10-13, mode 11), fewer total vertebrae (39-41, mode 40 vs. 40-43, mode 43), narrower body width at pectoral-fin origin (16.8-20.0\% SL vs. 21.1-25.7\% SL), slightly shorter snout (31.4-43.6\% HL vs. 40.3-57.1\% HL) and narrower gape $(34.8-53.6 \%$ HL vs. $51.3-65.3 \%$ HL), and a larger eye (24.3-35.7\% HL vs. 11.6-18.5\% HL). Tympanopleura piperata differs from $T$. rondoni in having a slightly longer anal fin (anal-fin rays 31-38, mode 35 vs. 28-37, mode 31), fewer pectoral-fin rays (6-10, mode 9 vs. 10-13, mode 11), fewer gill rakers (16-23 vs. 24-33), fewer pleural rib pairs (4-5, mode $4 v$ s. 4-6, mode 6), shorter predorsal length (28.8$34.4 \%$ SL vs. 35.2-47.4\% SL), shorter prepectoral length (23.6-28.3\% SL vs. 29.2-39.0\% SL), shorter distance from pectoral- to dorsal-fin origin (15.2-20.9\% SL vs. 19.8-29.0\% $\mathrm{SL}$ ), greater distance from pelvic- to adipose-fin origin (36.7-50.0\% SL vs. $24.0-41.5 \%$ SL), greater distance from dorsal- to adipose-fin origin (45.9-55.4\% SL vs. 38.1-46.8\% SL), narrower body width at pectoral-fin origin $(16.8-20.0 \%$ SL $v$ s. 21.8-29.5\% SL), shorter pectoral-fin spine (13.9-18.1\% SL vs. $17.1-21.0 \% \mathrm{SL}$ ), longer anal-fin base (30.9-39.3\% SL vs. $23.1-32.5 \% \mathrm{SL})$, shorter head (22.2-27.8\% SL vs. 26.5$39.0 \%$ SL), slightly shorter snout (31.4-43.6\% HL vs. 41.7$53.6 \% \mathrm{HL})$ and narrower gape (34.8-53.6\% HL vs. 51.0$65.6 \% \mathrm{HL})$, larger eye (24.3-35.7\% HL vs. 8.4-17.0\% HL). Additionally, unlike $T$. piperata, $T$. rondoni has a heavily spotted pigmentation pattern and an elongated gas bladder with a pair of long, recurved diverticula.
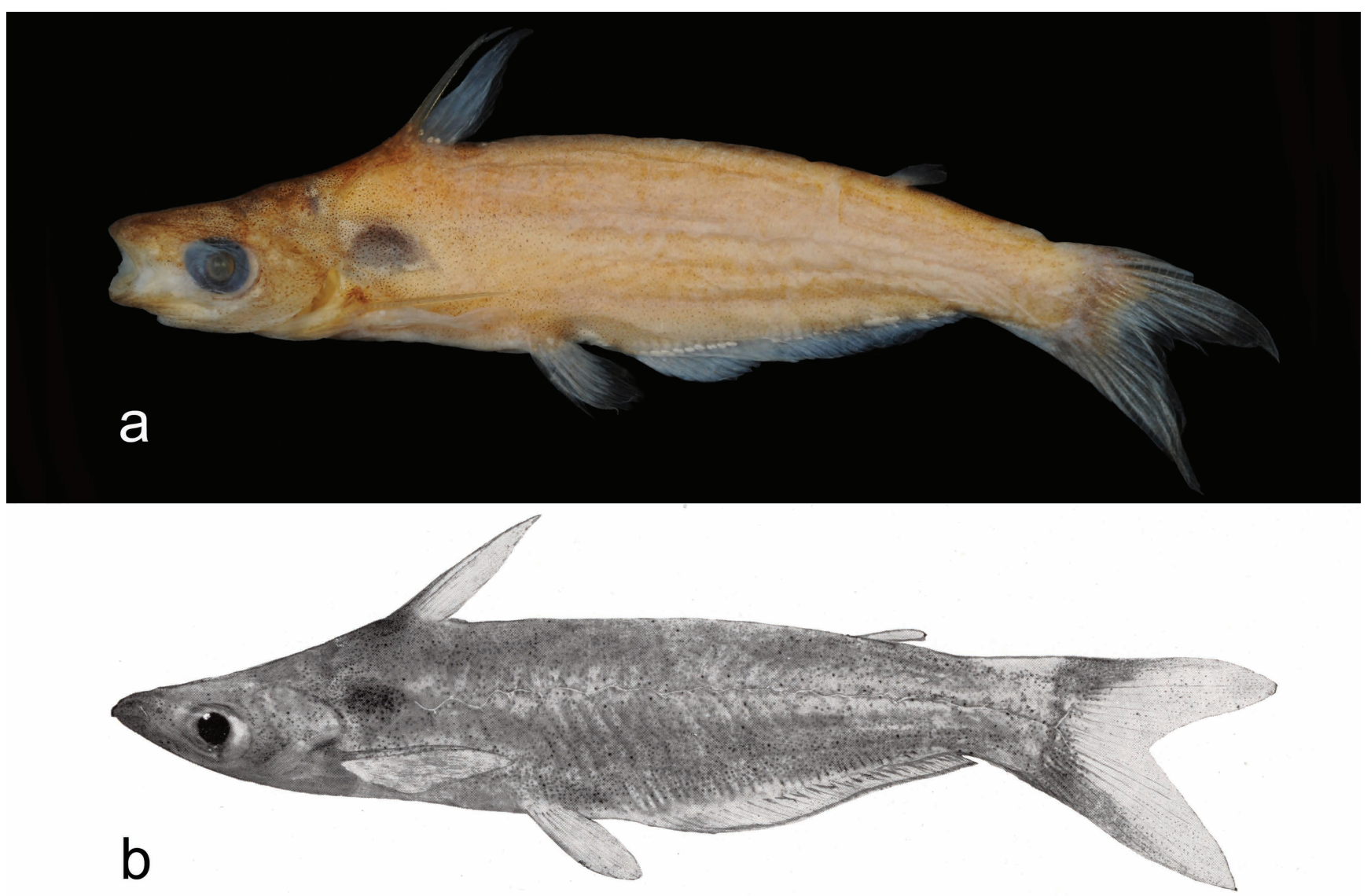

Fig. 16. Tympanopleura piperata. (a) ANSP 194022 (47.5 mm SL), female, rio Negro, Amazonas State, Brazil; (b) holotype, FMNH 53243 (ex. CM 1708; 47.3 mm SL), male, Essequibo River, Cuyuni-Mazaruni Region, Guyana, reproduced from Eigenmann (1912; originally cited as $64 \mathrm{~mm} \mathrm{TL})$. 


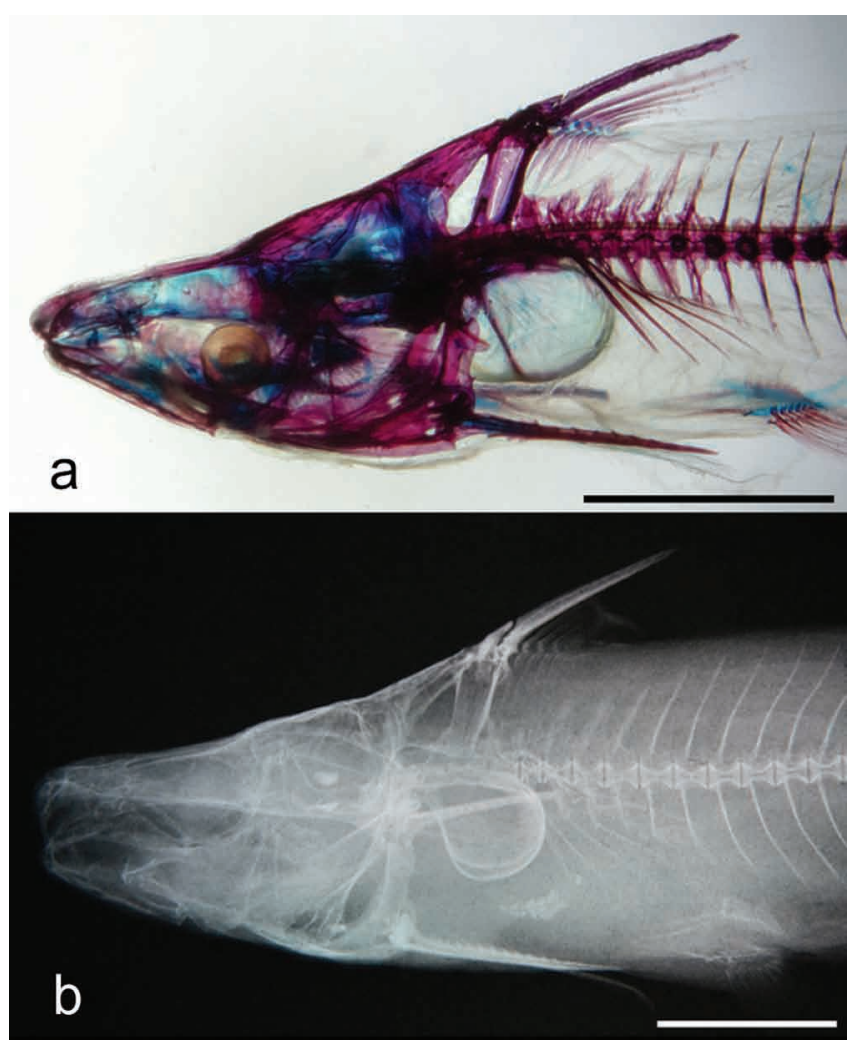

Fig. 17. Ossification of the median septum and tunica of the gas bladder in Tympanopleura piperata. (a) UF 181564 (33.5 mm SL), cleared/stained; (b) INHS 36738 (40.0 mm $\mathrm{SL}$ ), nuptial male, radiograph. Scale bars $=5 \mathrm{~mm}$.

Description. Morphometric data are summarized in Table 12. Tympanopleura piperata is the smallest species of the genus. Size range 23.0-47.5 mm SL $(n=80)$ for immature specimens, females, and non-nuptial males. Size range 38.5-46.9 mm SL $(n=11)$ for pre-nuptial males. No peak nuptial males were examined. Dorsal profile of head and nape gently sloping upward, nearly straight or slightly concave from tip of snout to base of dorsal-fin spine. Head depressed but not greatly flattened; head relatively deep at midpoint of supraoccipital, 54.3-69.7\% HL. Dorsal profile of body posterior to dorsal fin slightly convex to base of upper caudal-fin lobe. Caudal peduncle moderately deep, $7.6-10.5 \%$ SL. Body widest at origin of pectoral fin, gradually tapering in width to base of caudal fin.

Head length 22.2-27.8\% SL. Mouth subterminal, upper jaw extended only slightly anterior to tip of lower jaw. Snout moderately short, 31.4-43.6\% HL. Anterior margin of upper jaw weakly rounded to squared off in dorsal profile. Premaxillary and dentary tooth bands narrow, teeth small, conical. Premaxillary teeth in a series of about 2-4 irregular rows at midline, tapered to 1-2 rows on lateral edges, posteriormost area of premaxilla devoid of teeth. Dentary tooth patch in an irregular series of about 3-4 rows. Eye large, 24.3-35.7\% HL, nearly equally visible from dorsal and ventral profile, covered by thin layer of epidermis (Fig. 1e). Posterior edge of lower jaw approximately below middle of eye. Fontanelle groove relatively short, extending from posterior margin of mesethmoid to a point anterior to the plane passing through the rear margins of the orbits. Anterior nares just lateral to tips of mesethmoid wings; posterior nares offset from central margin of mesethmoid. Gill membranes broadly fused to isthmus at anterolateral margins of cleithra. Branchiostegal rays $7-8$ (mode $7 ; n=35)$. Total gill rakers on anterolateral margin of first arch 16-23 (mode 19; $n=28$ ); epibranchial with 5-9 (mode 6) and ceratobranchial with 10-15 (mode 12) long, thin gill rakers.

Maxillary barbels of females and immature males filamentous, thread-like, concealed in groove above premaxilla, length 6.3-16.1\% HL (mean=10.1 \pm 2.9 SD; $\mathrm{n}=16$ ). Barbel of prenuptial males ossified at base with filamentous tip, length 27.8-33.7\% HL (mean=31.1 \pm 2.6 $\mathrm{SD} ; \mathrm{n}=4)$, some specimens with about 3-4 low-crowned, incipient hooks on dorsomedial surface; full armature of peak nuptial male maxillary barbel not observed in material examined.

Dorsal fin rays II,6, consisting of a small spinelet, elongated spine, and branched rays; first ray longest, tip extending anterior to midpoint between dorsal-fin origin and adipose-fin origin when fin is adpressed. Dorsal-fin origin about equal with vertical passing through pectoral-fin insertion. Dorsal-fin spine relatively short, 12.8-19.2\% SL (mean=16.1 $\pm 1.7 \mathrm{SD} ; \mathrm{n}=20$ ), with weak longitudinal ridges on lateral margin. Posterior margin of spine in females and non-nuptial males with 8-17 (mode 10; mean=12.1 $\pm 2.2 \mathrm{SD}$; $\mathrm{n}=58$ ) sharp, retrorse serrae, not quite to base. Posterior margin of spine in pre-nuptial males smooth (Eigenmann, 1912). Anterior margin of spine weakly to moderately crenulated with low-crowned points, in tighter cluster proximally. Full extent of dorsal-fin spine development in peak nuptial males not observed.

Anal fin long, base 30.9-39.3\% SL, with 31-38 rays (mode $35 ; n=73$ ), distal margin nearly straight to slightly convex except in nuptial males. Anal-fin pterygiophores 3135 (mode 34; mean=33.2 \pm 1.1 SD; $n=13$ ). First 6-7 anal-fin rays of prenuptial males elongated and coalesced to form intromittent organ, gonopore displaced near tips of rays.

Pectoral-fin spine well developed, relatively thin, short, 13.9-18.1\% SL, not strongly grooved or furrowed. Longest pectoral rays exceed length of spine, tip of adpressed fin falling short of or just reaching to pelvic-fin origin. Anterior margin of spine crenulate. Posterior margin of spine with single series of prominent, sharp, retrorse serrae, counted from both sides in some specimens, range from 8-17 (mode 10; mean=12.0 $\pm 2.1 \mathrm{SD} ; \mathrm{n}=61$ ). Pectoral fin with 8-9, rarely 6-7 or 10 , branched rays (mode 9; $\mathrm{n}=73$ ). Postcleithral process generally absent, occasionally present as a small rudimentary splint.

Pelvic-fin origin anterior to vertical through tip of longest adpressed dorsal-fin ray; margin of fin straight to slightly rounded. Pelvic fin rays i,6; first branched ray longest, subsequent rays progressively shorter. 
Caudal fin deeply forked, lobes equal, with $8+9$ principal rays, rarely with 6 upper, 8 lower principal rays; 16-20 (mode $18 ; \mathrm{n}=48$ ) upper and 11-16 (mode 14) lower procurrent rays.

Preanal vertebrae $14-16$ (mode $15 ; n=31)$. Total vertebrae 39-41 (mode 40; $\mathrm{n}=31$ ). Pairs of pleural ribs 4-5 (mode 4; $\mathrm{n}=28)$.

Pseudotympanum large, ovoid, semi-translucent, epidermis covering muscle hiatus bulging outward and variably pigmented on exterior surface, ranging from nearly hyaline to moderately pigmented, especially on dorsal half
(Figs. 5, 16); projected light visible between sides due to the size and transparency of the gas bladder and thin overlying epidermis. Gas bladder of adult large, cordiform, apple shaped, moderately turgid, smooth-walled on dorsal, lateral, and anteroventral margin; posteroventral margin with an inverted "V" shaped thickened area of tunica with weak to moderate external ridges (Fig. 6f). No terminal diverticula. Internal median septum thin, laminar, together with posteroventral margin of gasbladder capsule weakly ossified in adults (Fig. 17).

Table 12. Morphometric data for specimens of Tympanopleura piperata. Synoptic material includes the holotype and six paratypes of $T$. piperata (FMNH 53244, CAS 58382[3], MCZ 30189, BMNH 1911.10.31.102). SD=standard deviation.

\begin{tabular}{|c|c|c|c|c|c|}
\hline & $\mathrm{N}$ & Range & Mean & SD & Holotype FMNH 53243 \\
\hline Standard length (SL, mm) & 22 & $30.3-47.5$ & --- & --- & 47.3 \\
\hline \multicolumn{6}{|c|}{ Percent of SL } \\
\hline Preadipose length & 22 & $77.3-82.1$ & 79.6 & 1.4 & 79.3 \\
\hline Preanal length & 22 & $52.5-59.7$ & 54.9 & 1.9 & 52.9 \\
\hline Predorsal length & 22 & $28.8-34.4$ & 31.7 & 1.6 & 30.7 \\
\hline Prepelvic length & 22 & $41.3-47.0$ & 44.9 & 1.7 & 41.9 \\
\hline Prepectoral length & 22 & $23.6-28.3$ & 25.8 & 1.4 & 24.9 \\
\hline Pectoral-fin origin to dorsal-fin origin & 22 & $15.2-20.9$ & 18.0 & 1.6 & 19.5 \\
\hline Pelvic-fin origin to dorsal-fin origin & 22 & $19.6-25.8$ & 23.5 & 1.9 & 19.9 \\
\hline Pelvic-fin origin to adipose-fin origin & 22 & $36.7-50.0$ & 40.0 & 2.8 & 40.8 \\
\hline Dorsal-fin origin to adipose-fin origin & 22 & $45.9-55.4$ & 50.0 & 2.2 & 51.6 \\
\hline Adipose-fin origin to anal-fin insertion & 22 & $13.5-18.4$ & 16.0 & 1.3 & 13.5 \\
\hline Body depth at dorsal-fin origin & 22 & $16.5-24.2$ & 20.3 & 1.6 & 16.5 \\
\hline Caudal peduncle depth & 22 & $7.6-10.5$ & 9.6 & 0.8 & 7.6 \\
\hline Caudal peduncle length & 22 & $9.6-15.2$ & 11.4 & 1.4 & 12.5 \\
\hline Body width at pectoral-fin origin & 22 & $16.8-20.0$ & 18.8 & 0.9 & 18.2 \\
\hline Body width at pelvic-fin origin & 21 & $7.6-12.5$ & 10.3 & 1.5 & --- \\
\hline Pectoral spine length & 20 & $13.9-18.1$ & 16.0 & 1.2 & --- \\
\hline Anal-fin base length & 22 & $30.9-39.3$ & 36.2 & 2.1 & 37.2 \\
\hline Head length (HL) & 22 & $22.2-27.8$ & 24.6 & 1.6 & 23.0 \\
\hline \multicolumn{6}{|c|}{ Percent of HL } \\
\hline Head depth at supraoccipital & 22 & $54.3-69.7$ & 63.5 & 4.4 & 63.3 \\
\hline Head width at postorbitals & 22 & $58.3-79.8$ & 70.7 & 5.7 & 63.3 \\
\hline Dorsal interopercular width & 22 & $45.0-63.6$ & 54.9 & 5.2 & 50.5 \\
\hline Anterior internarial distance & 19 & $18.9-33.3$ & 26.6 & 3.9 & --- \\
\hline Preisthmus length & 21 & $63.0-81.8$ & 71.9 & 4.7 & 68.8 \\
\hline Snout length & 22 & $31.4-43.6$ & 38.3 & 3.3 & 42.2 \\
\hline Gape width & 22 & $34.8-53.6$ & 46.5 & 4.7 & 45.0 \\
\hline Upper jaw length & 22 & $25.7-36.5$ & 31.7 & 2.8 & 32.1 \\
\hline Lower jaw length & 22 & $25.2-37.5$ & 30.2 & 3.0 & 29.4 \\
\hline Eye diameter & 22 & $24.3-35.7$ & 28.8 & 2.8 & 28.4 \\
\hline
\end{tabular}


Color in alcohol. The description and illustration in Eigenmann (1912: 204, plate 20, fig. 3; reproduced here in Fig. 16b) indicates the holotype of T. piperata, as the specific epithet alludes, to originally have relatively uniform "peppered" pigmentation over the head, dorsum, and sides of body, with dense concentrations of melanophores at the base of the caudal fin, base of the dorsal fin, over the pseudotympanum, and tip of the snout. The preserved holotype is now faded, and, due to shrinkage, it is now difficult to discern pigmentation pattern. In freshly collected specimens, the background color is typically tan to beige or dusky yellowish, with many specimens showing sparse traces of pigmentation. In well-pigmented individuals, the dorsum, sides of the body, and the head are covered with diffuse minute brown specks consisting of individual melanophores, occasionally enlarged or coalesced and forming weak spots or slight mottling. A prominent hourglass-shaped vertical bar at the base of the caudal fin, consisting of fine, densely clustered brown or black melanophores, is characteristic of this species (Fig. 16b); the leading vertical edge of the bar is nearly straight. Pigment on dorsal aspect of body generally confined to a relatively narrow stripe, sometimes broken into irregular patches, extending down midline of back and with scattered specks distributed ventrally above lateral line and over pseudotympanum. Venter generally depigmented, occasionally with melanophores dispersed on chin, isthmus, and lower portion of opercula and body near pectoral-fin base. Top and sides of head moderately and irregularly pigmented, with some light areas around nares, between orbits, and on lower half of opercula. Skin above supraoccipital generally brownish, somewhat more intense at base of dorsal spine. Pigment extending along part or most of anterior margin of the dorsal spine. Dorsal fin only lightly pigmented, occasionally with distal tips of rays darkened. Adipose and distal portion of caudal-fin lobes hyaline or only lightly speckled. Anal fin generally with little pigment, but in some specimens with thin black margin, most intense at distal tips of anterior rays. Pectoral and pelvic fins dusky, with melanophores concentrated along anterior rays and interradial membranes, near base, and occasionally along distal margin of fin.

Distribution. Tympanopleura piperata is distributed in the Essequibo River drainage of Guyana, including the Potaro and Rupununi rivers, and in the central and upper Amazon River basin in Brazil and Peru (Fig. 15).

Remarks. Eigenmann (1912) designated as cotypes of $T$. piperata two males and five females (ex. CM 1709a and IU 12090), 57-61 mm, presumably TL. Based on examination of external morphology and radiographs of the paratypes, i.e., ossification of the maxillary barbel and anterior analfin rays, we provisionally identify the extant type series, excluding the holotype, to consist of four males and two females; a seventh specimen was not located in museum material examined. Given the small size of the species and difficulty in accurately determining gender of specimens in the absence of pronounced sexually dimorphic features, we conclude that Eigenmann erred in assigning sex to some of the type specimens; confirmation of this would require dissection of the gonads. The holotype (FMNH 53243) and one cotype (FMNH 53244) appear to have been desiccated or exposed to circumstances that caused severe shrinkage and are in poor condition. Etymology of the specific epithet is derived from the Latin piper, meaning pepper, in reference to the finely stippled pigmentation pattern on the body.

Material examined. Holotype. FMNH 53243 (ex CM 1708), 1 (47.3 mm SL, male), British Guiana (=Guyana), Cuyuni-Mazaruni Region, Essequibo River at Crab Falls, 1908, C.H. Eigenmann and party. Paratypes. 6 specimens (41.7-47.5 mm SL). FMNH 53244 (ex CM 1709a or IU 12090), 1 (41.7 mm SL, male [?]), same collection data as holotype. CAS 58382 (ex IU 12090), 3 (1, 47.5 mm SL, female [?]; 2, 44.6-46.9 mm SL, males), same collection data as holotype. MCZ 30189 (ex CM 1709a or IU 12090), 1 (46.4 mm SL, female), same collection data as holotype. BMNH 1911.10.31.102 (ex CM 1709a or IU 12090), 1 (44.8 mm SL, male), same collection data as holotype.

Non-type material. 364 specimens (23.0-56.3 mm SL). Brazil. Amazonas: ANSP 137688, 1 (40.4 mm SL), W of Moura near junction of rio Negro and rio Branco, date unknown, J. Faughn; ANSP 194018, 2 (34.9-40.8 mm SL), rio Jutaí between Porto Antunes and Foz do Jutai, c. 02 50 '6.1'S 66 55'38.9'W, 13 Nov 1993, J.P. Sullivan et al.; ANSP 194019, 3 (36.9-42.5 mm SL), rio Jutaí downriver of Porto Antunes and upriver of Copatana, c. $02^{\circ} 58^{\prime} 9.0$ 'S $67^{\circ} 00^{\prime} 43.6^{\prime \prime} \mathrm{W}, 16$ Nov 1993, O.T. Oyakawa et al.; ANSP 194020, 1 (42.5 mm SL), rio Jutaí downriver of Porto Antunes and upriver of Foz do Jutai, c. 0257'3.8'S 6700'48.5”'W, 16 Nov 1993, J.P. Friel et al.; ANSP 194021, 1 (39.9 mm SL), same collection data as ANSP 194019; ANSP 194022, 5 (43.2-47.5 mm SL), rio Negro $34.3 \mathrm{~km}$ downriver of Moura, $9.8 \mathrm{~km}$ upriver of Novo Caioé, c. 0142'16.0"S 61²9'56.1”W, 11 Dec 1993, J.N. Baskin et al.; INPA 10263, 1 (41.4 mm SL), rio Negro, Novo Airão, Lago do Prato, collected with bottom trawl, c. 02 $36^{\circ}$ 'S 6056'W, 17 Mar 1991, M. Garcia; INPA 12562, 4 (30.7-37.2 mm SL), rio Negro, rio Jaú, Copaíba pool, c. 02³9'S 6059’W, 15 Oct 1995, M. Garcia; INPA 12564, 13 (33.9-41.7 mm SL), rio Negro, rio Jaú, Copaíba pool, 15 Oct 1995, M. Garcia; INPA 12584, 5 (26.8$30.3 \mathrm{~mm} \mathrm{SL}$ ), rio Negro, rio Jaú, lake at mouth of rio Paunini, 17 Jun 1995, M. Garcia; INPA 12603, 11 (24.4-31.6 mm SL), same locality as INPA 12584, 19 Jun 1995, M. Garcia; INPA 12608, 8 (25.2-30.7 mm SL), rio Negro, rio Jaú, lake above rio Paunini, 18 Jun 1995, M. Garcia; INPA 12613, 4 (27.5-50.7 mm SL), same collection data as INPA 12608; INPA 12636, 158 (31.2-56.3 mm SL, 1 c/s), rio Negro, rio Jaú, Lago Tambor Velho, 15 Oct 1995, M. Garcia; INPA 12682, 39 (40.8-50 mm SL, $1 \mathrm{c} / \mathrm{s})$, rio Negro, rio Jaú, canal Miratuca, 28 Oct 1995, M. Garcia; MZUSP 114006, 5 (29.0-32.8 $\mathrm{mm} \mathrm{SL}$ ), rio Jauaperi approximately $30 \mathrm{~km}$ from the mouth, 19 Nov 1968, T. Roberts; MZUSP 56199, 1 (unmeasured), 
rio Negro $1.3 \mathrm{~km}$ below Jufarí, c. $01^{\circ} 15^{\prime} \mathrm{S} 68^{\circ} 58^{\prime} \mathrm{W}, 9$ Dec 1993 , J.G. Lundberg et al.; MZUSP 56200, 3 (unmeasured), rio Jutaí

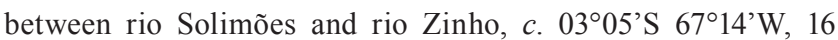
Nov 1993, J.G. Lundberg et al.; MZUSP 56724, 1 (unmeasured), rio Jutaí between rio Solimões and rio Zinho, 16 Nov 1993, O. Oyakawa et al. Rondônia: UNIR 1589, 20 (41.1-54.0 mm SL), rio Madeira, rio Jaci Paraná, Jaci Paraná, beach in front of Lago Madalena, c. $09^{\circ} 17^{\prime} 12^{\prime}$ 'S 64²4'00' W, 10 Dec 2008, C. P. Röpke. Guyana. Upper Demerara Berbice: INHS 49234, 4 (26.5-31.0 mm SL), Essequibo River 0.72 mi SW Rockstone at sandbar, 19 Oct 1998, M.H. Sabaj Pérez et al.; INHS 49357, 3 (29.6-32.4 mm SL), large sandbar and small cataract $31.9 \mathrm{mi}$ SSW Rockstone, bearing $204^{\circ}$, c. $05^{\circ} 31^{\prime} 39.5^{\prime \prime} \mathrm{N} 58^{\circ} 37^{\prime} 43.6^{\prime \prime} \mathrm{W}, 21$ Oct 1998, M.H. Sabaj Pérez et al.; INHS 49443, 1 (32.5 mm SL), beach on $\mathrm{N}$ bank downriver of Tumatumari cataract, c. $05^{\circ} 21^{\prime} 48.4^{\prime \prime} \mathrm{N}$ 5900'04.4”W, 22 Oct 1998, M.H. Sabaj Pérez et al.; UF 181564 (ex. MCZ 50742), 1 (33.5 mm SL, c/s), North Rupununi, Mobay Pond, c. 05¹0'0.01'N 58³7'59.9'”, 4 May 1971, C.D. Hopkins \& F. Cichocki. Potaro-Siparuni: ANSP 175838, 1 (46.4 mm SL), Essequibo River at Essequibo campsite (=WGS97-15), 26 Jan 1997, D. Torres et al. Upper Takutu-Upper Essequibo: ANSP 179676, 2 (33.7-38.4 mm SL), Rupununi River, sand beach and inlet at Karanambo Ranch, 29 Oct 2002, M.H. Sabaj Pérez et al. Peru. Loreto: ANSP 191444, 4 (42.5-37.4 mm SL), río Nanay above Santa Clara, c. 0346'45"S 73²2'06”W, 14 Aug 2003, M. Sabaj et al.; ANSP 191445, 5 (32.5-35.0 mm SL), río Nanay, village of Pampa Chica, $4.5 \mathrm{~km}$ from Iquitos, c. 0345'09' $\mathrm{S} 73^{\circ} 17^{\prime} 00^{\prime} \mathrm{W}$, 18 Aug 2003, M. Sabaj Pérez et al.; INHS 36738, 5 (40.0-44.8 $\mathrm{mm} \mathrm{SL}, 1 \mathrm{c} / \mathrm{s}$ ), río Nanay and tributary, Santa Clara, W of Iquitos, 22 Jul 1995, L.M. Page et al.; INHS 44201, 20 (23.0-44.2 mm $\mathrm{SL}, 5 \mathrm{c} / \mathrm{s}$ ), río Nanay upriver from Santa Clara at Mizplaya, 13.9 $\mathrm{km}$ W of Iquitos, c. 0346'54.6"S 73²1'49.6”W, 29-30 Jul 1997, M.H. Sabaj Pérez et al.; MZUSP 115006, 2 (38.1-38.4 mm SL), same data as INHS 44201; SIUC 29483, 1 of 6 (32.4 mm SL), río
Nanay at Misplaya, just upriver from Santa Clara, $13.9 \mathrm{~km}\left(78^{\circ}\right.$ bearing) from Iquitos, c. 0346'54.6”S 7321'49.6”W, 29-30 Jul 1997, M.H. Sabaj Pérez et al.; SIUC 29510, 11 (25.5-32.3 mm SL), same data as SIUC 29483; SIUC 29880, 3 (27.8-39.0 mm SL), río Nanay at Pampachica, $4.5 \mathrm{~km}$ from Iquitos center ( $269^{\circ}$ bearing), c. $03^{\circ} 45^{\prime} 8.8^{\prime}$ S $73^{\circ} 17^{\prime} 00.1^{\prime \prime} W, 11$ Aug 1997, M.W. Littmann \& R.E. Weitzell; UF 185774, 10 (31.5-39.3 mm SL), same data as SIUC 29483; UF 185775, 6 (38.5-43.5 mm SL, 1 c/s), río Nanay at Santa Clara near Iquitos, 22 Jul 1995, B.M. Burr et al.

\section{Tympanopleura rondoni (A. Miranda Ribeiro, 1914)} Figs. 1f, 2, 6g, 18

Ageneiosus rondoni A. Miranda Ribeiro, 1914: 12-13 [typelocality: Brazil, rio Negro, Manáos (=Manaus); syntypes MNRJ 962, 2]. -Miranda Ribeiro, 1953 [type specimens listed; lectotype designated]; -Miranda Ribeiro, 1962: 4 [catalog of MNRJ material, only 1 specimen cited (MNRJ 962)]. -Gosline, 1945: 25 [citation]. -Fowler, 1951: 453, fig. 480 [partial synonymy; distribution; figure possibly based on T. atronasus]. -Santos, 1954: 123-124, fig. 64 [reference]. -Burgess 1989: 286 [citation]. -Ferraris, 2003: 471 [checklist; as synonym of Ageneiosus brevis after Walsh, 1990; typelocality; lectotype designation by Miranda Ribeiro, 1953]. -Ferraris, 2007: 69 [type checklist; as synonym of $A$. brevis after Walsh, 1990; information duplicated from Ferraris, 2003].

Ageneiosus madeirensis Fisher 1917: 426-427, pl. 42 [typelocality: San Joaquin, Bolivia; comparisons with Ageneiosus ucayalensis and A. valenciennesi]. -Henn, 1928: 74 [holotype listed]. -Gosline, 1945: 24 [citation]. -Fowler, 1951: 452453, fig. 479 [partial synonymy; distribution]. -Lauzanne \& Loubens, 1985: 111 [checklist of species from rio Mamoré].

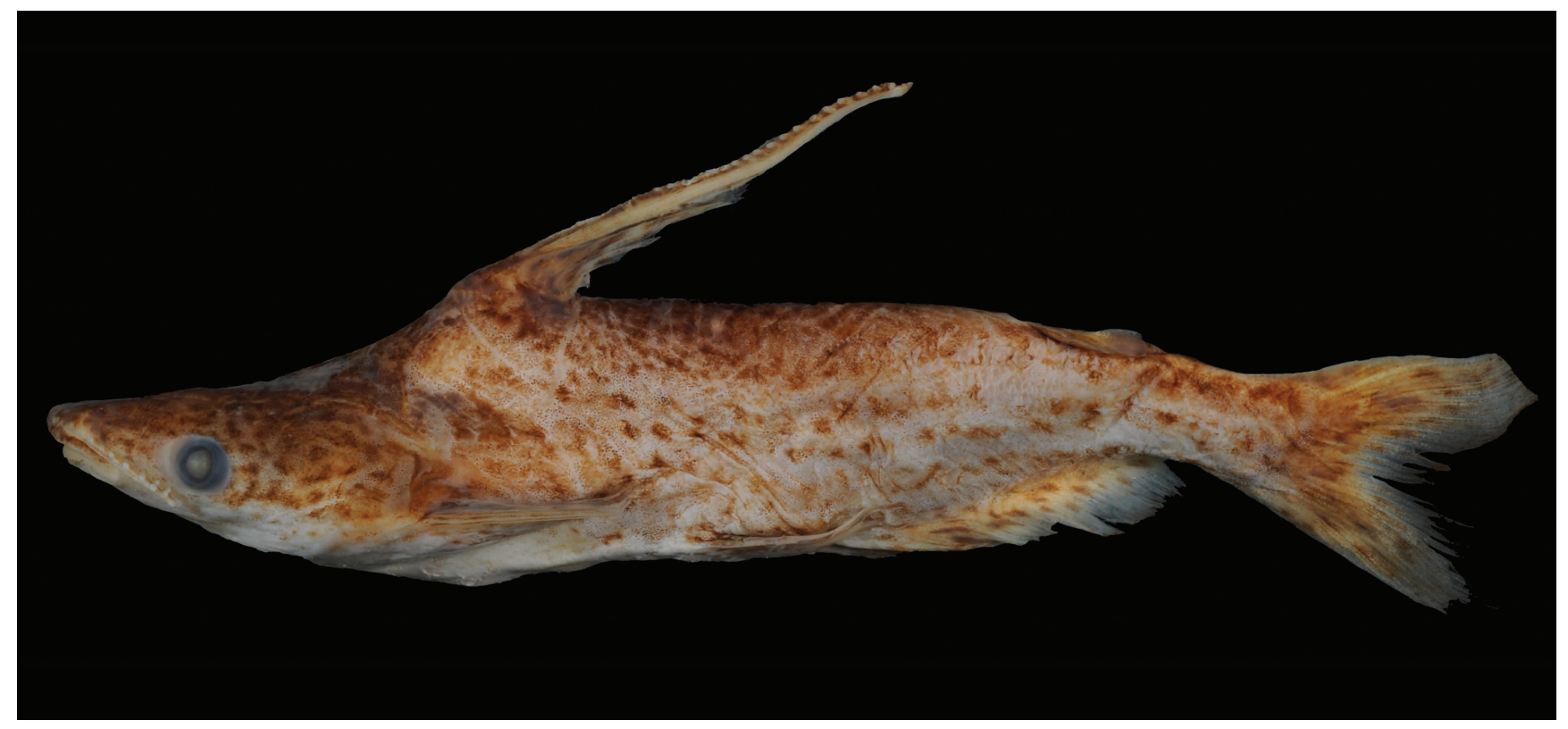

Fig. 18. Tympanopleura rondoni. UF 185776 (124.0 mm SL), nuptial male, río Mamoré, Beni Department, Bolivia. 
-Ibarra \& Stewart, 1987: 6, 86 [type specimens listed]. -Burgess, 1989: 285-286 [citation; illustration after Fisher 1917, erroneously attributed to Eigenmann, 1917]. -Lauzanne et al., 1991: 68 [annotated checklist of species from Bolivian Amazon; Région de Trinidad; Itenez (Guaporé); identification not verified]. -Willink et al., 1999: 104 [in checklist of species from Bolivian Amazon, after Lauzanne et al., 1991]. -Chernoff et al., 2000: 281 [in table of species from Bolivian Amazon, after Lauzanne et al., 1991 and Willink et al., 1999]. -Ten et al., 2001: 103 [checklist; Bolivia, Reserva Inmovilizada Iténez, río San Martin, río Iténez; identification not verified]. -Ferraris, 2003: 471 [checklist; as synonym of $A$. brevis after Walsh, 1990; type-locality; holotype]. -Ferraris, 2007: 69 [type checklist; as synonym of A. brevis after Walsh, 1990; information duplicated from Ferraris, 2003].

Diagnosis. Tympanopleura rondoni has a more robust body shape and reaches a larger maximum size (about 160 $\mathrm{mm} \mathrm{SL}$ ) than congeners (all less than $120 \mathrm{~mm}$ SL in the material examined). In addition, $T$. rondoni has a unique, prominently spotted pigmentation pattern on the head, body, and fins, and an elongated gas bladder with two moderately long, recurved terminal posterior diverticula. Tympanopleura rondoni further differs from T. atronasus in having a greater number of anal-fin rays (28-37, mode 31 vs. 23-30, mode 27), more pectoral-fin rays (10-13 vs. 7-9), more gill rakers on the first arch (24-33 vs. 14-23), fewer preanal vertebrae (14-16, mode 15 vs. 16-19, mode 17), fewer pairs of pleural ribs (4-6 vs. 7-8), greater distance from pectoral- to dorsal-fin origin (19.8-29.0\% SL $v s$. $15.7-20.9 \%$ SL), slightly greater body width at pectoral-fin origin (21.8-29.5\% SL vs. 17.8-22.9\% SL), slightly longer pectoral-fin spine (17.1-21.0\% SL vs. 13.3-19.0\% SL), and a smaller eye diameter (8.4-17.0\% HL vs. 16.0-27.8\% HL). Tympanopleura rondoni differs from $T$. brevis in having more gill rakers (24-33, mode 29-30 vs. 20-24, mode 23), a slightly shorter-pectoral fin spine (17.1-21.0\% SL vs. 19.1$24.4 \% \mathrm{SL}$ ), and a smaller eye (8.4-17.0\% HL vs. $13.8-21.0 \%$ HL); otherwise, these two species are differentiated mainly on the basis of pigmentation pattern and structure of the gas bladder. Tympanopleura rondoni differs from T. cryptica in having a longer anal fin (anal-fin rays 28-37, mode 31 vs. 23-30, mode 29), more pectoral-fin rays (10-13, mode 11 vs. 8-10, mode 9), more gill rakers (24-33, mode 29-30 vs. 21-26, mode 22), greater number of total vertebrae (3842 , mode 40 vs. 38-41, mode 38), pleural rib pairs (4-6, mode 6 vs. 4-5, mode 5), and a smaller eye (8.4-17.0\% HL vs. 16.7-25.6\% HL). Tympanopleura rondoni differs from T. longipinna in having a somewhat shorter anal fin (analfin rays 28-37, mode 31 vs. 32-42, mode 37), more gill rakers (24-33, mode 29-30 vs. 19-25, mode 23), fewer total vertebrae (38-42, mode 40 vs. 40-43, mode 43), pleural rib pairs (4-6, mode $6 v s .4-5$, mode 5), longer predorsal length (35.2-47.4\% SL vs. 29.5-36.1\% SL), shorter distance from pelvic- to adipose-fin origin (24.0-41.5\% SL vs. 37.6-45.1\% $\mathrm{SL}$ ), shorter distance from dorsal- to adipose-fin origin
(38.1-46.8\% SL vs. 46.5-54.0\% SL), and a shorter anal-fin base (23.1-32.5\% SL vs. 33.9-39.9\% SL). Tympanopleura rondoni differs from $T$. piperata in having more pectoralfin rays (10-13, mode 11 vs. 6-10, mode 9), more gill rakers (24-33 vs. 16-23), pleural ribs pairs (4-6, mode 6 vs. 4-5, mode 4), longer prepectoral length (29.2-39.0\% SL vs. $23.6-28.3 \% \mathrm{SL}$ ), greater distance from pectoral- to dorsalfin origin (19.8-29.0\% SL vs. 15.2-20.9\% SL), greater body width at pectoral-fin origin $(21.8-29.5 \%$ SL vs. $16.8-20.0 \%$ SL), shorter anal-fin base (23.1-32.5\% SL vs. 30.9-39.3\% SL), longer head (26.5-39.0\% SL vs. 22.2-27.8\% SL), longer snout (41.7-53.6\% SL vs. 31.4-43.6\% SL), proportionally longer jaws and a wider gape, and a smaller eye (8.4-17.0\% HL vs. 24.3-35.7\% HL).

Description. Morphometric data are provided in Table 13. Tympanopleura rondoni is a medium-sized auchenipterid. Size range 32.8-160.4 mm SL $(n=56)$ for female and nonnuptial male specimens. Size range 90.7-127.8 mm SL $(n=12)$ for pre-nuptial and nuptial males. Head moderately depressed and broad. Dorsal profile from tip of snout to top of supraoccipital nearly straight, ascending and weakly convex posteriorly to dorsal-fin origin. From dorsal-fin insertion to base of upper caudal-fin lobe nearly straight to convex. Ventral contour of head and abdomen straight to weakly convex. Body compressed, widest at pectoralfin origin, 21.8-29.5\% SL, gently tapered posteriorly from pectoral-fin insertion to base of caudal fin. Caudal peduncle moderately deep, 7.1-9.9\% SL.

Head length 26.5-39.0\% SL. Mouth inferior, upper jaw projecting anterior to tip of lower jaw approximately the width of the premaxillary tooth patch. Snout long, 41.7$53.6 \% \mathrm{HL}$, broadly crescentic in dorsal or ventral profile. Premaxillary and dentary tooth bands broad, with 5-7 irregular rows of teeth at midline, tapered to about 3-5 rows posterolaterally; teeth single cusped, moderately long, sharp, recurved. Midline area of dentary near symphsis elevated, teeth projected slightly outward. Eye small, 8.4$17.0 \%$ HL, slightly more visible dorsally than ventrally, covered with thick, opaque epidermis (Fig. 1f). Fontanelle groove long and deep, extending posterior to eyes, bound on either side by high ridges; dorsal surface of frontals, supraoccipital, nuchal shield rugose, ornamented with network of ridges and granulations. Anterior nares lateral to tips of mesethmoid wings, directed anteriorly; posterior nares lateral to frontals, directed upward, with short flap of epidermis surrounding margin. Posterior edge of lower jaw extending posteriorly to or slightly beyond midpoint of eye. Gill membranes broadly fused to isthmus along anterolateral margin of cleithrum. Branchiostegal rays 8-10 (mode 9; $\mathrm{n}=55)$. Total gill rakers on anterolateral margin of first arch 24-33 (mode 29; n=47); epibranchial with 8-10 (mode 9) and ceratobranchial with 16-24 (mode 19) gill rakers. Gill rakers long, those near middle of arch about $4-7 \% \mathrm{HL}$, crenulate on ventromedial margin, gradually reduced in length anteriorly. 
Table 13. Morphometric data for specimens of Tympanopleura rondoni. Synoptic material includes the lectotype and paralectotype of Ageneiosus rondoni (MNRJ 962[2]) and holotype (FMNH 58143) and seven paratypes (FMNH 58144) of A. madeirensis. $\mathrm{SD}=$ standard deviation.

\begin{tabular}{|c|c|c|c|c|c|}
\hline & $\mathrm{N}$ & Range & Mean & $\mathrm{SD}$ & Lectotype MNRJ 962(1) \\
\hline Standard length (SL, mm) & 30 & $37.8-160.4$ & --- & --- & 160.4 \\
\hline \multicolumn{6}{|c|}{ Percent of SL } \\
\hline Preadipose length & 30 & $77.4-83.5$ & 80.4 & 1.6 & 80.2 \\
\hline Preanal length & 30 & $52.4-69.5$ & 64.7 & 4.0 & 64.1 \\
\hline Predorsal length & 30 & $35.2-47.4$ & 39.8 & 2.4 & 37.6 \\
\hline Prepelvic length & 30 & $43.3-56.2$ & 52.1 & 3.1 & 52.6 \\
\hline Prepectoral length & 30 & $29.2-39.0$ & 35.1 & 2.5 & 34.9 \\
\hline Pectoral-fin origin to dorsal-fin origin & 30 & $19.8-29.0$ & 23.9 & 2.1 & 22.3 \\
\hline Pelvic-fin origin to dorsal-fin origin & 30 & $10.3-28.6$ & 24.5 & 3.5 & 25.9 \\
\hline Pelvic-fin origin to adipose-fin origin & 30 & $24.0-41.5$ & 32.8 & 3.2 & 32.3 \\
\hline Dorsal-fin origin to adipose-fin origin & 30 & $38.1-46.8$ & 42.3 & 2.2 & 45.1 \\
\hline Adipose-fin origin to anal-fin insertion & 30 & $9.2-16.7$ & 14.8 & 1.6 & 14.1 \\
\hline Body depth at dorsal-fin origin & 30 & $18.5-24.8$ & 21.9 & 1.6 & 21.2 \\
\hline Caudal peduncle depth & 30 & 7.1-9.9 & 8.8 & 0.7 & 9.3 \\
\hline Caudal peduncle length & 30 & $9.4-12.5$ & 10.9 & 0.9 & 12.5 \\
\hline Body width at pectoral-fin origin & 30 & $21.8-29.5$ & 26.5 & 2.3 & 25.0 \\
\hline Body width at pelvic-fin origin & 30 & $9.4-13.9$ & 11.5 & 1.1 & 11.7 \\
\hline Pectoral spine length & 30 & $17.1-21.0$ & 19.1 & 1.0 & 19.6 \\
\hline Anal-fin base length & 30 & $23.1-32.5$ & 26.0 & 2.4 & 26.1 \\
\hline Head length (HL) & 30 & $26.5-39.0$ & 35.0 & 3.1 & 33.7 \\
\hline \multicolumn{6}{|c|}{ Percent of HL } \\
\hline Head depth at supraoccipital & 30 & $44.9-66.9$ & 53.3 & 5.1 & 50.2 \\
\hline Head width at postorbitals & 30 & $55.7-80.3$ & 68.7 & 4.9 & 76.9 \\
\hline Dorsal interopercular width & 30 & $42.9-54.3$ & 46.8 & 2.9 & 47.6 \\
\hline Anterior internarial distance & 30 & $31.0-36.9$ & 33.9 & 1.7 & 35.2 \\
\hline Preisthmus length & 30 & $61.0-78.0$ & 68.3 & 4.1 & 72.2 \\
\hline Snout length & 30 & $41.7-53.6$ & 47.8 & 3.3 & 53.0 \\
\hline Gape width & 30 & $51.0-65.6$ & 58.0 & 3.4 & 65.6 \\
\hline Upper jaw length & 30 & $32.6-45.5$ & 37.2 & 2.9 & 42.2 \\
\hline Lower jaw length & 30 & $29.2-40.7$ & 33.3 & 2.7 & 36.1 \\
\hline Eye diameter & 30 & $8.4-17.0$ & 12.8 & 1.8 & 12.2 \\
\hline
\end{tabular}

Maxillary barbel of females and non-nuptial males small, ossified at base, filiform, concealed in premaxillary groove, 9.6-26.8\% HL (mean=16.2 $\pm 4.1 \mathrm{SD} ; \mathrm{n}=25$ ); groove extending obliquely to midpoint between corner of mouth and front of eye. Maxillary barbel of prenuptial and nuptial males ossified most or all of length, thickened, elongated, $30.1-38.6 \%$ HL (mean=34.0 $2.3 \mathrm{SD} ; \mathrm{n}=12$ ). Barbel of prenuptial males smooth, with a fleshy tip, covered with thin epidermis, and lacking hooks altogether or with few (about 6-8) small, blunt, incipient hooks beginning development on anterodorsal surface. Maxillary barbel of nuptial male with 10-17 ( $\mathrm{n}=3$, including left and right in one specimen) sharply pointed, recurved hooks, modally 9 on anterodorsal margin, 4-10 on ventromedial margin; entire barbel with thick epidermal sheath covering all but tips of hooks.
Dorsal fin rays II,6, consisting of a small spinelet, elongated spine, and branched rays; first ray longest, subsequent rays progressively shorter. Dorsal-fin origin about equal with or slightly posterior to vertical passing through pectoral-fin insertion. Dorsal-fin spine relatively long and stout in females and non-nuptial males, length 17.2-25.0\% SL (mean=19.8 $\pm 2.2 \mathrm{SD} ; \mathrm{n}=17$ ). Anterior margin of spine variable, from nearly smooth to strongly crenulated proximally; spine most rugose in larger individuals. Posterior margin of spine in all but nuptial males with 1538 relatively short, conical, retrorse serrae. Dorsal spine of nuptial male robust, greatly elongated, sinusoidal, anterior margin convex over basal half, inflected posteriorly near midpoint, convex again distally, tip slightly curved laterally; length of spine in pre-nuptial and nuptial males $25.5-40.9 \%$ 
SL (mean=30.6 $\pm 4.3 \mathrm{SD} ; \mathrm{n}=10$ ). Prominent antrorse serrae on anterior margin of spine in pre-nuptial and nuptial males; serrae shorter and relatively blunt proximally early in development of armature, becoming long, thin, recurved, and alternating laterally over distal half, embedded in thick sheath of epidermis. Lateral margins of spine with pronounced longitudinal ridges and deep furrows, obliquely distributed along length of spine, heavily pigmented. Posterior margin of spine in fully nuptial males smooth. Adipose fin relatively large, entire base well anterior to vertical through anal-fin insertion, posterior margin free.

Anal fin relatively short, base $23.1-32.5 \%$ SL, with 28 37 rays (mode $31 ; n=63$ ); distal margin rounded. Anal-fin pterygiophores 27-36 (mode 29; $n=45$ ). First 5-6 anal-fin rays of pre-nuptial and nuptial males thickened, elongated, unbranched, coalesced to form intromittent organ.

Pectoral-fin spine robust, relatively long, $17.1-21.0 \%$ $\mathrm{SL}$, short of or just reaching to pelvic-fin origin. Anterior margin of spine weakly crenulated proximally. Dorsal and ventral surfaces of spine with prominent, irregular longitudinal ridges and furrows. Posterior margin of spine with single series of short, conical, retrorse serrae, counted on one or both sides, ranging from 12-29 (mode 20-22; mean $=19.0 \pm 4.9 \mathrm{SD} ; \mathrm{n}=25)$. Pectoral fin with $10-13$ branched rays (mode $11 ; \mathrm{n}=59$ ); anterior rays longest, distal margin of fin straight to very slightly falcate. Postcleithral process moderately well developed, robust, conical, occasionally absent.

Pelvic-fin origin anterior to vertical through tip of longest adpressed dorsal-fin ray; margin of fin straight to slightly convex. Pelvic fin rays i,6; first branched ray longest, subsequent rays progressively shorter.

Caudal fin forked, lobes equal, with $8+9$ principal rays, 16-26 (mode $23 ; \mathrm{n}=27)$ upper and 15-18 (mode 17; $\mathrm{n}=27$ ) lower procurrent rays.

Preanal vertebrae $14-16($ mode $15 ; n=46)$. Total vertebrae 38-42 (mode 40; $n=46$ ). Pairs of pleural ribs 4-6 (mode 6; $\mathrm{n}=39)$.

Gas bladder of adult large, unencapsulated, elongated antero-posteriorly in comparison to congeners, moderately turgid, smooth-walled on external surfaces, with two moderately elongated fleshy terminal diverticula, close at their bases and typically recurved anteriorly in body cavity (Fig. 6g).

Color in alcohol. Background color tan, dusky yellow, or whitish purple, obscured in many specimens by dark pigmentation over most of dorsum. Distinctive pigmentation pattern consisting of dark brown to black irregular spots (usually 1-2 $\mathrm{mm}$ in diameter) over most of body, usually heavily concentrated on head and upper half of body. Spots consisting of coalesced melanophores and often obscured on head and dorsum by additional dense speckles of pigmentation. Spots on body sometimes forming irregular rows along midline of back, sides above the lateral line, and a lower row extending posteriorly from above the pectoral- fin base. Skin lateral to gas bladder darkly pigmented. Venter generally lightly pigmented with specks sometimes near tip of chin and extending along lateral branchiostegal membranes and near pectoral fin. Top of head with dense background of brown or black pigmentation overlain with spots. Leading edge of dorsal-fin spine brown to black; rays of dorsal fin with pigmentation at base and near tips, most heavily concentrated on anterior rays. Adipose fin with uniformly distributed melanophores, more evident near base. Caudal peduncle and base of caudal-fin rays darkly pigmented with a few specks scattered along rays and interradial membranes, sometimes with additional concentrations of pigment at tips of rays. Anal fin with dark margin and some specks scattered along base. Pectoral and pelvic fins pigmented on dorsal surface, most heavily along base, over first few anterior-most rays, and along ray tips forming a distinctive black or brown marginal edge.

Distribution. Tympanopleura rondoni is broadly distributed in the central Amazon River basin, including the rio Madeira in Brazil, and the río Mamoré and río Guaporé in Bolivia (Fig. 19).

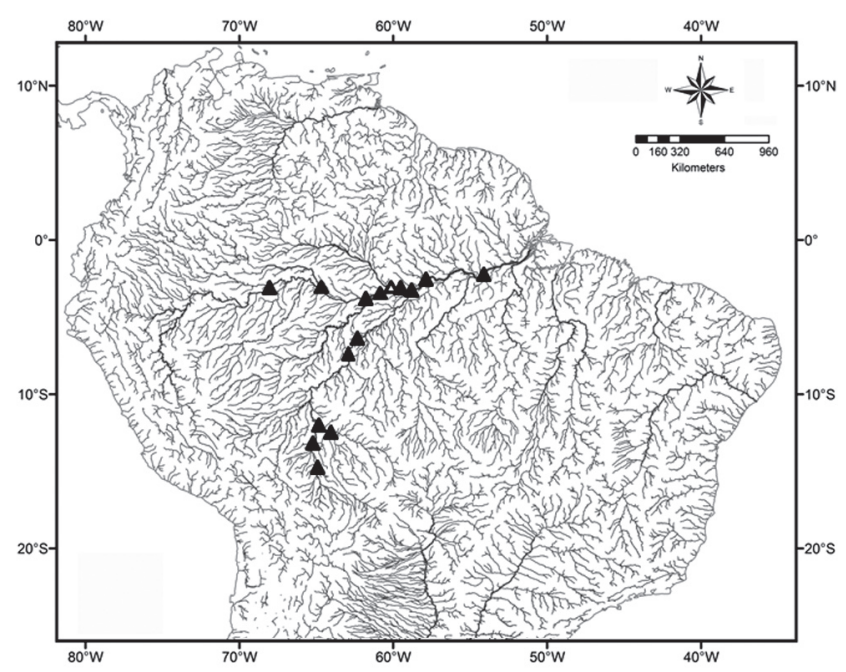

Fig. 19. Distribution of Tympanopleura rondoni based on material examined. Open triangle indicates type-locality.

Remarks. Miranda Ribeiro (1953) cited two cotypes and designated "Lectótipo-A," presumably to fix the name by designating as a lectotype the larger of the two specimens in the type series. However, in a subsequent type catalog, Miranda Ribeiro (1962) referred to only one specimen, listed under MNRJ 962. The specific epithet is a patronym named in honor of Cândido Mariano da Silva Rondon (18651958), famous Brazilian Army Marshal ("Marechal"), pioneering telegraph engineer, patriot, zealous explorer, and protector of indigenous tribes.

Material examined. Lectotype. MNRJ 962A, 1 (160.4 mm SL, presumed female). Type-locality: Brazil, rio Negro, Manáos (=Manaus), 1908, Miranda Ribeiro. Paralectotype. MNRJ 
962, 1 (134.4 mm SL, presumed female). Same collection data as lectotype. Other types. 15 specimens (32.8-108.3 mm SL). FMNH 58143, 1 (102.4 mm SL, male), holotype of Ageneiosus madeirensis, Bolivia, río Mamoré, San Joaquin, 6 Sep 1909, J.D. Haseman. FMNH 58144, 14 (32.8-108.3 mm SL, 1 c/s, paratypes of $A$. madeirensis), same collection data as holotype.

Non-type material. 102 specimens (40.0-165.4 mm SL). Bolivia. Beni: MZUSP 27805, 3 (79.5-110.8 mm SL), Laguna San José, Trinidad, Sep 1983, Conv. Pisc. ORSTOM-UTB; MZUSP 114008 (ex MZUSP 27818), 2 (51.2-55.7 mm SL), Trinidad, canal San Gregorio, Sep 1983, Conv. Pisc. ORSTOM-UTB; MZUSP 37880 , 1 (124.4 mm SL), Igarape Beem, Humaitá, Jul 1975, U. Caramaschi et al.; UF 185776, 2 (119.6-124.0 mm SL), same data as MZUSP 27805; UF 185777, 1 (69.0 mm SL), same data as MZUSP 114008. Locality unknown: INPA 652, 2 (106.8-117.6 mm SL), Sep 1983, G. Loubens \& L. Lauzanne. Brazil. Amazonas: ANSP 193989, 2 (63.3-77.0 mm SL), rio Purus, c. 0358'47.2”S 61²9'06.2”W, 27 Jul 1996, M. Toledo-Piza et al.; ANSP 194014, 5 (52.7-145.7 mm SL), rio Purus, c. 0359'06.5”S 61²9'20.7’W, 27 Jul 1996, M. Toledo-Piza et al.; ANSP 194015, 9 (40.0-75.3 mm SL), rio Purus along Ilha Tatu, c. 0359'26.9”'S 61²9'37.7'W, 27 Jul 1996, M. Toledo-Piza et al.; ANSP 194016, 5 (99.3-124.7 mm SL), rio Solimões $35.5 \mathrm{~km}$ downriver of Santa Maria, $20.6 \mathrm{~km}$ upriver of Itacoatiara, c. 03¹5'45.2”S 58³6'01.4”W, 20 Oct 1994, F.G. Langeani et al.; CAL unk., 1 (84.6 mm SL), rio Solimões $67.0 \mathrm{~km}$ downriver of Bela Vista, $26.0 \mathrm{~km}$ upriver of Manaus, c. 03¹1'28.2'S 5953'45.9'W, 23 Oct 1993, S.L. Jewett et al. (SLJ-93-005); CAL unk., 2 (71.5-83.7 mm SL), rio Solimões 23.5 $\mathrm{km}$ downriver of Santa Maria, $21.1 \mathrm{~km}$ upriver of Itacoatiara, $c$. 03¹7'16.0”S 58³5'23.1”W, 20 Oct 1994, J.G. Lundberg et al. (JGL-94-067); INPA 11758, 1 (160.9 mm SL), rio Solimões, Ilha do Careiro, Paraná do Rei, 27 Feb 1986, B. Merona; INPA 11759, 5 (117.2-165.4 mm SL), rio Solimões, Ilha do Caraeiro, Jul/Oct 1986, INPA ichthyology team; INPA 13393, 1 (111.1 mm SL), rio Solimões, Ilha da Marchantaria, 4 Feb 1993, P. Petry \& R. Sotero; INPA 18960, 2 (91.7-92.4 mm SL), rio Solimões, Paraná Maiana, Mamirauá Reserve, 9 Sep 1999, W.G.R. Crampton; INPA 18961, 1 (115.7 mm SL), rio Japurá, margin of Mamirauá Reserve, 2 Feb 2000, W.G.R. Crampton; INPA 22139, 7 (113.8-156.0 mm SL), rio Solimões, Lago do Rei, 31 Jan 2001, L.H. Rapp Py-Daniel et al.; INPA 22802, 5 (139.9-158.2 mm SL), rio Solimões, Lago do Rei, Lago Mingau, 24 Feb 1986, B. Merona et al.; INPA 25757, 1 (156.3 mm SL), rio Solimões, Lago Muratu, approximately $60 \mathrm{~km}$ from confluence with rio Negro, c. 03²0'51'S 60¹2’34”W, Apr 2003, M. Vega; INPA 25819, 1 (140.3 mm SL), rio Solimões, Lago Muratu, approximately $60 \mathrm{~km}$ from confluence with rio Negro, c. $03^{\circ} 20^{\prime} 51^{\prime \prime S} 60^{\circ} 12^{\prime} 34^{\prime \prime} W$, Jul 2003, M. Vega; INPA 26537, 1 (115.6 mm SL), rio Negro, Manaus, near confluence with the rio Solimões, 18 Jun 2006, J. Zuanon \& A. Akama; INPA 34087, 2 (110.9-129.0 mm SL), rio Negro, Manaus, Lago Catalão, 8 Aug 2008, F.R.V. Ribeiro; MCP 29875, 2 (103.9-139.5 mm SL), rio Solimões, Alvarães, Caborini beach, near confluence with rio Solimões and rio Japurá, c. 0309'34”S 6446’35”W, 7 Feb 2001, W.G.R. Crampton; MCP 29876, 2 (97.7-109.1 mm SL), same location as MCP 29875, 12 Feb 2001, W.G.R. Crampton; MCP
29877, 1 (88.0 mm SL), rio Solimões, Alvarães, Ilha de Içé, c. 0316’36”S 6441'01"W, Jan 2001, W.G.R. Crampton; MPEG 10048, 1 (unmeasured), Manacapuru, Lago Piranha floodplain, 11 Mar 2006, L. Montag \& A. Hercos; MZUSP 114007, 4 (103.8$116.6 \mathrm{~mm}$ SL), rio Solimões, Lago Janauaca and surroundings, Nov 1976-Jan 1977, Alpha Helix expedition; MZUSP 27616, 1 (127.8 mm SL), rio Solimões, mouth of rio Iça, Santo Antônio do Iça, 13 Oct 1982, L.P.S. Portugal; MZUSP 56649, 1 (73.1 mm SL), rio Purus, Berurí, 27 Jul 1996, M.T. Piza et al.; MZUSP 56656, 1 (75.6 mm SL), rio Amazonas, c. 03¹9'32”S 5851'54”W, 5 Aug 1996, M.T. Piza et al.; MZUSP 56660, 1 (94.4 mm SL), rio Purus, c. 0403'48”'S 61³3'49'W, 27 Jul 1996, M.T. Piza et al.; MZUSP 57697, 1 (63.7 mm SL), rio Purus, $15 \mathrm{~km}$ below Lago do Estopa, 27 Jul 1996, F.G. Langeani et al.; MZUSP 75400, $1(116.5 \mathrm{~mm}$ $\mathrm{SL}$ ), rio Solimões, stream on the right bank of the Lago Janauacá channel, c. $3^{\circ} 22^{\prime}$ S $60^{\circ} 11^{\prime} \mathrm{W}, 11$ Jan 1977, Alpha Helix expedition. Pará: INPA 22722, 2 (115.0-116.0 mm SL), rio Amazonas, Monte Alegre, Lago Grande de Monte Alegre, 12 Aug 1992, G. Santos \& J. Zuanon; MZUSP 7862, 7867-7874, 9 (86.2-117.6 mm SL), Parana Jacari, municipality of Faro, 13 Dec 1967, Expedição Permanente da Amazônia (EPA); UF 185778 (ex MZUSP 7863-7866, 4 (98.9$112.4 \mathrm{~mm}$ SL), same data as MZUSP 7862, 7867-7874. Rondônia: INPA 21720, 1 (117.7 mm SL), rio Madeira, rio Cautário, Vale do Guaporé, 14 Jul 2003, G. Torrente-Vilara; UFRO-I 682, 2 (53.3$95.6 \mathrm{~mm} \mathrm{SL}$ ), rio Madeira, date \& collectors unknown; UNIR 669, 8 (68.9-100.1 mm SL), rio Madeira, date \& collectors unknown.

\section{Key to the species of Tympanopleura}

1. Body typically with prominent, irregular spots scattered over top of head, dorsum, sides, and fins, or with a large dark blotch of melanophores on flanks above anal-fin base, streaks in each caudal-fin lobe, and dark pigment on chin (pigmentation occasionally light or faded in preserved specimens)

1'. Body with relatively uniform pigmentation, consisting of light to moderate stippling, darkest on top of head, dorsum, and sides, lacking well-defined spots or large blotches.

\section{3}

2. Pectoral-fin rays 7-9; anal-fin rays $23-30$, usually 25 29; total gill rakers on anterolateral margin of first arch usually 14-18, rarely greater (to 23); pigmentation variable, but usually consisting of: broad, dark, crescent shaped patch on chin (Fig. 1a); black upper lip; large blotch formed from diffuse melanophores on sides above anal fin; dark basal patch or longitudinal stripe in each caudal-fin lobe; pectoral, pelvic, and caudal fins often with dark marginal band.

Tympanopleura atronasus (Fig. 9).

2'. Pectoral-fin rays 10-13; anal-fin rays 28-37; total gill rakers on anterolateral margin of first arch 24-33; pigmentation usually consisting of large irregular spots extensively distributed on head, dorsum, sides of body, and fins .....................Tympanopleura rondoni (Fig. 18).

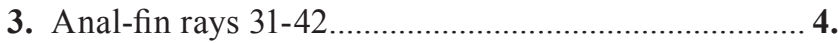
3'. Anal-fin rays 23-30...Tympanopleura cryptica (Fig. 13). 
4. Maximum body size $<50 \mathrm{~mm}$ SL; mouth weakly inferior; pseudotympanum typically ovoid, often bulging slightly outward and semi-translucent; gas bladder without posterior terminal diverticula; usually with prominent transverse bar of dark melanophores at base of caudal fin (pigmentation occasionally light or faded in preserved specimens).................Tympanopleura piperata (Fig. 16).

4'. Maximum body size $>50 \mathrm{~mm}$ SL; mouth distinctly inferior; pseudotympanum typically triangular, opaque; gas bladder with pair of posterior terminal diverticula; occasional scattered pigmentation at base of caudal fin, but not forming distinctive hourglass-shaped transverse bar.

5.

5. Pectoral-fin spine long, robust, about $19-24 \%$ SL, often reaching to or past pelvic-fin origin; anal-fin base short, about $26-34 \%$ SL; anal-fin rays $31-36$, usually 35 or fewer; postcleithral process typically well developed, short, rigid, triangular or lanceolate in shape; maximum body size $>80 \mathrm{~mm} \mathrm{SL}$

Tympanopleura brevis (Fig. 11).

5'. Pectoral-fin spine shorter, about 16-18\% SL, not reaching past pelvic-fin origin; anal-fin base longer, about $34-40 \%$ SL; anal-fin rays $32-42$, usually 35 or more; postcleithral process absent, or, if present, minute and feebly developed; maximum body size $<80$ mm SL ................Tympanopleura longipinna (Fig. 14).

\section{Acknowledgments}

We thank the following individuals for providing loans and exchange of specimens, hospitality during visits to their respective institutions, and other forms of assistance: Scott A. Schaefer, Melanie L.J. Stiassny, M. Norma Feinberg, and Barbara Brown (AMNH); John G. Lundberg, Mark H. Sabaj Pérez, William G. Saul, and Kyle R. Luckenbill (ANSP); James Maclaine and Patrick Campbell (BMNH); William N. Eschmeyer, Tomio Iwamoto, and David Catania (CAS); Mary Anne Rogers, Kevin Swagel, and Susan Mochel (FMNH); Christopher A. Taylor, Daniel B. Wylie, and Michael E. Retzer (INHS); Karsten E. Hartel (MCZ); Volker Mahnert, Claude Weber, and Sonia Fisch-Muller (MHNG); Romain Causse, Claude Ferrara, Zora Gabsi, and Jean-Claude Hureau (MNHN); Paulo A. Buckup (MNRJ); Horácio Higuchi and Wolmar Wosiacki (MPEG); Max Hidalgo and Silvia S. Valenzuela Reyna (MUSM); Heraldo A. Britski, Naercio Menezes, José L. Figueiredo, and Osvaldo T. Oyakawa (MZUSP); Barbara Herzig and Helmut Wellendorf (NMW); Carlos Lucena and Margarete Lucena (MCP); Brooks M. Burr (SIUC); Larry M. Page, Robert H. Robins, and George H. Burgess (UF); Douglas W. Nelson and William L. Fink (UMMZ); Richard P. Vari, Susan L. Jewett, Jeffrey T. Williams, and Sandra J. Raredon (USNM). For engaging discussions and sharing informative ideas about systematics and biology of neotropical fishes, we are indebted to James S. Albert, Jonathan W. Armbruster, José L.O. Birindelli, Heraldo A. Britski, Brooks M. Burr, Will
G.R. Crampton, Carl J. Ferraris, John P. Friel, Carter R. Gilbert, Michael Goulding, Flávio C.T. Lima, Leo G. Nico, Mário C.C. de Pinna, Ramiro Royero, Larry M. Page, Mark H. Sabaj Pérez, Michael E. Retzer, Luisa M. SarmentoSoares, Scott A. Schaefer, Horst O. Schwassmann, William F. Smith-Vaniz, Donald J. Stewart, Richard P. Vari, and João Paulo Viana. We especially thank John G. Lundberg for his generous assistance in providing specimens and data collected in association with the "Calhamazon" project, his hospitality during studies conducted at the University of Arizona, and his valued insights about catfish morphology and relationships. We also thank Francisco Langeani for taking counts and measurements of selected specimens collected during the "Calhamazon" expeditions. Selected photographs were provided by Howard L. Jelks. Zachary P. Martin aided with preparation of maps. The authors are grateful to two anonymous reviewers who provided constructive improvements to earlier drafts of the manuscript. Any use of trade, product, or firm names is for descriptive purposes and does not imply endorsement by the U.S. Government.

\section{References}

Akama, A. 2004. Revisão sistemática dos gêneros Parauchenipterus Bleeker, 1862 e Trachelyopterus Valenciennes, 1840 (Siluriformes, Auchenipteridae). Unpublished Ph.D. Dissertation, Universidade de São Paulo, São Paulo, 375p.

Akama, A. \& L. M. Sarmento-Soares. 2007. Familia Auchenipteridae. Pp. 116-120. In: Buckup, P.A., N.A. Menezes \& M.S. Ghazzi (Eds.). Catálogo das espécies de peixes de água doce do Brasil. Rio de Janeiro, Museu Nacional, Universidade Federal do Rio de Janeiro. Série Livros, 23.

Anjos, H. D. B., J. Zuanon, T. M. P. Braga \& K. N. S. Sousa. 2008. Fish, upper Purus River, state of Acre, Brazil. Check List: Journal of Species Lists and Distribution, 4: 198-213.

Arce, H. M., R. E. Reis, A. J. Geneva \& M. H. Sabaj Pérez. 2013. Molecular phylogeny of thorny catfishes (Siluriformes: Doradidae). Molecular Phylogenetics and Evolution, 67: 560577.

Arratia, G. 2003a. Catfish head skeleton - an overview. Pp. 3-46. In: Arratia, G., B. G. Kapoor, M. Chardon \& R. Diogo (Eds.). Catfishes, Enfield, New Hampshire, Science Publishers. v. 1.

Arratia, G. 2003b. The siluriform postcranial skeleton-an overview. Pp. 121-157. In: Arratia, G., B. G. Kapoor, M. Chardon \& R. Diogo (Eds.). Catfishes, Enfield, New Hampshire, Science Publishers. v. 1.

Barriga-Salazar, R. 2012. Lista de peces de agua dulce e intermareales del Ecuador. Revista Politécnica, 30: 83-119.

Birindelli, J. L. O. 2010. Relações filogenéticas da superfamília Doradoidea (Ostariophysi, Siluriformes). Unpublished Ph.D. Dissertation, Universidade de São Paulo, São Paulo, 376p.

Birindelli, J. L. O. 2014. Phylogenetic relationships of the South American Doradoidea (Ostariophysi: Siluriformes). Neotropical Ichthyology, 12: 451-564.

Birindelli, J. L. O., A. Akama \& H. A. Britski. 2012. Comparative morphology of the gas bladder in driftwood catfishes (Siluriformes: Auchenipteridae). Journal of Morphology, 273: 651-660. 
Birindelli, J. L. O., L. M. Sousa \& M. H. Sabaj Pérez. 2009. Morphology of the gas bladder in thorny catfishes (Siluriformes: Doradidae). Proceedings of the Academy of Natural Sciences of Philadelphia, 158: 261-296.

Bogotá-Gregory, J. D. \& J. A. Maldonado-Ocampo. 2006. Peces de la zona hidrogeográfica de la Amazonia, Colombia. Biota Colombiana, 7: 55-94.

Bookstein, F. L., B. Chernoff, R. L. Elder, J. M. Humphries, Jr., G. R. Smith \& R. E. Strauss. 1985. Morphometrics in evolutionary biology: the geometry of size and shape change with examples from fishes. Philadelphia, Academy of Natural Sciences of Philadelphia. 277p. Special publication, 15.

Bridge, T. W. \& A. C. Haddon. 1889. Contributions to the anatomy of fishes. I. The air-bladder and Weberian ossicles in the Siluridae. Proceedings of the Royal Society, London, 46: 309-328.

Bridge, T. W. \& A. C. Haddon. 1892. Contributions to the anatomy of fishes. II. The air-bladder and Weberian ossicles in the siluroid fishes. Proceedings of the Royal Society, London, 52: 139-157.

Bridge, T. W. \& A. C. Haddon. 1893. Contributions to the anatomy of fishes. II. The air-bladder and Weberian ossicles in the siluroid fishes. Philosophical Transactions of the Royal Society of London, Series B, 184: 65-333.

Britski, H. A. 1972. Sistematica e evolução dos Auchenipteridae e Ageneiosidae (Teleostei, Siluriformes). Unpublished Ph.D. Dissertation, Universidade de São Paulo, São Paulo, 171p.

Burgess, W. E. 1989. An atlas of freshwater and marine catfishes: a preliminary survey of the Siluriformes. Neptune City, New Jersey, T.F.H. Publications. 784p.

Cailliet, G. M., M. S. Love \& A. W. Ebeling. 1986. Fishes: a field and laboratory manual on their structure, identification, and natural history. Reissued (1996) by Waveland Press, Illinois. Belmont, California, Wadsworth. 194p.

Chardon, M. 1968. Anatomie comparee de l'appareil de weber et des structures connexes chez les Siluriformes. Annales de Musee Royal de l'Afrique Centrale, 169: 1-277.

Chardon, M., E. Parmentier \& P. Vandewalle. 2003. Morphology, development and evolution of the Weberian apparatus in catfish. Pp. 71-120. In: Arratia, G., B. G. Kapoor, M. Chardon \& R. Diogo (Eds.). Catfishes. Enfield, New Hampshire, Science Publishers. v. 1.

Chernoff, B., A. Machado-Allison, P. Willink, J. Sarmiento, S. Barrera, N. Menezes \& H. Ortega. 2000. Fishes of three Bolivian rivers: diversity, distribution and conservation. Interciencia, 25: 273-283.

Curran, D. J. 1989. Phylogenetic relationships among the catfish genera of the family Auchenipteridae (Teleostei: Siluroidea). Copeia, 1989: 408-419.

Diogo, R. \& M. Chardon. 2000. The structures associated with catfish (Teleostei: Siluriformes) mandibular barbels: origin, anatomy, function, taxonomic distribution, nomenclature and synonymy. Netherlands Journal of Zoology, 50: 455-478.

Duque, S. R. \& A. Patiño. 2000. Caracterización de la laguna La Paya (PNN La Paya), Amazonia colombiana. Bogotá, Universidad Nacional de Colombia-Sede Leticia/Parque Nacional Natural La Paya. Fundación Natura, 22p.

Eigenmann, C. H. 1910. Catalogue of the fresh-water fishes of tropical and south temperate America. Reports of the Princeton University Expeditions to Patagonia 1896-1899. Princeton, Princeton University. v. 3: Zoology, pt. 2, p. 375-511.

Eigenmann, C. H. 1912. The freshwater fishes of British Guiana, including a study of the ecological grouping of species, and the relation of the fauna of the plateau to that of the lowlands. Memoirs of the Carnegie Museum, 5: 1-578, 103 pls.
Eigenmann, C. H. 1917. New and rare species of South American Siluridaee in the Carnegie Museum. Annals of the Carnegie Museum, 11: 398-404.

Eigenmann, C. H. 1925. A review of the Doradidae, a family of South American nematognathi or catfishes. Transactions of the American Philosophical Society, 22: 280-365.

Eigenmann, C. H. \& W. R. Allen. 1942. Fishes of western South America. University of Kentucky, Lexington, Ky. 494p.

Eigenmann, C. H. \& R. S. Eigenmann. 1888. Preliminary notes on South American Nematognathi. I. Proceedings of the California Academy of Sciences, (Series 2), 1, pt. 2: 119-172.

Eigenmann, C. H. \& R. S. Eigenmann. 1890. A revision of the South American Nematognathi or cat-fishes. Occasional Papers of the California Academy of Sciences, 1: 1-508.

Eigenmann, C. H. \& R. S. Eigenmann. 1891. A catalogue of the fresh-water fishes of South America. Proceedings of the U.S. National Museum, 14: 1-81.

Eschmeyer, W. N. 2015. Catalog of fishes: genera, species, references. California, California Academy of Sciences. Online version. Available from: http://researcharchive. calacademy.org/research/ichthyology/catalog/fishcatmain.asp (accessed March 2015).

Eschmeyer, W. N. \& J. D. Fong. 2015. Species by family/subfamily. In: Eschmeyer, W. N. (Ed.). Catalog of fishes. California, California Academy of Sciences. Online version. Available from:http://researcharchive.calacademy.org/research/ ichthyology/catalog/fishcatmain.asp (accessed March 2015).

Ferraris, C. J., Jr. 1988. The Auchenipteridae: putative monophyly and systematics, with a classification of the Neotropical doradoid catfishes (Ostariophysi: Siluriformes). Unpublished Ph.D. Dissertation, City University of New York, New York, $229 \mathrm{p}$.

Ferraris, C. J., Jr. 2003. Family Auchenipteridae (driftwood catfishes). Pp. 470-482. In: Reis, R. E., S. O. Kullander \& C. J. Ferraris, Jr. (Eds.). Checklist of the freshwater fishes of South and Central America (CLOFFSCA). Porto Alegre, Edipucrs.

Ferraris, C. J., Jr. 2007. Checklist of catfishes, recent and fossil (Osteicththyes: Siluriformes), and catalogue of siluriform primary types. Zootaxa, 1418: 1-628.

Ferraris, C. J., Jr. \& R. P. Vari. 1999. The South American catfish genus Auchenipterus Valenciennes, 1840 (Ostariophysi: Siluriformes: Auchenipteridae): monophyly and relationships, with a revisionary study. Zoological Journal of the Linnean Society, 126: 387-450.

Ferraris, C. J., Jr., R. P. Vari \& S. J. Raredon. 2005. Catfishes of the genus Auchenipterichthys (Osteichthyes: Siluriformes: Auchenipteridae); a revisionary study. Neotropical Ichthyology, 3: 89-106.

Fine, M. L. \& F. Ladich. 2003. Sound production, spine locking, and related adaptations. Pp. 249-290. In: Arratia, G., B. G. Kapoor, M. Chardon \& R. Diogo (Eds.). Catfishes. Enfield, New Hampshire, Science Publishers. v. 1.

Fisher, H. G. 1917. A list of the Hypophthalmidae, the Diplomystidae and of some unrecorded species of Siluridae in the collections of the Carnegie Museum. Annals of the Carnegie Museum, 11: 405-427, pl. 42.

Fowler, H. W. 1941. Los peces del Peru. (Continuación). Boletín del Museo de Historia Natural "Javier Prado", 5: 466-487.

Fowler, H. W. 1945. Los peces del Peru. Catálogo sistemático de los peces que habitan en aquas peruanas. Reprinted from Boletín del Museo de Historia Natural "Javier Prado" (1941-1944). Lima, Universidad Nacional Mayor de San Marcos. 298p. 
Fowler, H. W. 1951. Os peixes de água doce do Brasil. Arquivos de Zoologia do Estado de São Paulo, 6: 405-628.

Fox, H. 1999. Barbels and barbel-like tentacular structures in submammalian vertebrates: a review. Hydrobiologia, 403: 153193.

Fumihito, A. 1989. Morphological comparison of the Mekong giant catfish, Pangasianodon gigas, with other pangasiid species. Japanese Journal of Ichthyology, 36: 113-119.

Gosline, W. A. 1945. Catálogo dos nematognatos de água-doce da América do Sul e Central. Boletim do Museu Nacional do Rio de Janeiro. Nova série. Zoologia, 33: 1-138.

Granado-Lorencio, C., C. R. M. Araujo Lima \& J. Lobón-Cerviá. 2005. Abundance - distribution relationships in fish assembly of the Amazonas floodplain lakes. Ecography, 28: 515-520.

Granado-Lorencio, C., J. Lobón-Cerviá \& C. R. M. Araujo Lima. 2007. Floodplain lake fish assemblages in the Amazon River: directions in conservation biology. Biodiversity and Conservation, 16: 679-692.

Hardman, M. 2005. The phylogenetic relationships among non-diplomystid catfishes as inferred from mitochondrial cytochrome $b$ sequences; the search for the ictalurid sister taxon (Otophysi: Siluriformes). Molecular Phylogenetics and Evolution, 37: 700-720.

Hardman, M., L. M. Page, M. H. Sabaj, J. W. Armbruster \& J. H. Knouft. 2002. A comparison of fish surveys made in 1908 and 1998 of the Potaro, Essequibo, Demerara, and coastal river drainages of Guyana. Ichthyological Exploration of Freshwaters, 13: 225-238.

Henn, A. W. 1928. List of types of fishes in the collection of the Carnegie Museum on September 1, 1928. Annals of the Carnegie Museum, 19: 51-99.

Hercos, A. P., C. Arantes \& M. X. Amaral. 2007. Lista dos peixes do acervo do Instituto de Desenvolvimento Sustentável Mamirauá. UAKARI, 3: 37-48.

Higuchi, H. 1992. A phylogeny of the South American thorny catfishes (Osteichthyes: Siluriformes, Doradidae). Unpublished Ph.D. Dissertation, Harvard University, Cambridge, Massachusetts, 372p.

Ibarra, M. \& D. J. Stewart. 1987. Catalogue of type specimens of recent fishes in Field Museum of Natural History. Fieldiana, Zoology, New Series, 35: 1-112.

IBM SPSS. 2009. PASW Statistics Version 17.0. SPSS, Illinois. Available from: http://www.spss.com.

ICZN (International Commission on Zoological Nomenclature). 1999. International code of zoological nomenclature. 4th ed. London, The International Trust for Zoological Nomenclature. 306p.

Kaatz, I. M. \& D. J. Stewart. 2012. Bioacoustic variation of swimbladder disturbance sounds in Neotropical doradoid catfishes (Siluriformes: Doradidae, Auchenipteridae): potential morphological correlates. Current Zoology, 58: 171-188.

Karamchandani, S. J. \& M. P. Motwani. 1956. On the larval development of four species of freshwater cat fishes from the River Ganga. Journal of the Zoological Society of India, 7: 115-126.

Kner, R. 1858. Ichthyologische Beiträge. II. Abtheilung Sitzungsberichte der Kaiserlichen Akademie der Wissenschaften in Wien, Mathematisch-Naturwissenschaftlich. Classe 26: 373448,9 pls.

Lauzanne, L. \& G. Loubens. 1985. Peces del Rio Mamoré. Paris, Institut Français de Recherche Scientifique pour le Développement en Coopération, ORSTOM. 116p.
Lauzanne, L., G. Loubens \& B. Le Guennec. 1991. Liste commentée des poissons de l'Amazonie bolivienne. Revista Hydrobiologia Tropical, 24: 61-76.

Lucinda, P. H. F., I. S. Freitas, A. B. Soares, E. E. Marques, C. S. Agostinho \& R. J. de Oliveira. 2007. Fish, Lajeado Reservoir, rio Tocantins drainage, State of Tocantins, Brazil. Check List: Journal of Species Lists and Distribution, 3: 70-83.

Lundberg, J. G. \& J. N. Baskin. 1969. The caudal skeleton of the catfishes, order Siluriformes. American Museum Novitates, 2398: 1-49.

Maldonado-Ocampo, J. A., R. P. Vari \& J. S. Usma. 2008. Checklist of the freshwater fishes of Colombia. Biota Colombiana, 9: 143-237.

Marrero, C. \& D. C. Taphorn. 1991. Notas sobre la historia natural y la distribución de los peces Gymnotiformes en la cuenca del Río Apure y otros ríos de la Orinoquía. Biollania, 8: 123142.

Miranda Ribeiro, A. 1911. Fauna Brasiliense, Peixes IV (A), Eleutherobranchios Aspirophoros. Archivos do Museu Nacional do Rio de Janeiro, 16: 511p.

Miranda Ribeiro, A. 1914. Pimelodidae, Trachycorystidae, Cetopsidae, Bunocephalidae, Auchenipteridae, e Hypophthalmidae. Commissão de Linhas Telegraphicas Estrategicas de Matto-Grosso ao Amazonas, Matto-Grosso, Annexo no. 5. Historia Natural, Zoologia, 15: 1-13, 2 pls.

Miranda Ribeiro, A. 1917. De scleracanthis fluvio "Solimoes" anno MCMVIII a cl. F. Machado da Silva duce brasiliense inventis et in Museo Urbis "Rio de Janeiro" servatis. Revista da Sociedade Brasiliera de Sciencias, 1: 49-57.

Miranda Ribeiro, P. 1953. Tipos das espéces e subespécies do Prof. Alipio de Miranda Ribeiro depositados no Museu Nacional. Arquivos do Museu Nacional do Rio de Janeiro, 42: 389-417.

Miranda Ribeiro, P. 1962. Catálogo dos peixes do Museu Nacional, XI. Publicações Avulsas do Museu Nacional, Rio de Janeiro, 45: 1-12.

Mojica, J. I., G. Galvis, F. Arbeláez, M. Santos, S. Vejarano, E. Prieto-Piraquive, M. Arce, P. Sánchez-Duarte, C. Castellanos, A. Gutiérrez, S. R. Duque, J. Lobón-Cerviá \& C. GranadoLorencio. 2005. Peces de la cuenca del río Amazonas en Colombia: región de Leticia. Biota Colombiana, 6: 191-210.

Moyer, G. R., B. M. Burr \& C. Krajewski. 2004. Phylogenetic relationships of thorny catfishes (Siluriformes: Doradidae) inferred from molecular and morphological data. Zoological Journal of the Linnean Society, 140: 551-575.

Myers, G. S. 1928. New fresh-water fishes from Peru, Venezuela, and Brazil. Annals and Magazine of Natural History (Series 10), 2: 83-90.

Ortega, H., J. I. Mojica, J. C. Alonso \& M. Hidalgo. 2006. Listado de los peces de la cuenca del río Putumayo en su sector colombo-peruano. Biota Colombiana, 7: 95-112.

Ortega, H. \& R. P. Vari. 1986. Annotated checklist of the freshwater fishes of Peru. Smithsonian Contributions to Zoology, 437: 1-25.

Pacheco, A. M. F., P. S. Pinheiro, L. M. Scoss, M. Camargo \& P. C. Ceotto. 2001. Estrutura da ictiofauna associada a bancos de macrófitas flutuantes em uma área de várzea do Rio Solimões, AM. Curso de Campo Ecologia da Floresta Amazônica (2001): 31-34.

Peixoto, L. A. W. \& W. B. Wosiacki. 2010. Description of a new species of Tetranematichthys (Siluriformes: Auchenipteridae) from the lower Amazon basin, Brazil. Neotropical Ichthyology, 8: 69-75. 
de Pinna, M. C. C. 1993. Higher-level phylogeny of Siluriformes, with a new classification of the order (Teleostei, Ostariophysi). Unpublished Ph.D. Dissertation, City University of New York, New York, 482p.

de Pinna, M. C. C. 1998. Phylogenetic relationships of Neotropical Siluriformes (Teleostei: Ostariophysi): historical overview and synthesis of hypotheses. Pp. 279-330. In: Malabarba, L. R., R. E. Reis, R. P. Vari, Z. M. S. Lucena \& C. A. S. Lucena (Eds.). Phylogeny and classification of Neotropical fishes. Porto Alegre, Edipucrs.

Potthoff, T. 1984. Clearing and staining techniques. Pp. 35-37. In: Moser, H. G., W. J. Richards, D. M. Cohen, M. P. Fahay, A. W. Kendall, Jr. \& S. L. Richardson (Eds.). Ontogeny and systematics of fishes. Kansas, American Society of Ichthyologists and Herpetologists Special Publication 1.

Pouilly, M., F. Lino, J.-G. Bretenoux \& C. Rosales. 2003. Dietarymorphological relationships in a fish assemblage of the Bolivian Amazonian floodplain. Journal of Fish Biology, 62: 1137-1158.

Pouilly, M. \& M. A. Rodriguez. 2004. Determinism of fish assemblage structure in Neotropical floodplain lakes: influence of internal and landscape lake conditions. Pp. 243265. In: Welcomme, R. L. \& T. Petr (Eds.). Proceedings of the second international symposium on the management of large rivers for fisheries: sustaining livelihoods and biodiversity in the new millenium. Thailand, FAO \& The Mekong River Commission, v. 2.

Pouilly, M., T. Yunoki, C. Rosales \& L. Torres. 2004. Trophic structure of fish assemblages from Mamoré River floodplain lakes (Bolivia). Ecology of Freshwater Fish, 13: 245-257.

Ribeiro, F. R. V. 2011. Sistemática do gênero Ageneiosus La Cépède (Siluriformes; Auchenipteridae). Unpublished Ph.D. Dissertation, Instituto Nacional de Pesquisas da Amazônia, Manaus, 355p.

Ribeiro, F. R. V. \& L. H. Rapp Py-Daniel. 2010. Ageneiosus uranophthalmus, a new species of auchenipterid catfish (Osteichthyes: Siluriformes) from river channels of the central Amazon basin, Brazil. Neotropical Ichthyology, 8: 97-104.

Rosa, R. S. \& N. A. Menezes. 1996. Relação preliminar das espécies de peixes (Pisces, Elasmobranchii, Actinopterygii) ameaçadas no Brasil. Revista Brasileira de Zoologia, 13: 647-667.

Royero, R. 1987. Morfología de la aleta dorsal en los bagres (Teleostei: Siluriformes), con especial referencia a las familias americanas. Unpublished thesis, Escuela de Biología, Universidad Central de Venezuela, Caracas, 232p.

Royero, R. 1999. Studies on the systematics of the catfish family Auchenipteridae (Teleostei: Siluriformes). Unpublished Ph.D. Dissertation, University of Bristol, United Kingdom, 375p.

Santos, E. 1954. Zoologia Brasilica. II. Peixes da água doce (vida e costumes dos peixes do Brasil). Rio de Janeiro, F. Briguiet \& Cia., 270p.

Santos, G. M. 1991. Pesca e ecologia dos peixes de Rondônia. Unpublished Ph.D. Dissertation, Instituto Nacional de Pesquisas da Amazônia, Manaus, 213p.

Sarmento-Soares, L. M. \& R. F. Martins-Pinheiro. 2008. A systematic revision of Tatia (Siluriformes: Auchenipteridae: Centromochlinae). Neotropical Ichthyology, 6: 495-542.

SAS Institute. 2008. SAS, version 9.1. North Carolina, SAS Institute Inc. Available from: http://www.sas.com.

Soares-Porto, L. M. 1996. Análise filogenética dos Centromochlidae. Redefinição e revisão taxonômica de Tatia A. de Miranda Ribeiro, 1911 (Osteichthyes, Siluriformes, Doradoidea). Unpublished PhD. Dissertation, Universidade de São Paulo, São Paulo, 278p.
Soares-Porto, L. M. 1998. Monophyly and interrelationships of the Centromochlinae (Siluriformes: Auchenipteridae). Pp. 331-350. In: Malabarba, L. R., R. E. Reis, R. P. Vari, Z. M. S. Lucena \& C. A. S. Lucena (Eds.). Phylogeny and classification of Neotropical Fishes. Porto Alegre, Edipucrs.

Sousa, L. M. 2010. Revisão taxonômica e filogenia de Astrodoradinae (Siluriformes, Doradidae). Unpublished PhD. Dissertation, Universidade de São Paulo, São Paulo, 276p.

de Souza, L. S., J. W. Armbruster \& D. C. Werneke. 2012. The influence of the Rupununi portal on distribution of freshwater fish in the Rupununi district, Guyana. Cybium, 36: 31-43.

Steindachner, F. 1881. Beiträge zur Kenntniss der Flussfische Südamerika's, III. Denkschriften der Kaiserliche Akademie der Wissenschaften in Wien, MathematischNaturwissenschaftliche, Classe 44 (for 1882), 1: 1-18, pls. 1-5.

Steindachner, F. 1915. Beiträge zur Kenntniss der Flussfische Südamerikas, V. Denkschriften der MathematischNaturwissenschaftlichen Classe der Kaiserlichen Akademie der Wissenschaften, Wien, 93 [for 1917]: 15-106.

Stewart, D. J. 1986. Revision of Pimelodina and description of a new genus and species from the Peruvian Amazon (Pisces: Pimelodidae). Copeia, 1986: 653-672.

Sullivan, J. P., J. G. Lundberg \& M. Hardman. 2006. A phylogenetic analysis of the major groups of catfishes (Teleostei: Siluriformes) using rag1 and rag2 nuclear gene sequences. Molecular Phylogenetics and Evolution, 41: 636-662.

Taylor, W. R. \& G. C. van Dyke. 1985. Revised procedures for staining and clearing small fishes and other vertebrates for bone and cartilage study. Cybium, 9: 107-119.

Ten, S., I. Liceaga, M. González, J. Jiménez, L. Torres, R. Vázquez, J. Heredia \& J. M. Padial. 2001. Reserva Inmovilizada Iténez: primer listado de vertebrados. Revista Boliviana de Ecología y Conservacíon Ambiental, 10: 81-110.

Vari, R. P. \& C. J. Ferraris, Jr. 1998. The Neotropical catfish genus Epapterus Cope (Siluriformes: Auchenipteridae): a reappraisal. Proceedings of the Biological Society of Washington, 111: $992-$ 1007.

Vari, R. P. \& C. J. Ferraris, Jr. 2006. The catfish genus Tetranematichthys (Auchenipteridae). Copeia, 2006: 168-180.

Vari, R. P., C. J. Ferraris, Jr., A. Radosavljevic \& V. A. Funk (Eds.). 2009. Checklist of the freshwater fishes of the Guiana Shield. Bulletin of the Biological Society of Washington, 17: 1-93.

Walsh, S. J. 1990. A systematic revision of the Neotropical catfish family Ageneiosidae (Teleostei: Ostariophysi: Siluriformes). Unpublished Ph.D. Dissertation, University of Florida, Gainesville, 364p.

Watkins, G., W. Saul, E. Holm, C. Watson, D. Arjoon \& J. Bicknell. 2004. The fish fauna of the Iwokrama Forest. Proceedings of the Academy of Natural Sciences of Philadelphia, 154: 39-53.

Willink, P. W., J. Sarmiento \& B. Chernoff. 1999. Comparative list of fishes reported from the Bolivian Amazon. Appendix 7, Pp. 96-113. In: Chernoff, B. \& P. W. Willink (Eds.). A biological assessment of the aquatic ecosystems of the Upper río Orthon basin, Pando, Bolivia. Washington, D.C., Conservation International, Bulletin of Biological Assessment 15.

Submitted December 13, 2013

Accepted December 16, 2014 by Luiz Roberto Malabarba Published March 31, 2015 